\title{
MYOP/ToPS/SGEval: Um ambiente computacional para estudo sistemático de predição de genes
}

\author{
André Yoshiaki Kashiwabara
}

\author{
TESE APRESENTADA \\ $\mathrm{AO}$ \\ Instituto DE MATEMÁticA E EstatísticA \\ DA \\ UnIVERSIDADE DE SÃO PAULO \\ PARA \\ OBTENÇÃO DO TÍTULO \\ $\mathrm{DE}$ \\ Doutor EM CiÊnCIAS \\ Programa: Ciência da Computação \\ Orientador: Prof. Dr. Alan Mitchell Durham
}

Durante o desenvolvimento deste trabalho o autor recebeu auxílio financeiro da CNPq

São Paulo, dezembro de 2011 


\title{
MYOP/ToPS/SGEval: Um ambiente computacional para estudo sistemático de predição de genes
}

\author{
Esta tese contém as correções e alterações \\ sugeridas pela Comissão Julgadora durante a defesa \\ realizada por André Yoshiaki Kashiwabara em 10/02/2012. \\ $\mathrm{O}$ original encontra-se disponível no Instituto de \\ Matemática e Estatística da Universidade de São Paulo.
}

Comissão Julgadora:

- Prof. Dr. Alan Mitchell Durham - IME-USP

- Profa. Dra. Florencia Graciela Leonardi - IME-USP

- Prof. Dr. André Fujita - IME-USP

- Prof. Dr. João Carlos Setubal - IQ-USP

- Prof. Dr. Sergio Verjovski de Almeida - IQ-USP 


\section{Agradecimentos}

Agradeço a minha família o apoio que me deram durante o tempo de meu estudo. Agradeço ao Prof. Dr. Alan Mitchell Durham a paciência e as importantes orientações durante todo o trabalho. Agradeço ao Prof. Dr. Arthur Gruber e a Prof ${ }^{a}$. Dr ${ }^{a}$. Ariane MachadoLima que me ajudaram a estudar com mais profundidade sobre a Bioinformática. Agradeço ao Prof. Dr. Fábio Passetti as colaborações e sugestões para melhoria deste trabalho. Agradeço a todos os colegas que ajudaram e irão continuar a ampliar esta pesquisa: Ígor Bonadio, Vitor Onuchic, e Felipe Amado. Agradeço aos amigos e colegas Alexandre Rossi Paschoal, Fabio Vicente, e Fabrício Lopes que estão sempre presentes quando eu preciso deles (e um viva para a UTFPR-CP!). Não posso esquecer de agradecer também o amigo Artur Queiroz, a querida Thaís Gaudêncio, a Liliane Santana, o Jesus Mena-Chalco, o amigo David da Silva Pires, a Jihan Zoghbi, e a Talita Perciano. Finalmente, agradeço a todos as memórias e emoções que ajudam no meu autoconhecimento.

"Alegrando-se por nossa alegria, sofrendo por nosso sofrimento assim se faz um amigo" Friedrich Nietzche 


\section{Resumo}

O desafio de encontrar corretamente genes eucarióticos codificadores de proteínas nas sequências genômicas é um problema em aberto. Neste trabalho, implementamos uma plataforma, com o objetivo de melhorar a forma com que preditores de genes são implementados e avaliados. Três novas ferramentas foram implementadas: ToPS (Toolkit of Probabilistic Models of Sequences) foi o primeiro arcabouço orientado a objetos que fornece ferramentas para implementação, manipulação, e combinação de modelos probabilísticos para representar sequências de símbolos; MYOP (Make Your Own Predictor) é um sistema que tem como objetivo facilitar a construção de preditores de genes; e SGEval utiliza grafos de splicing para comparar diferente anotações com eventos de splicing alternativos. Utilizamos nossas ferramentas para o desenvolvimentos de preditores de genes em onze genomas distintos: $A$. thaliana, C. elegans, Z. mays, P. falciparum, D. melanogaster, D. rerio, M. musculus, $R$. norvegicus, O. sativa, G. max e H. sapiens. Com esse desenvolvimento, estabelecemos um protocolo para implementação de novos preditores. Além disso, utilizando a nossa plataforma, desenvolvemos um fluxo de trabalho para predição de genes no projeto do genoma da cana de açúcar, que já foi utilizado em 109 sequências de BAC geradas pelo BIOEN (FAPESP Bioenergy Program).

Palavras-chave: predição ab initio de genes, modelos probabilísticos, cadeia oculta generalizada de Markov, Bioinformática. 


\section{Abstract}

The challenge of correctly identify eukaryotic protein-coding genes in the genomic sequences is an open problem. In this work, we implemented a plataform with the aim of improving the way that gene predictors are implemented and evaluated. ToPS (Toolkit of Probabilistic Models of Sequence) was the first object-oriented framework that provides tools for implementation, manipulation, and combination of probabilistic models that represent sequences of symbols. MYOP (Make Your Own Predictor) facilitates the construction of gene predictors. SGEval (Splicing Graph Evaluation) uses splicing graphs to compare different annotations with alternative splicing events. We used our plataform to develop gene finders in eleven distinct genomes: A. thaliana, C. elegans, Z. mays, P. falciparum, D. melanogaster, D. rerio, M. musculus, R. norvegicus, O. sativa, G. max e H. sapiens. With this development, we established a protocol for implementing new gene predictors. In addition, using our platform, we developed a pipeline to find genes in the 109 sugarcane BAC sequences produced by BIOEN (FAPESP Bioenergy Program).

Palavras-chave: $a b$ initio gene prediction, probabilistic models, generalized hidden Markov models, bioinformatics. 


\section{Sumário}

Lista de Abreviaturas $\quad$ xi

Lista de Figuras $\quad$ xiii

Lista de Tabelas $\quad$ Xv

1 Introdução $\quad 1$

1.1 Motivação . . . . . . . . . . . . . . . . . . . . . . . . . . . 2

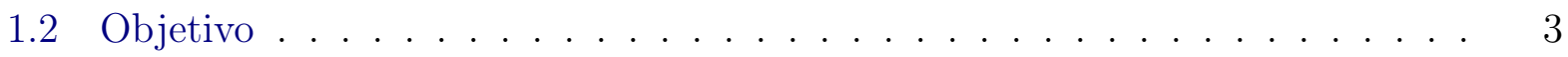

1.3 Organização do texto . . . . . . . . . . . . . . . . . . . . . . 3

2 Predição $a b$ initio de genes $\quad 5$

2.1 Estrutura dos genes eucarióticos codificadores de proteínas . . . . . . . . . 5

2.2 Preditores de genes . . . . . . . . . . . . . . . . . . . 7

2.3 Modelos para predição de genes . . . . . . . . . . . . . . . . 8

2.3.1 Cadeias de Markov . . . . . . . . . . . . . . . . . . . . 8

2.3.2 Utilização de modelos de Markov para predição de genes . . . . . . . 9

2.4 Integrando os sensores . . . . . . . . . . . . . . . . . . . 12

2.4 .1 Definição de GHMM . . . . . . . . . . . . . . . . . . . . 15

2.4.2 Parâmetros arbitrários . . . . . . . . . . . . . . . . . 17

3 GHMMs com algoritmos de decodificação eficientes $\quad 19$

3.1 Algoritmo de Viterbi . . . . . . . . . . . . . . . . . . . . . . . . . . . . . 19

3.2 GHMMs com decodificação eficiente . . . . . . . . . . . . . . . . . . 22

3.2 .1 Outras otimizações . . . . . . . . . . . . . . . . . . . . 23

3.3 Tempo médio empírico de execução . . . . . . . . . . . . . . . . . . . . . . . 24

4 ToPS: um arcabouço para manipular modelos probabilísticos $\quad 27$

4.1 Utilização do ToPS . . . . . . . . . . . . . . . . . . . . 28

4.1.1 Descrevendo um modelo probabilístico . . . . . . . . . . . . . 28

4.1.2 Inferência dos parâmetros . . . . . . . . . . . . . . . . . . . . 30

4.1 .3 Gerando sequências simuladas . . . . . . . . . . . . . . . . . . 31

4.1.4 Decodificando uma sequência . . . . . . . . . . . . . . . 32 
4.1.5 Utilizando outros modelos . . . . . . . . . . . . . . . . . . 32

4.1.6 Integrando os modelos . . . . . . . . . . . . . . . . . . . . 33

4.2 Implementação . . . . . . . . . . . . . . . . . . . . . . . . 35

4.2.1 A classe ProbabilisticModel . . . . . . . . . . . . . 36

4.2 .2 Fábricas de modelos . . . . . . . . . . . . . . . . . . . . . 37

4.3 Testando a implementação . . . . . . . . . . . . . . . . . . . . . . . . . 38

4.3.1 Processo discreto independente identicamente distribuído . . . . . . . 38

4.3 .2 Cadeia oculta de Markov . . . . . . . . . . . . . . . . . . . . 38

5 MYOP: desenvolvendo preditores de genes 41

5.1 Introdução . . . . . . . . . . . . . . . . . . . . . . . . 41

5.2 Utilização do MYOP . . . . . . . . . . . . . . . . . . . . . . . . . 42

5.3 Implementação . . . . . . . . . . . . . . . . . . . . . . . . . . . 44

6 SGEval: calculando a exatidão dos preditores de genes 47

6.1 Uso do SGEval . . . . . . . . . . . . . . . . . . . . . . . . . . . 48

6.2 Grafos de splicing . . . . . . . . . . . . . . . . . . . . 49

6.3 Medidas de exatidão . . . . . . . . . . . . . . . . . . 50

6.4 Diagramas de Venn . . . . . . . . . . . . . . . . . . . . . 51

6.5 Implementação . . . . . . . . . . . . . . . . . . . . . . . . . . 51

7 Avaliando preditores de genes $\quad 53$

7.1 Amostras de genes . . . . . . . . . . . . . . . . . . . 54

7.2 Validação cruzada . . . . . . . . . . . . . . . . . . . 55

7.3 Critério de avaliação . . . . . . . . . . . . . . . . . . 57

7.4 Splicing alternativo nas avaliações . . . . . . . . . . . . . . . . 57

8 Implementando arquiteturas de preditores de genes $\quad 59$

8.1 Passos gerais para construir preditores de genes . . . . . . . . . . . . . 59

8.2 Arquiteturas da GHMM . . . . . . . . . . . . . . . . . . . 60

8.3 Submodelos de emissão . . . . . . . . . . . . . . . . . . . . . . . . 62

8.3 .1 Uso do método BIC . . . . . . . . . . . . . . . . . . . 62

8.3.2 Sensores de conteúdo . . . . . . . . . . . . . . . . . 64

8.3 .3 Sensores de sinais . . . . . . . . . . . . . . . . . . 65

8.4 Submodelos de duração . . . . . . . . . . . . . . . . . . . . . . 67

8.5 Treinamento dependente de conteúdo GC . . . . . . . . . . . . . . 68

9 Experimentos para construir uma biblioteca de preditores $\quad 71$

9.1 Avaliando arquiteturas de preditores amplamente utilizadas . . . . . . . . . . 71

9.2 Comparações com o AUGUSTUS . . . . . . . . . . . . . . . . 72 
9.3 Eliminar códon de terminação conflitante na estrutura predita melhora a predição . . . . . . . . . . . . . . . . . . . . . . . . 81

9.4 Submodelo de íntron treinado com sequências de íntrons podem piorar a exatidão . . . . . . . . . . . . . . . . . . . . . 82

9.5 Estimar a probabilidade de transição pode piorar a exatidão das predições $\quad$ • $\quad 83$

9.6 Target GHMM e variação do conteúdo GC . . . . . . . . . . . . . . 83

10 Preditores em novos genomas $\quad \mathbf{8 5}$

10.1 Fluxo de trabalho para análise em novos genomas . . . . . . . . . . . . 85

10.2 Resultados e discussão . . . . . . . . . . . . . . . . . . . . 86

11 Conclusão e considerações futuras $\quad 89$

A Usando outros modelos com o ToPS 95

A.0.1 Distribuição multinomial . . . . . . . . . . . . . . . . . 95

A.0.2 Cadeias de alcance variável de Markov . . . . . . . . . . . . . . 95

A.0.3 Modelo não homogêneo de Markov . . . . . . . . . . . . . . . . . . . 96

A.1 Usando seleção de modelos . . . . . . . . . . . . . . . . . . . . . 97

$\begin{array}{ll}\text { B MYOP detalhes de uso } & 99\end{array}$

B.0.1 Predição de genes . . . . . . . . . . . . . . . . . . . . . . . . . 99

B.0.2 Treinamento com genes de referência . . . . . . . . . . . . . 100

B.0.3 Treinamento sem genes de referência . . . . . . . . . . . . . 100

B.0.4 Desenvolvendo novas arquiteturas . . . . . . . . . . . . . . . . 101

B.0.5 Programas auxiliares . . . . . . . . . . . . . . . . . 103

$\begin{array}{ll}\text { C Outras curvas de aprendizados } & 107\end{array}$

$\begin{array}{ll}\text { Referências Bibliográficas } & 113\end{array}$ 


\section{Lista de Abreviaturas}

GHMM modelo de Markov oculto generalizado (Generalized Hidden Markov Model)

HMM modelo de Markov oculto (Hidden Markov Model)

IHMC cadeia de Markov não-homogênea (Inhomogeneous-Markov-Chain)

IMM modelo de Markov interpolado (interpolated Markov models)

VLMC cadeia de Markov de alcance variável (variable-length Markov chain)

WAM weigth array model

WMM weigth matrix model

WWAM windowed weigth array model

3PMC cadeia de Markov com três fases (three-periodic Markov chain)

BAC Bacterial Artificial Chromosome

GPHMM modelo de Markov oculto pareados (generalized pair hidden Markov models)

RN redes neurais artificiais 


\section{Lista de Figuras}

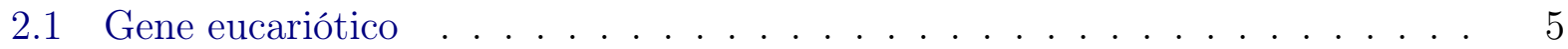

2.2 Ilustração de uma arquitetura simplificada de GHMM para representar a estrutura do gene. . . . . . . . . . . . . . . . . . . . 13

2.3 Ilustração de uma arquitetura de GHMM representando apenas uma das fitas e com as fases de leituras dos éxons. . . . . . . . . . . . . . . 14

3.1 Tempo de execução do algoritmo de Viterbi . . . . . . . . . . . . . . . 25

4.1 Diagrama com o uso do ToPS. Caixas retangulares representam arquivos com os dados ou processos manuais, caixas arredondadas representam programas.

4.2 HMM para o cassino desonesto . . . . . . . . . . . . . . 30

4.3 GHMM que representa regiões codificadoras em bacterias. . . . . . . . . 34

4.4 Diagrama de classes da hierarquia ProbabilisticModel. . . . . . . . . . 36

5.1 Diagrama com o uso do MYOP. . . . . . . . . . . . . . . . 43

5.2 MYOP passos para treinamento . . . . . . . . . . . . . . 45

6.1 Diagrama com o uso do SGEval. . . . . . . . . . . . . . . . . . . . . 48

6.2 Exemplos ilustrativos de eventos de splicing alternativos. Exclusão de éxon (transcrito $t_{2}$ ); sítio doador alternativo (transcrito $t_{3}$ ); sítio aceitador alternativo (transcrito $t_{4}$ ), e retenção de intron (transcrito $t_{5}$ ) . . . . . . 49

6.3 Grafo de splicing obtido a partir do exemplo da Figura 6.2 . . . . . . . 49

6.4 Grafo com as predições $p_{1}$ e $p_{2} \ldots \ldots \ldots \ldots \ldots \ldots \ldots$

6.5 Contagem feita para dois pontos de vista: estruturas, e éxons. . . . . . . 50

6.6 Fluxograma do SGEval . . . . . . . . . . . . . . . . . . 52

8.1 GHMM implementado na arquitetura fixed do MYOP . . . . . . . . . . 63

8.2 Representação de um sítio aceitador. A parte em vermelho indica uma região não-codificadora (íntron) e a parte em azul é a região codificadora (éxon). O deslocamento é a quantidade de nucleotídeos antes da sequência conservada, neste caso, deslocamento é de 5nt. O comprimento é a quantidade de nucleotídeos que o modelo representa, neste caso, o comprimento é de 10nt. .

9.1 Comprimento de íntrons exclusivos corretamente preditos . . . . . . . . . 
9.2 Diagrama de Venn para éxons corretamente preditos. Os diagramas mostram resultados que se complementam. . . . . . . . . . . . . . . . .

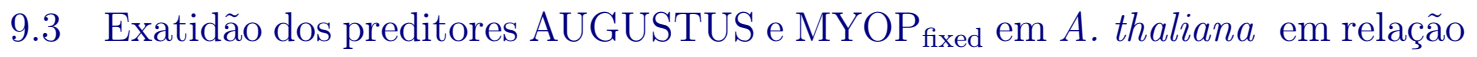
ao tamanho da amostra de treinamento . . . . . . . . . . . . . 76

9.4 Exatidão dos preditores AUGUSTUS e $\mathrm{MYOP}_{\text {fixed }}$ em C. elegans em relação ao tamanho da amostra de treinamento . . . . . . . . . . . . . . . . 77

9.5 Exatidão dos preditores AUGUSTUS e MYOP fixed em D. melanogaster em relação ao tamanho da amostra de treinamento . . . . . . . . . . . . . . . . 78

9.6 Exatidão dos preditores AUGUSTUS e MYOP fixed em H. sapiens em relação ao tamanho da amostra de treinamento . . . . . . . . . . . . . . . . . . . . . 79

9.7 Exatidão dos preditores AUGUSTUS e MYOP fixed em Z. mays em relação ao tamanho da amostra de treinamento . . . . . . . . . . . . . . . 80

9.8 Códons de terminação conflitantes . . . . . . . . . . . . . . . . . . . . 81

10.1 Fluxo de trabalho para predição em novos genomas . . . . . . . . . . . . . 87

10.2 Diagrama de Venn que mostra nucleotídeos exônicos de cada anotação. . . 87

B.1 MYOP passos para treinamento . . . . . . . . . . . . . . . . . 104

C.1 Exatidão dos preditores AUGUSTUS e MYOP em D. rerio em relação ao tamanho da amostra de treinamento . . . . . . . . . . . . . 107

C.2 Exatidão dos preditores AUGUSTUS e MYOP em $R$. norvegicus em relação ao tamanho da amostra de treinamento . . . . . . . . . . . . . . . . . . . . 108

C.3 Exatidão dos preditores AUGUSTUS e MYOP em O. sativa em relação ao tamanho da amostra de treinamento . . . . . . . . . . . . . . . 109

C.4 Exatidão dos preditores AUGUSTUS e MYOP em G. max em relação ao tamanho da amostra de treinamento . . . . . . . . . . . . . . 110

C.5 Exatidão dos preditores AUGUSTUS e MYOP em P. falciparum em relação ao tamanho da amostra de treinamento . . . . . . . . . . . . . . . . 111

C.6 Exatidão dos preditores AUGUSTUS e MYOP em M. musculus em relação ao tamanho da amostra de treinamento . . . . . . . . . . . . . . . . . 112 


\section{Lista de Tabelas}

2.1 Modelos para implementação de preditores de genes utilizando abordagem generativa. 3PMC, three-periodic Markov chain; WAM, weight array method; FH, frequência de hexâmeros; RN, redes neurais, GHMM, generalized hidden Markov model; WMM, weight matrix model; HMM, hidden markov model; VLMC variable-length Markov chain; MDD, maximum dependence decomposition; GE, gramática estocástica, SBSW (similarity based sequence weighting, 3PIMM (three-periodic Interpolated Markov Chain . . . . . . . . . . . . . . 11

2.2 Número de estados em uma GHMM para predição de genes . . . . . . . . . . 15

4.1 Lista de modelos implementados utilizando o ToPS. . . . . . . . . . . . . 32

4.2 Valores estimados . . . . . . . . . . . . . . . . . . . . . . . . . . . . 38

4.3 Parâmetros estimados para uma HMM de dois estados . . . . . . . . . . . 39

4.4 Parâmetros estimados para uma cadeia de alcance variável de Markov . . . . 39

4.5 Parâmetros estimados de uma WAM . . . . . . . . . . . . . . . . . . 39

7.1 Genomas e genes selecionados . . . . . . . . . . . . . . 55

9.1 Estruturas de genes corretamente previstas em H. sapiens no conjunto $G_{15}$. 73

9.2 Éxons corretamente previstos em H. sapiens no conjunto $G_{15}$. . . . . . . . 74

9.3 Comparação entre a implementação pura de GHMM com a GHMM com heurística na validação cruzada em $G_{15}$ de H. sapiens . . . . . . . . . . . . . . . 82

9.4 Comparação entre a implementação pura de GHMM com a GHMM com heurística na validação cruzada em $G_{15}$ de $P$. falciparum . . . . . . . . . . . . . 82

9.5 Íntrons corretamente previstos em $H$. sapiens para a validação cruzada em $G_{15} 83$

9.6 Íntrons corretamente previstos em C. elegans para a validação cruzada em $G_{15} 83$

9.7 Éxons corretamente previstos em $P$. falciparum para a validação cruzada em $G_{15} \ldots \ldots \ldots \ldots \ldots \ldots$

9.8 Éxons corretamente previstos em $H$. sapiens para a validação cruzada em $G_{15} \quad 84$

9.9 Target GHMM e variantes corretamente preditas . . . . . . . . . . . 84

10.1 Quantidade de genes preditos por preditor . . . . . . . . . . 88 


\section{Capítulo 1}

\section{Introdução}

Prever a estrutura dos genes eucarióticos utilizando métodos computacionais ainda é um grande desafio. Os melhores programas classificados como ab initio conseguem identificar corretamente $90 \%$ das posições que codificam proteínas, mas apenas cerca de $20 \%$ das estruturas éxon/íntron dos genes são corretamente previstas em H. sapiens (Capítulo 9). Para considerarmos correta a previsão de uma das estruturas de um gene, é necessário que todos os éxons preditos estejam corretos. Assim, esta baixa exatidão indica que o problema de encontrar as fronteiras entre éxons e íntrons, chamadas de sítios de splicing, ainda está em aberto.

A demanda por técnicas eficientes tornou o problema de predição de genes um assunto amplamente estudado e bastante competitivo (Coghlan et al., 2008; Guigo, 2000; Guigó et al., 2006; Zhang, 2002). Em uma das revisões, Mathé et al. (2000) publicaram uma lista de 22 programas que utilizam comparações entre sequências e de mais 25 programas ab initio, que utilizam apenas a sequência de nucleotídeos como fonte de informação. A página web http://www.geneprediction.org tem uma lista das publicações da área (desde 1980). Além disso, existem livros específicos sobre predição de genes (Axelson-Fisk, 2010; Majoros et al., 2007) e sobre modelos probabilísticos de análise de sequência (Durbin et al., 1998).

Uma das possíveis razões do aparecimento de muitos programas é que alguns foram desenvolvidos visando apenas um genoma ou um conjunto de genomas filogeneticamente próximos. Por exemplo, Genscan (Burge, 1997) foi criado para H.sapiens, Phat (Cawley et al., 2001) para P. falciparum, Geneid (Kulp. et al., 1996) para D. melanogaster, e AUGUSTUS (Stanke, 2003) para vertebrados e principalmente para H. sapiens. Além disso, embora a maioria dos preditores utiliza o mesmo arcabouço matemático, as avaliações presentes na literatura mostram que eles não funcionam igualmente bem mesmo quando aplicados no mesmo genoma.

As abordagens probabilísticas de predição de genes são utilizadas para o desenvolvimento de outras mais avançadas, tais como as que combinam diferentes fontes de evidências: por exemplo, o EVIGAN (Allen e Salzberg, 2005), Semi-Markov Conditional Random 
Fields (DeCaprio et al., 2007; Gross et al., 2007) e Semi-Markov Support Vector Machines (Schweikert et al., 2009). Assim, o estudo das abordagens probabilísticas pode implicar em aumento de exatidão nos combinadores de evidência.

A maior parte dos programas de predição utiliza modelos GHMM (generalized hidden Markov model) (Kulp. et al., 1996), que permite combinar vários modelos probabilísticos para a predição de diferentes partes da estrutura do gene. Mudanças pequenas na arquitetura do modelo GHMM podem fornecer diferenças significativas na exatidão das predições. Dentro da bibliografia que estudamos, apenas os programas Genezilla (Majoros et al., 2004) e Twinscan (Korf et al., 2001) permitem a troca de submodelos, mas com algumas limitações, que dificultam a comparação de modelagens: fundamental para escolhermos os melhores preditores. Ambos são difíceis de serem treinados, e não permitem modificar a arquitetura da GHMM sem modificar o código-fonte. Apresentaremos uma nova solução que explora a modularidade do modelo GHMM, que gera preditores de genes com eficiência computacional similar e exatidão competitiva com relação aos melhores programas.

As nossas ferramentas facilitaram o desenvolvimento de um novo protocolo de implementação de preditores de genes. Aplicamos esse protocolo com sucesso para desenvolver preditores em onze genomas diferentes. Para esses preditores, mostramos que o MYOP é altamente competitivo.

Finalmente, iniciamos o teste do nosso sistema em aplicações práticas, em particular o MYOP foi utilizado no fluxo de processamento para predição em 109 sequências de BAC (Bacterial Artificial Chromosome) do projeto BIOEN (FAPESP Bioenergy Program) de sequenciamento do genoma de cana-de-açúcar.

\subsection{Motivação}

Embora existam muitos programas para predição $a b$ initio de genes, eles apresentam pouca flexibilidade que dificulta o processo de avaliação e desenvolvimento de novas metodologias. Nas implementações de alguns programas, observamos que muitos parâmetros dos modelos representando a estrutura do gene estão fixados no código-fonte ou em arquivos sem a documentação necessária. Muitos programas não fornecem as ferramentas necessárias para o treinamento dos modelos probabilísticos de predição de gene. Esses fatos tornam qualquer tipo de comparação entre os programas bastante injusto (Zhang, 2002).

Muito mais produtivo do ponto de vista científico do que comparar programas é a comparação entre diferentes modelagens. Muitos programas de predição exploram um mesmo arcabouço matemático, mas as diferentes implementações desse arcabouço podem dar origem a diferentes artefatos difíceis de serem controlados. A maneira de permitir essa comparação é a utilização de um ambiente unificado como uma forma de eliminar algumas variabilidades (Majoros et al., 2007).

Modelos generalizados ocultos de Markov (GHMM) possuem uma modularidade natural, 
que foi pouco explorada. As otimizações feitas com o objetivo de manter eficiente a decodificação tornaram os programas engessados e específicos para o problema de predição de genes. A maior parte dos programas fornece apenas uma arquitetura fixada no código-fonte e não explora todo o potencial do modelo GHMM.

Calcular a exatidão dos preditores é um passo importante, mas devemos também considerar os eventos de splicing alternativo. Esses eventos permitem a existência de muitas variantes de transcritos que são geradas pela escolha de diferentes sítios de splicing (Nilsen e Graveley, 2010). Encontramos na literatura a descrição de duas ferramentas para calcular medidas de exatidão utilizando as predições e a anotação de um conjunto de genes de referência: Eval (Keibler e Brent, 2004) e GFPE (Wang, 2003). Contudo, não está claro como os eventos de splicing alternativos são tratados por essas ferramentas.

\subsection{Objetivo}

O objetivo deste trabalho foi melhorar o processo de implementação e avaliação de preditores ab initio de genes codificadores de proteínas. A maior parte dos preditores de genes baseados em GHMM não explora a modularidade natural do modelo de GHMM e o processo de treinamento não é trivial, tendo como consequência a dificuldade de comparar diferentes modelagens. Desenvolver um protocolo para implementação que aponte direções promissoras é importante para desenvolvermos preditores mais precisos e específicos para um dado genoma de interesse. As avaliações que estão na literatura não deixam claro quais métodos trouxeram melhorias significativas, já que as comparações são feitas entre programas e não entre diferentes estratégias de modelagem probabilística.

\subsection{Organização do texto}

No Capítulo 2, escrevemos uma revisão das metodologias de predição ab initio de genes, descrevemos o modelo GHMM na sua forma mais geral e como ele é utilizado para modelar genes codificadores de proteínas. O Capítulo 3 mostra a nossa implementação do algoritmo de Viterbi (Guédon, 2003; Rabiner, 1989) que tornou possível a implementação do ToPS e do MYOP. Os três capítulos seguintes mostram as ferramentas que forneceram suporte para o desenvolvimento do protocolo de avaliação e para o protocolo de implementação de novos preditores: ToPS, SGEval, e MYOP. ToPS é um arcabouço para manipulação de modelos probabilísticos que representam sequências de símbolos. SGEval realiza comparações entre anotações levando em consideração eventos de splicing alternativos. MYOP fornece um ambiente para o desenvolvimento de preditores de genes. Em seguida, mostraremos o nosso protocolo de avaliação de preditores de genes, e o protocolo de implementação de novos preditores. Descrevemos também o nosso estudo sobre preditores no genoma de cana de açúcar. A Tese termina com uma discussão sobre os possíveis trabalhos futuros. 


\section{Capítulo 2}

\section{Predição $a b$ initio de genes}

Neste Capítulo, discutiremos sobre os métodos computacionais para o problema de predição de genes eucarióticos.

\subsection{Estrutura dos genes eucarióticos codificadores de pro- teínas}

Um gene é uma sequência de DNA que é utilizada para produzir uma outra molécula de ácidos nucléicos, RNA, com sequência correspondente a uma das duas cadeias polinucleotídicas do DNA (Krebs et al., 2011). Em alguns casos, o RNA é utilizado diretamente para a produção de polipeptídeos. Em outros casos, tais como genes de tRNA, microRNA, rRNAs, o RNA é o produto final funcional. Assim, um gene é uma sequência de DNA que codifica para RNA, e um gene codificador de proteína codifica para uma mólecula de RNA que codifica para proteína (Krebs et al., 2011).

A Figura 2.1 ilustra a estrutura primária dos genes eucarióticos codificadores de proteínas. Neste caso, o gene pode ser formado por segmentos chamados de éxons e segmentos que estão entre os éxons chamados de íntrons. As regiões fronteiras entre éxons e íntrons são chamadas de sítios de splicing. O processo de splicing do RNAm (RNA mensageiro) remove os íntrons e religa os éxons numa única molécula (Sharp, 1994). Se o gene codifica proteína, então a molécula resultante consistirá de uma região $5^{\prime}$ não traduzida, uma região codificadora, e uma região $3^{\prime}$ não traduzida.

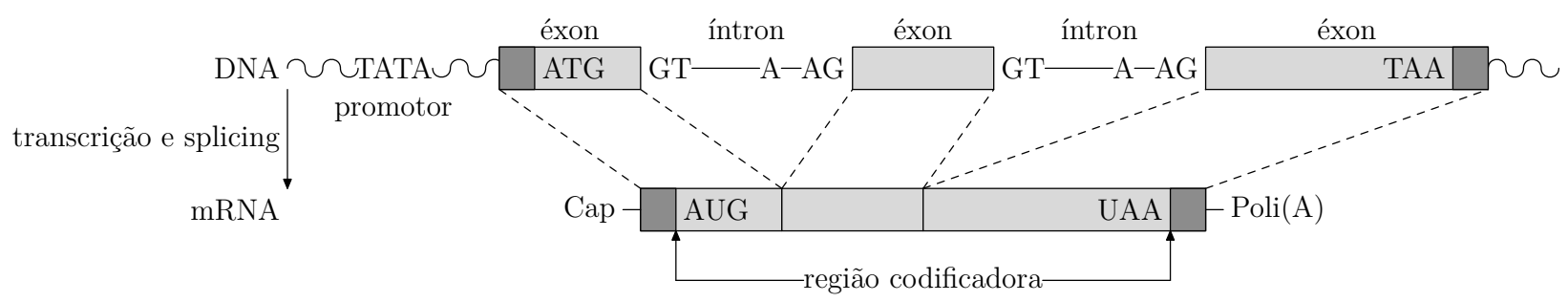

Figura 2.1: Gene eucariótico

Um mesmo gene pode gerar diferentes transcritos a partir de escolhas alternativas de 
sítios de splicing. Este fenomeno conhecido como splicing alternativo ocorre com a maioria dos genes com múltiplos éxons em H. sapiens (Nilsen e Graveley, 2010). Entender como tais eventos ocorrem é um problema em aberto, em geral, preditores ab initio assumem apenas a existência de uma única variante por gene.

Existem diversos sinais biológicos, explorados pelos preditores de genes, que atuam durante os processos de transcrição (síntese de RNA a partir do DNA), splicing do pré-RNAm, e tradução (síntese de proteína a partir do RNA), entre eles:

- Sítio de início de transcrição indica quando ocorre o início da transcrição do gene, pode conter uma região conservada com composição A+T rica, chamada de TATA-box.

- Sítio aceitador de íntron indica o fim do íntron. Geralmente, contém a sequência conservada AG.

- Sítio doador de íntron indica o início do íntron. Geralmente, contém a sequência conservada GT.

- Ponto de ramificação é uma região do íntron que atua durante o splicing do préRNAm, e tem função durante as reações de transesterificações.

- Códon de iniciação indica o começo da região codificadora de proteína e pode conter, entre outras, a sequência conservada ATG.

- Códon de terminação indica o fim da região codificadora de proteína e pode conter, entre outras, as sequências conservadas TAA, TAG, e TGA.

Como podemos ver na Figura 2.1 nem todos os éxons são totalmente traduzidos para proteína: no ínicio e no final do gene existem regiões (em cinza claro) que não são traduzidas chamadas de UTRs (untranslated regions). As regiões do gene que não codificam proteínas são difíceis de serem corretamente preditas e assim a maioria dos preditores reconhecem apenas as regiões codificadoras de proteínas do gene. Nesse caso, o problema de predição é equivalente a identificar corretamente os sinais biológicos na sequência de DNA, que separam um trecho codificador de um trecho não codificador. Esta tarefa não é trivial uma vez que a grande maioria das ocorrências das sequências conservadas dos sinais (AG,GT,ATG,TAA,TAG,TGA) que aparecem no genoma não correspondem a sinais reais. Desse modo, devemos utilizar tanto sequências vizinhas a esses sinais, quanto restrições estruturais do éxon/íntron para identificar tais sinais (Majoros et al., 2007). Devemos ressaltar que os preditores de genes não modelam a dinâmica das moléculas que estão envolvidas. Em vez disso, eles utilizam quaisquer viés da sequência num único arcabouço matemático para encontrar regiões mais provavelmente codificadoras.

O preditor de gene está mais diretamente relacionado com as estatísticas obtidas utilizando as sequências do que com os processos evolutivos e celulares que deram origem aos genes. Em outras palavras, um preditor ab initio explora estatísticas dos sinais biológicos 
de diferentes processos bioquímicos para construir um "analisador sintático probabilístico" que fornece probabilidade diferente de zero para qualquer sequência de DNA (Dong e Searls, 1994). Este analisador é ambíguo no sentido que existem muitas árvores sintáticas possíveis para cada sequência de entrada. Os preditores aplicam algoritmos de programação dinâmica para encontrar a árvore sintática mais provável.

\subsection{Preditores de genes}

Preditores de genes são programas utilizados com o objetivo de prever tanto a localização quanto a estrutura dos genes em uma dada sequência genômica. Podemos listar duas estratégias fundamentais para predições de genes (Mathé et al., 2000):

- Abordagem intrínseca explora padrões existentes nas sequências de entrada. Modelos probabilísticos são amplamente aplicados para capturar tais padrões.

- Abordagem extrínseca explora elementos que não estão na sequência de entrada. A principal fonte de informação externa é obtida de comparações com sequências de macromoléculas já conhecidas. Para isso há amplo uso de diversos tipos de algoritmos que fazem o alinhamento de três tipos de sequências: (i) transcritos; (ii) sequências genômica; e (iii) sequências protéicas.

Abordagens intrínsecas são capazes de encontrar novas evidências sobre as localizações de genes que são difíceis de serem encontradas apenas aplicando-se abordagens extrínsecas. Para ilustrar a importância das abordagens ab initio, podemos citar dois artigos publicados em revistas de alto impacto que mostram alguns resultados relacionados com o preditor GENSCAN (Burge, 1997). Em Shoemaker et al. (2001), das 325 predições ab initio exclusivas feitas pelo mesmo preditor, 185 foram comprovadas experimentalmente utilizando tecnologias de microarranjos. Em Bertone et al. (2004), das 42,645 predições no genoma humano feitas pelo GENSCAN, um total de 14,884 transcrevem para RNA sugerindo que essas regiões são realmente funcionais.

Uma desvantagem das abordagens extrínsecas está no fato de que não é viável amostrar transcritos de todos os estados de um organismo. Existem genes que são expressos em curtos periodos de tempo, e há pouca chance de observar tais transcritos através da utilização de sequenciamento de larga escala. Nesses casos, a abordagem intrínseca pode levantar sequências específicas que devem servir para um estudo mais detalhado de um determinado gene.

As abordagens extrínsecas mais promissoras segundo Gross et al. (2007) utilizam modelos discriminativos, que transformam o problema de predição de genes em uma série de problemas de classificação, ou seja, cada posição da sequência é classificada como pertencendo a um tipo de região do gene. Uma desvantagem dessa abordagem é que ela precisa de um grande recurso computacional e uma grande amostra de treinamento para estimar os 
pesos associados a cada característica. O programa CONRAD (DeCaprio et al., 2007) é um exemplo de programa que aplica métodos discriminativos, e foi aplicado para prever genes em diversos tipos de fungos (por exemplo Aspergilus nidulans). Infelizmente, não há modelos do CONRAD para H. sapiens pela dificuldade de treinamento para grandes organismos. Esta dificuldade é ilustrada com a seguinte frase extraída do artigo do programa CONTRAST (Gross et al., 2007): "We were not able to test Conrad on the human or Drosophila melanogaster genomes as its current implementation does not support the parallelization of training computations across a compute cluster, making training on large genomes prohibitively expensive" (Gross et al., 2007). Além disso, é difícil fornecer interpretação para os pesos estimados, o modelo discriminativo funciona como uma "caixa-preta", pois tais pesos foram obtidos com a finalidade de diminuir o erro de predição e nem sempre é possível fornecer alguma interpretação biológica para esses pesos.

Quando consideramos abordagens intrínsecas que utilizam modelos generativos, a inclusão de novas fontes de evidências não é trivial, pois precisamos fornecer o algoritmo com o qual a sequência é gerada dando um sentido probabilístico para as novas fontes de evidências. Por outro lado, os parâmetros dos modelos generativos são simples de serem interpretados, eles são simplesmente valores de probabilidades. Além disso, estimar os parâmetros dos modelos generativos é computacionalmente eficiente e requer uma amostra de treinamento menor em relação a preditores discriminativos. Em particular, muitos preditores ab initio de sucesso, tal como a primeira versão do GENSCAN e o preditor Phat (Cawley et al., 2001), foram treinados com cerca de apenas 400 genes.

\subsection{Modelos para predição de genes}

A grande maioria dos programas exploram modelos de Markov para realizar a predição de genes, discutiremos a seguir alguns desses modelos.

\subsubsection{Cadeias de Markov}

A definição de cadeia de Markov diz que um processo estocástico, $X_{1}, X_{2}, X_{3}, \cdots$, é uma cadeia de Markov se o processo possui a propriedade markoviana, ou seja, a probabilidade do próximo estado dado todo o histórico é igual a probabilidade dado apenas o estado atual (Taylor e Karlin, 1998).

$$
\operatorname{Pr}\left\{X_{n+1}=x \mid X_{1}=x_{1}, \cdots, X_{n}=x_{n}\right\}=\operatorname{Pr}\left\{X_{n+1}=x \mid X_{n}=x_{n}\right\}
$$

Como esta definição não deixa claro como o processo é gerado pelo modelo, adotaremos a mesma definição de cadeias de Markov estudada por Ferrari e Galves (Ferrari e Galves, 1997), na qual esta baseado o algoritmo de simulação que utilizamos durante a implementação do nosso sistema. 
Definição 2.3.1. Um processo estocástico $\left(X_{n}\right)_{n \in \mathbf{N}}$ assumindo valores em um alfabeto finito $A$ é uma cadeia de Markov de alcance $k$ se pudermos simular com um algoritmo da forma:

- inicialização: $X_{-1}^{-k}=a_{-1}^{-k}, a_{-1}^{-k} \in A^{k}$

- para todo $n \geq 0: X_{n}=F\left(X_{n-1}^{n-k} ; U_{n}\right)$

em que $U_{0}, U_{1}, U_{2}, \ldots$ são variáveis aleatórias independentes e uniformemente distribuídas no intervalo $[0,1]$. Nesta notação, $X_{b}^{a}$ é a sequência que começa na posição $a$ e termina em $b$, ou seja, $X_{b}^{a}=X_{a}, \ldots, X_{b}$. Se $a>b$, então a sequência $X_{b}^{a}$ é uma sequência vazia. Quando a função $F$ é a mesma para todas as posições da sequência, chamamos a cadeia de homogênea, caso contrário a cadeia é não-homogênea.

Podemos definir uma função $p: A \times A^{k} \rightarrow[0,1]$ que chamaremos de probabilidade de transição se para todo $y \in A^{k}$ temos $\sum_{x \in A} p(x \mid y)=1$. O valor de $p(x \mid y)$ corresponde a probabilidade de $x$ dado $y$, ou seja,

$$
p(x \mid y)=\operatorname{Pr}\left\{X_{n}=x \mid X_{n-1}^{n-k}=y\right\}
$$

Para cadeias não-homogêneas, a função de probabilidade de transição depende do tempo t. Ou seja,

$$
p_{t}(x \mid y)=\operatorname{Pr}\left\{X_{t}=x \mid X_{t-1}^{t-k}=y\right\}
$$

\subsubsection{Utilização de modelos de Markov para predição de genes}

Desde a implementação dos primeiros métodos de predição, diversos modelos de Markov com diferentes propriedades foram utilizados para representar as diferentes regiões do gene. São utilizados basicamente dois tipos de modelos de Markov para representar as regiões codificadoras, regiões não codificadoras, sítios de splicing, sítios de início e sítios de fim de tradução:

- Modelos para cadeias de Markov homogêneas representam principalmente as regiões com tamanho variável: éxons, íntron, região intergênica, e regiões não traduzidas.

- Modelos para cadeias de Markov não-homogêneas representam os sinais biológicos e regiões codificadoras.

Na literatura de predição de genes, há um conjunto de nomes para esses modelos:

- WMM (Weight Matrix Model) é um modelo de Markov não-homogêneo de ordem zero e que representa sítios de splicing e outros sinais (Staden, 1984).

- WAM (Weight Array Matrix) de ordem $k$ é uma generalização da WMM, ou seja, é uma cadeia de Markov não-homogênea de ordem $k$ para $k>0$ (Zhang e Marr, 1993). 
- WWAM (Windowed Weight Array Model) também é um modelo de Markov nãohomogêno em que os parâmetros da posição $t$ são estimados utilizando também posições vizinhas da posição $t$ (Burge, 1997).

- IMM (Interpolated Markov Model) de ordem $k$ é equivalente a um modelo de Markov homogêneo de ordem $k$, difere apenas na forma com que os parâmetros são estimados em que os contextos com poucas amostras observadas possuem a mesma distribuição estimada do que contextos com comprimento menor (Salzberg et al., 1998).

- 3PMC (three-periodic Markov Chain) é um tipo de modelo de Markov não-homogêneo específico para representar região codificadora. Cada uma das três posições do códon é representado por uma matriz de probabilidade diferente (Borodovsky e McIninch, 1993).

Além dos modelos markovianos, existem outros os quais conseguem capturar dependências entre posições não adjacentes da sequência.

- MDD (Maximum dependence decomposition) que foi introduzido pelo GENSCAN (Burge, 1998) e aplicado para caracterizar o sítio doador de splicing.

- Rendes Neurais Artificiais foi descrito pelo programa Genie (Reese e Eeckman, 1997) para representar sítio de splicing.

- SBSW (Similarity Based Sequence Weighting) (Stanke et al., 2006) introduzido pelo AUGUSTUS e utilizado para representar o sítio doador de splicing.

- Redes Bayesianas o uso foi descrito por Yeo e B. (2004) para melhorar a modelagem das dependências no sítio doador.

- Máquinas de vetores de suporte (Support Vector Machines) usado por Huang et al. (2006) como um novo método para predição de sítio de splicing.

Os modelos apresentados acima são utilizados para gerar dois tipos de sensores (Mathé et al., 2000):

1. Sensor de sinais recebe uma sequência de comprimento constante $N$ e devolve um valor para classificar a sequência como pertencente à uma dada classe de sinal biológico, tais como sítios de splicing, sinal de poliadenilação, códon de iniciação, e códon de terminação.

2. Sensor de conteúdo classifica uma sequência de comprimento $N>0$ como pertencente a uma família de sequências com comprimentos variáveis, tais como éxon, íntron, e região intergênica. 
Uma vez que há um submodelo para cada tipo de região do gene, utilizamos também um outro modelo que integra esses submodelos a fim de representar a estrutura do gene eucariótico. A grande maioria dos preditores de sucesso aplica o modelo integrador chamado de GHMM (generalized Hidden Markov Model) (Kulp. et al., 1996).

Na Tabela 2.1, apresentamos os modelos probabilísticos utilizados em um conjunto de programas de predição para construir tanto sensores de sinais, quanto sensores de conteúdo. Para fazer o reconhecimento de sinais biológicos, os programas desta lista aplicam praticamente os mesmos tipos de modelos (exceto o programa Genie (Reese e Eeckman, 1997) que aplica redes neurais). A metade desses preditores de genes utiliza GHMM para modelar a estrutura do gene.

Tabela 2.1: Modelos para implementação de preditores de genes utilizando abordagem generativa. 3PMC, three-periodic Markov chain; WAM, weight array method; FH, frequência de hexâmeros; RN, redes neurais, GHMM, generalized hidden Markov model; WMM, weight matrix model; HMM, hidden markov model; VLMC variable-length Markov chain; MDD, maximum dependence decomposition; GE, gramática estocástica, SBSW (similarity based sequence weighting, 3PIMM (three-periodic Interpolated Markov Chain

\begin{tabular}{lccc}
\hline & \multicolumn{3}{c}{ Modelos } \\
\cline { 2 - 4 } Preditor & Sinais & Conteúdo & Gene \\
\cline { 2 - 4 } GenMark (Borodovsky e McIninch, 1993) & - & 3 PMC & - \\
GenLang (Dong e Searls, 1994) & WAM & FH & GE \\
Genie (Reese e Eeckman, 1997) & RN & RN & GHMM \\
GENSCAN (Burge, 1997) & WMM,WAM,MDD & $3 P M C$ & GHMM \\
HMMGene (Krogh, 1997) & HMM & HMM & CHMM \\
Glimmer (Salzberg et al., 1998) & - & IMM & - \\
GlimmerM (Salzberg et al., 1999) & WAM,MDD & IMM & - \\
GeneId (Parra et al., 2000) & WMM & MC & - \\
Phat (Cawley et al., 2001) & VLMC & $3 P M C$ & GHMM \\
AUGUSTUS (Stanke e Waack, 2003) & WMM,WAM,SBSW & IMM,3PIMM & GHMM \\
Tigrscan (Majoros et al., 2004) & WAM,MDD & IMM,3PMC & GHMM \\
GlimmerHmm (Majoros et al., 2004) & WMM,MDD & IMM & GHMM \\
GeneMark.hmm (Lomsadze et al., 2005) & WAM & $3 P M C$ & GHMM \\
Agene (Munch e Krogh, 2006) & HMM & HMM & HMM \\
\hline
\end{tabular}

\section{Sensor de sinais}

Cadeias de Markov não-homogêneas representam sinais biológicos. Se a cadeia for de alcance $k=0$, então o modelo é equivalente a uma matriz WMM (weight matrix model) (Staden, 1984) ou a uma matriz PSSM (positional specific scoring matrix), para $k>0$ temos um modelo equivalente a uma WAM (weight array model) de ordem $k$ (Zhang e Marr, 1993). Estes modelos representam sequências de comprimento $L$ constante. Se temos o modelo $M=\left(p_{0}, p_{1}, . ., p_{L-1}\right)$, a probabilidade do modelo gerar uma dada sequência $X_{L-1}^{0}=x_{L-1}^{0}$ de comprimento $L$, é dada por: 


$$
\operatorname{Pr}\left\{X_{L-1}^{0}=x_{L-1}^{0} \mid M\right\}=\prod_{i=0}^{L-1} p_{i}\left(x_{i} \mid x_{i-1}^{i-k}\right)
$$

Note que há uma função de probabilidade de transição $p_{i}$ para cada posição $i$ da sequência, $p_{i}$, para $i \in\{0,1, \cdots, L-1\}$.

\section{Sensor de conteúdo}

Em predição de genes não se assume estrutura para regiões não-codificadoras. Desta maneira, utilizamos para sua caracterização modelos de Markov homogêneos, que utilizam a mesma função para caracterizar todas as posições da sequência. Se temos um modelo de Markov, $M=(p)$, de ordem $k \geq 0$, a verossimilhança de uma sequência $X_{n-1}^{0}=x_{n-1}^{0}$ dado $M$ é dada por uma multiplicação de fatores:

$$
\operatorname{Pr}\left\{X_{n-1}^{0}=x_{n-1}^{0} \mid M\right\}=\prod_{i=0}^{n-1} p\left(x_{i} \mid x_{i-1}^{i-k}\right)
$$

Para representar regiões codificadoras, utilizamos modelos de Markov não-homogêneos. Neste caso, utilizamos três funções de probabilidade de transição, $\left(p_{0}, p_{1}, p_{2}\right)$, uma função para cada posição do códon. Chamamos este modelo de cadeia de três fases de Markov (three-periodic Markov chain) (Borodovsky e McIninch, 1993). Se $M=\left(p_{0}, p_{1}, p_{2}\right)$, a verossimilhança de $X_{n-1}^{0}=x_{n-1}^{0}$ é dada por:

$$
\operatorname{Pr}\left\{X_{n-1}^{0}=x_{n-1}^{0} \mid M, \omega\right\}=\prod_{i=0}^{n-1} p_{(i+\omega) \bmod 3}\left(x_{i} \mid x_{i-1}^{i-k}\right)
$$

em que $\omega \in\{0,1,2\}$ é a fase de leitura da primeira posição da sequência.

\section{$2.4 \quad$ Integrando os sensores}

O modelo de Markov oculto generalizado (GHMM - generalized Hidden Markov model) integra os diferentes modelos das regiões do gene em um único arcabouço estatístico. Kulp (Kulp. et al., 1996) introduziu o modelo na Bioinformática para representar a estrutura do gene em H. sapiens em 1996. GENSCAN (Burge, 1997), Tigrscan (Majoros et al., 2004), e AUGUSTUS (Stanke e Waack, 2003) são exemplos de preditores de sucesso baseados em GHMM que surgiram depois. GHMM também é conhecido como modelo oculto semi-markoviano (HSMM - hidden semi-Markov model) e foi introduzido por Fegurson para modelagem em reconhecimento de voz (Guédon, 2003).

GHMM é um modelo mais flexível que o modelo de Markov oculto (HMM - hidden Markov model) (Rabiner, 1989) no sentido que ele permite modelar as emissões e as durações de cada estado usando submodelos arbitrários. A HMM força duração com distribuição geométrica para cada estado, mas sabemos que os comprimentos das regiões do gene, por 


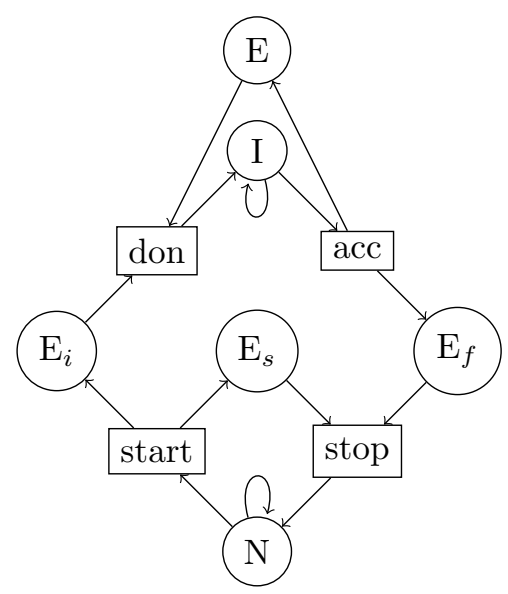

Figura 2.2: Ilustração de uma arquitetura simplificada de GHMM para representar a estrutura do gene.

exemplo comprimentos de éxons, não são geometricamente distribuídos. A GHMM permite representar precisamente a distribuição dos comprimentos das regiões melhorando assim a modelagem. Além disso, os símbolos observados na HMM são condicionalmente independentemente distribuídos, enquanto que na GHMM a emissão de cada estado pode ser dado por um outro submodelo.

Um exemplo de uma arquitetura de um modelo GHMM para representar a estrutura do gene está na Figura 2.2. Nesta modelagem, há três tipos de estados:

- Estados de duração constante representam sinais biológicos. No modelo da Figura 2.2, existem 4 estados para sinais biológicos: (i) códon de iniciação, start; (ii) códon de terminação, stop; (iii) sítio aceitador, acc; (iv) sítio doador, don.

- Estados de duração geométrica representam as regiões não codificadoras. No modelo da Figura 2.2, há dois estados representando a região não-codificadora: (i) Íntron, I; (ii) e região intergênica, N. As distribuições de duração desses dois estados são dadas pelas probabilidades de transição $p(I, I)$ e $p(N, N)$, ou seja, a duração de cada estado segue uma distribuição geométrica.

- Estados de duração explícita representam os éxons. No modelo da Figura 2.2, há 4 estados para representar éxons: (i) éxon inicial, $\mathrm{E}_{i}$; (ii) éxon interno, E; (iii) éxon único, $\mathrm{E}_{s}$; (iv) éxon terminal, $\mathrm{E}_{t}$. Eles emitem palavras com comprimentos escolhidos usando uma distribuição discreta arbitrária.

Existe um problema com este modelo simples, não é possível rastrear em qual fase de leitura que cada éxon pertence. A solução consiste em criar outros estados para os éxons e para os íntrons, um novo estado para cada configuração de fase de leitura de entrada e fase de leitura de saída. A fase de leitura de entrada indica com qual fase de leitura o éxon começa e a fase de leitura de saída indica com qual fase o éxon termina. Precisamos de três novos estados para éxon inicial, pois o éxon inicial começa sempre com a fase de leitura 0 e termina 
em qualquer uma das três fases. O éxon terminal começa com uma fase de leitura arbitrária e termina sempre com a fase de leitura 2, então precisamos de três novos estados para éxon terminal. O éxon interno começa com qualquer fase de leitura e termina com qualquer fase de leitura, assim outros 9 estados são necessários. Não precisamos de outros estados para éxon único uma vez que ele sempre começa com fase 0 e termina na fase 2. A distribuição de duração de cada estado do tipo éxon também é controlada para ser consistente com a fase de saída dada uma fase de entrada. A Figura 2.3 mostra o modelo considerando as fases de leituras de cada éxon. Os estados, EI0, EI1, e EI2, representam éxons iniciais que terminam respectivamente nas fases de leitura 0,1 , e 2. Os éxons internos são representados por estados do tipo EAB, em que $A \in\{0,1,2\}$ é a fase de leitura de início do éxon e $B \in\{0,1,2\}$ é a fase de leitura de fim do éxon. ET0, ET1, ET2 são os estados para éxons terminais que começam respectivamente nas fases 0,1 , e 2 .

Em vez de usar este modelo "puro" de GHMM, muitos preditores implementam as restrições de fase de leitura diretamente na implementação dos algoritmos relacionados a GHMM. Em vez de 9 estados de éxons internos para cada uma das fitas do DNA, a arquitetura típica usa apenas 3 estados para representar o éxon interno e 3 estados para representar íntrons.

Para diminuir o número de falsos positivos (predições sobrepostas em fitas opostas), os preditores costumam modelar ambas as fitas ao mesmo tempo. Borodovsky e McIninch (1993) introduziram com grande sucesso esta idéia para modelar genes procarióticos. A

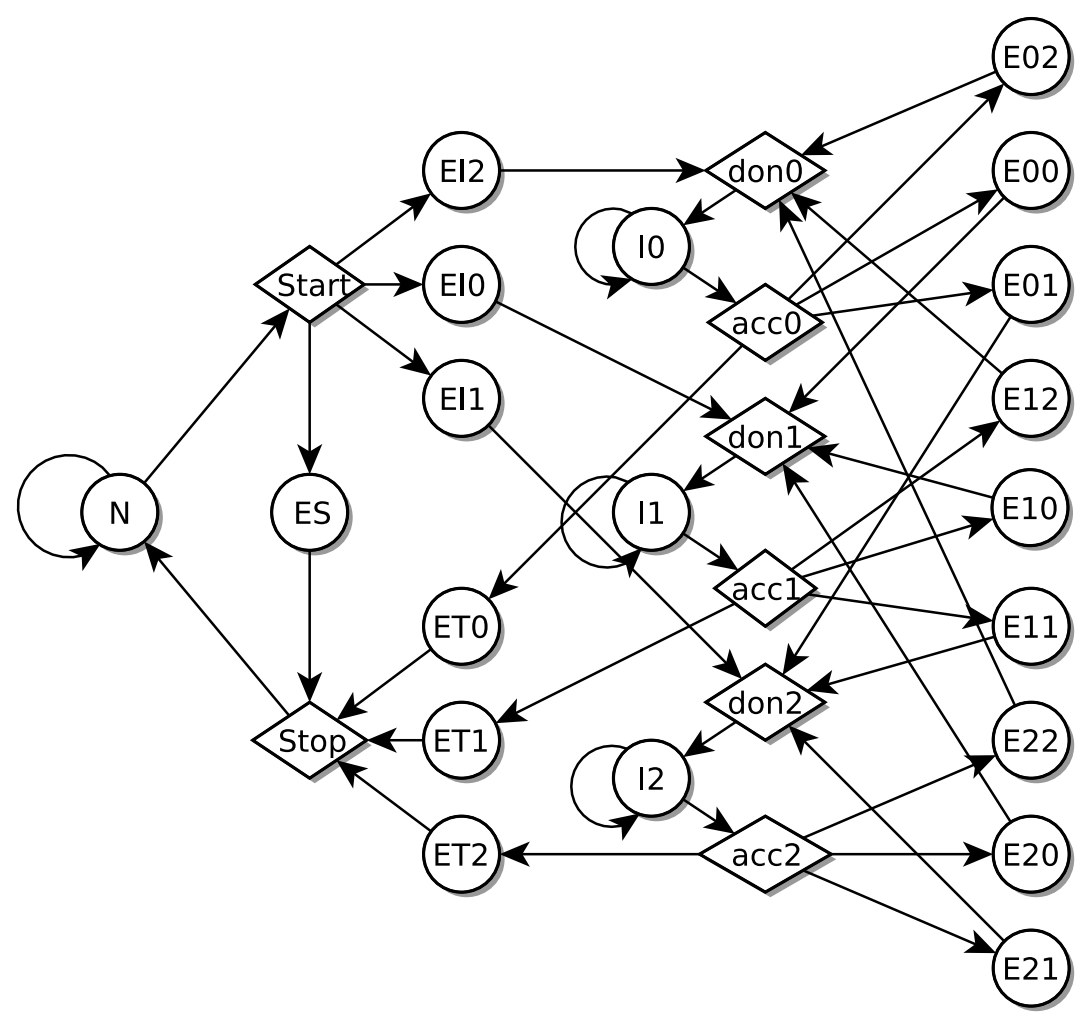

Figura 2.3: Ilustração de uma arquitetura de GHMM representando apenas uma das fitas e com as fases de leituras dos éxons. 
Tabela 2.2: Número de estados em uma GHMM para predição de genes

\begin{tabular}{lcc}
\hline Região do gene & Tipo de duração & $\begin{array}{c}\text { Quantidade de estados } \\
\text { (ambas as fitas do DNA) }\end{array}$ \\
\hline Éxon inicial & Duração explícita & $3+3$ \\
Éxon interno & Duração explícita & $9+9$ \\
Éxon terminal & Duração explícita & $3+3$ \\
Éxon único & Duração explícita & $1+1$ \\
Íntron & Duração geométrica & $3+3$ \\
região intergênica & Duração geométrica & 1 \\
sítio aceitador & Duração constante & $3+3$ \\
sítio doador & Duração constante & $3+3$ \\
códon de iniciação & Duração constante & $1+1$ \\
códon de terminação & Duração constante & $1+1$ \\
\hline
\end{tabular}

total de 55 estados

modelagem de ambas as fitas também é aplicado na maioria dos preditores ab initio para organismos eucarióticos. A Tabela 2.2 mostra a quantidade de estados usados para representar cada região do gene. Um modelo GHMM, obtido a partir do modelo da Figura 2.2, que considera as modificações para modelar ambas as fitas e que representa as fases de leitura tem um total de 55 estados. Este modelo é a base para implementar qualquer preditor de genes baseado em GHMM. GENSCAN (Burge, 1997) possui, além desses estados, outros estados para a região promotora, sinal de poliadenilação, 5'UTR, 3’UTR e sinal de ponto de ramificação. AUGUSTUS (Stanke e Waack, 2003) possui também estados de duração explícita para representar os íntrons curtos (comprimento menor que 584 nucleotídeos em $H$. sapiens).

\subsubsection{Definição de GHMM}

Uma GHMM é descrito usando uma septupla $(Q, A, \pi, d, m, p, f)$ em que:

- $Q$ é o conjunto de estados do modelo GHMM.

- $A$ é o conjunto de símbolos observáveis.

- $\pi: Q \rightarrow[0,1]$ é a função de probabilidade inicial, $\sum_{i \in Q} \pi(i)=1$.

- $f: Q \rightarrow[0,1]$ é a função de probabilidade final, $0 \leq f(i) \leq 1$.

- $p: Q \times Q \rightarrow[0,1]$ é a função de probabilidade de transição de estados, $\sum_{i \in Q} p(i, j)=1$, para todo $j \in Q$.

- $d: \mathbf{N}^{*} \times Q \rightarrow[0,1]$ é a função de probabilidade de duração, $\sum_{\ell \in N^{*}} d(\ell, j)=1$ para todo $j \in Q$ e $N^{*}$ é o conjunto de números naturais não nulos. 
- $m: A^{*} \times Q \rightarrow[0,1]$ é a função de probabilidade de emissão, $\sum_{a \in A^{\ell}} m(a, j)=1$ para todo $j \in Q, \ell \in N^{*}$ e $A^{*}$ é o conjunto de todas as palavras sobre o alfabeto finito $A$.

Geralmente, é mais fácil entender através da simulação deste modelo. O algoritmo que usamos para gerar uma sequência dado o modelo GHMM contém os seguintes passos:

1. Com probabilidade $\pi(q)$ escolha o estado inicial $q$.

2. Se $q$ for de duração explícita ou de duração constante, então escolha uma duração $\ell$ com probabilidade $d(\ell, q)$, senão faça $\ell \leftarrow 1$.

3. Escolha uma palavra $y \in A^{\ell}$ de tamanho $\ell$ com probabilidade $m(y, q)$ e concatene a palavra a saída.

4. Com probabilidade $f(q)$ termine.

5. Escolha o próximo estado $q^{\prime}$ com probabilidade $p\left(q^{\prime} \mid q\right)$.

6. Atribua o valor de $q^{\prime}$ em $q$ e repita, quantas vezes for necessário, os passos $2,3,4$, e 5 .

A saída resultante corresponde ao processo $\left(X_{t}\right)_{t \in \mathbf{N}}$ que é observado.

\section{HMM e GHMM}

Uma cadeia de Markov oculta é um par de processos estocásticos $\left(X_{t}, Y_{t}\right)_{t \in \mathbf{N}}$ em que o processo observado $\left(X_{t}\right)_{t \in \mathbf{N}}$ está relacionado com a cadeia de Markov $\left(Y_{t}\right)_{t \in \mathbf{N}}$ por um mapeamento $f$, isto é, $X_{t}=f\left(Y_{t}\right)$. Em vez de uma cadeia de Markov, a cadeia de Markov generalizada oculta é dado por um processo semi-markoviano $\left(S_{t}\right)_{t \in \mathbf{N}}$ o qual é formado por uma cadeia de Markov de alcance $k=1$ representando transições entre os estados, e distribuições discretas para representar o tempo gasto nos estados. Usamos algumas restrições para a construção da cadeia semi-markoviana (Guédon, 2003):

- probabilidade inicial $i: \pi(i)=\operatorname{Pr}\left\{S_{0}=i\right\} \operatorname{com} \sum_{i} \pi(i)=1$.

- probabilidade de transição:

- estado de duração constante $i: p(i \mid i)=\operatorname{Pr}\left\{S_{t+1}=i \mid S_{t}=i\right\}=0$ e $\sum_{j \in Q} p(j \mid i)=1$ para cada $i \in Q$.

- estado de duração explícita $i$ : para cada $i \neq j, p(j \mid i)=\operatorname{Pr}\left\{S_{t+1}=j \mid S_{t+1} \neq\right.$ $\left.i, S_{t}=i\right\} \operatorname{com} \sum_{i \neq j} p(j \mid i)=1$.

- estado de duração geométrica $i: p(i \mid i)=\operatorname{Pr}\left\{S_{t+1}=i \mid S_{t}=i\right\} \geq 0$ e $\sum_{j \in Q} p(j \mid i)=$ 1 para cada $i \in Q$. 
Para cada estado $j$ de duração explícita, uma distribuição arbitrária de duração é anexada. A probabilidade, $d(\ell, j)$, de ficar no estado $j$ por um tempo $\ell \in\left\{1, \cdots, M_{j}\right\}$ é dada por uma distribuição finita e discreta,

$$
d(\ell, j)=\operatorname{Pr}\{S_{t+\ell+1} \neq j, S_{t+\ell}^{t+2}=\underbrace{j j \cdots j}_{\text {tamanho } \ell-1} \mid S_{t+1}=j, S_{t} \neq j\}
$$

em que $M_{j}$ é o tempo máximo de duração no estado $j$ de duração explícita. Estamos supondo que o tempo é dado por um conjunto finito de pontos.

Os estados de duração constante tem $d(\ell, j)=1$ para algum $\ell \in \mathbf{N}^{*}$.

Seja $m\left(x_{t+\ell-1}^{t}, j\right)$ a probabilidade de emissão de um segmento $x_{t+\ell-1}^{t}$ durante a permanência no estado $j$ é dado por:

$$
\left.m\left(x_{t+\ell-1}^{t}, j\right)=\operatorname{Pr}\{X_{t+\ell-1}^{t}=x_{t+\ell-1}^{t} \mid X_{t-\ell}^{0}=x_{t-\ell}^{0}, S_{t-\ell}^{0}=s_{t-\ell}^{0}, S_{t+\ell-1}^{t}=\underbrace{j j \cdots j}_{\text {tamanho } \ell}\}\right\}
$$

No modelo GHMM, a função $m(\cdot, j)$ é definida para cada estado $j \in Q$ por um modelo probabilístico arbitrário que represente cadeias de símbolos, tais como modelos da Seção 2.3.

\subsubsection{Parâmetros arbitrários}

Existem muitos parâmetros arbitrários que definimos durante a implementação ou durante o treinamento de um preditor. Tais parâmetros influenciam de forma significativa na exatidão do preditor e não são triviais de serem refinados. Majoros e Salzberg (2004) descreveram um procedimento de gradiente ascendente para melhorar a exatidão dos preditores variando os valores de um conjunto de parâmentros arbitrários. Embora esta abordagem não garanta um ótimo global, ele conseguiu de forma significativa melhorar a qualidade das predições em troca de um grande custo computacional. Exemplos de parâmetros arbitrários são:

- Alcance do modelo de Markov de cada região do gene.

- Comprimento dos sinais biológicos.

- Limiar de corte para selecionar sinais biológicos candidatos.

- Comprimento médio da região intergênica.

Existem alguns valores típicos para cada parâmetro arbitrário. A cadeia de Markov para a região codificadora e região não-codificadora é geralmente de ordem 5 ou ordem 4 . A cadeia de Markov para sinais é geralmente de ordem 1. O comprimento dos sinais biológicos é definido usando um limiar para cortar posições com entropia muito alta, considerando que as posições distantes da sequência conservada do sinal possuem entropia maior do que 
posições próximas. O valor do comprimento médio da região intergênica está geralmente descrito na literatura. Finalmente, na configuração padrão, o Tigrscan e o GlimmerHMM usam um limiar de corte com $99 \%$ de sensibilidade para selecionar sinais candidatos. A implementação do Viterbi do AUGUSTUS faz com que não seja necessário o uso de limiar para selecionar sinais candidatos. 


\section{Capítulo 3}

\section{GHMMs com algoritmos de decodificação eficientes}

Uma versão eficiente do algoritmo de Viterbi (Guédon, 2003; Rabiner, 1989), que execute em tempo $O(L)$ em que $L$ é o tamanho da sequência, para o modelo GHMM é fundamental para a decodificação de grandes sequências em tempo relativamente curto. A necessidade de programas eficientes motivou a implementação de algoritmos de decodificação específicos para o problema de predição de genes (Majoros et al., 2005a). Como consequência das otimizações, os modelos GHMMs e os algoritmos associados a eles ficaram acoplados e difíceis de serem alterados para a realização de experimentações. Por outro lado, um algoritmo de Viterbi, que funcione para casos gerais, pode não ser eficiente a ponto de ser utilizado para analisar sequências genômicas.

Apresentaremos uma nova versão do algoritmo de Viterbi para modelos GHMMs que foi implementada no ToPS. Essa versão ao mesmo tempo é eficiente para modelos que satisfazem um conjunto de restrições e fornece uma liberdade para o usuário construir modelos arbitrários.

\subsection{Algoritmo de Viterbi}

Existem diferentes formas de fornecer uma predição para a estrutura do gene, mas a utilizada pela grande maioria consiste em buscar no conjunto de todos os caminhos o caminho mais provável dada uma sequência e um modelo GHMM. Seja o modelo GHMM, $M=(Q, A, \pi, d, m, p, f)$, o algoritmo de Viterbi tenta encontrar um caminho $\phi^{*}$ de maior probabilidade, ou seja, que satisfaz a seguinte fórmula:

$$
\phi^{*} \in \arg \max _{\phi \in Q^{L}} \operatorname{Pr}\left\{S_{L}^{1}=\phi, X_{L}^{1}=x_{L}^{1} \mid M\right\}
$$

Existem várias formas diferentes de encontrar um caminho que satisfaz a fórmula acima. A estratégia mais simples para encontrarmos um $\phi^{*}$ consiste em calcular a probabilidade 
de cada $\phi \in Q^{L}$ e selecionar aquele que forneceu o maior valor. Porém, listar todos os caminhos possíveis é ineficiente, pois a quantidade de caminhos cresce exponencialmente com o tamanho da sequência.

Uma outra estratégia consiste em utilizar programação dinâmica o qual resolve o problema através da solução de subproblemas menores. Em muitos casos, quando a técnica de programação dinâmica consegue reaproveitar soluções de subproblemas recorrentes, conseguimos fornecer um algoritmo mais eficiente.

Em particular, o algoritmo de Viterbi utiliza programação dinâmica e explora a chamada variável de Viterbi, $\gamma_{i}(j)$, que é a probabilidade conjunta entre o caminho ótimo e a sequência $x_{j}^{1}$ que termina no estado $i$ na posição $j$.

$$
\gamma_{i}(j)=\max _{\phi_{j}^{1} \in Q^{j} \mathrm{e} \phi_{j}=i} \operatorname{Pr}\left\{S_{j}^{1}=\phi_{j}^{1}, X_{j}^{1}=x_{j}^{1} \mid M\right\}
$$

Podemos aplicar uma recursão para computar a variável de Viterbi:

$$
\begin{aligned}
\gamma_{i}(j) & =\max _{\phi_{j}^{1} \in Q^{j} \mathrm{e} \phi_{j}=i} \operatorname{Pr}\left\{S_{j}^{1}=\phi_{j}^{1}, X_{j}^{1}=x_{j}^{1} \mid M\right\} \\
& =\max \left\{\operatorname{Pr}\{S_{j}^{1}=\phi_{j}^{1}, X_{j}^{1}=x_{j}^{1} \mid M, \phi_{j}^{1}=\underbrace{i i \cdots i}_{\text {tamanho } j}\}\right. \\
& \left.\operatorname{Pr}\{S_{j}^{1}=\phi_{j}^{1}, X_{j}^{1}=x_{j}^{1} \mid M, \phi_{j}^{1}=\phi^{\prime} \underbrace{i i \cdots i}_{\text {tamanho } l}\}\right\} \\
& =\max _{q \in Q}\left\{\pi(i) m\left(x_{j}^{1}, i\right) d(j, i),\right. \\
& \phi_{j}^{1} \in Q^{j-l} \mathrm{e} \phi_{j-l}=q \\
& =\max _{q \in Q}\left\{\pi(i) m\left(x_{j}^{1}, i\right) d(j, i), \gamma_{q}(j-\ell) p(i \mid q) m\left(x_{j}^{j-\ell+1}, i\right) d(\ell, i)\right\}
\end{aligned}
$$

O algoritmo que calcula o valor da variável de Viterbi é dado por:

\section{- Inicialização:}

$$
\gamma_{i}(1)=\pi(i) m\left(x_{1}^{1}, i\right) d(1, i) \text { para } i \in Q
$$

- Recursão: Para todo $i \in Q$ e $1<j<L$ faça

$$
\gamma_{i}(j)=\max _{k \in Q, \ell \in\{1, \cdots, j-1\}} \gamma_{k}(j-\ell) m\left(x_{j}^{j-\ell+1}, i\right) p(i \mid k) d(\ell, i) \text { para } i \in Q
$$

\section{- Terminação:}

$$
\gamma_{i}(L)=\max _{k \in Q, \ell \in\{1, \cdots, L-1\}} \gamma_{k}(L-\ell) m\left(x_{L}^{L-\ell+1}, i\right) p(i \mid k) d(\ell, i) f(i) \text { para } i \in Q
$$


O valor $\max _{i \in Q} \gamma_{i}(L)$ é a probabilidade do caminho mais provável e para recuperá-lo basta armazenar em cada passo do algoritmo um ponteiro para o estado anterior mais provável e utilizar um algoritmo de backtracing. Esta versão do algoritmo de Viterbi funciona para casos gerais de GHMM em tempo $O\left(|Q|^{2} \times L^{3}\right)$, assumindo que o cálculo de $m\left(X_{\ell}^{1}, i\right)$ consome tempo $O(\ell)$. Um algoritmo com complexidade cúbica não é eficiente o suficiente para analisar sequências genômicas, já que ele iria demorar muitos anos para decodificar uma sequência de alguns megabytes.

Uma outra possível implementação que tenta resolver este problema, descrita em Burge (1997) e Majoros et al. (2005b), consiste em identificar na sequência de entrada os possíveis sinais biológicos utilizando para cada sinal um modelo probabílistico, $M_{\text {sinal }}$, treinado com uma amostra do respectivo sinal e um outro modelo, $N$, treinado com sequências de falsos sinais, ou seja, sequências que possuem a sequência conservada do sinal mas que não foram anotadas como sendo da mesma família do sinal. Para cada posição $i$ da sequência de entrada, o preditor calcula o logaritmo da razão de verossimilhança da subsequência $X_{i}^{i-n+1}=x_{i}^{i-n+1}$ dado ambos os modelos, em que $n$ é o comprimento da sequência do sinal:

$$
R_{\text {SINAL }}\left(X_{i}^{i-n+1}=x_{i}^{i-n+1}\right)=\log \left(\frac{P\left(X_{i}^{i-n+1}=x_{i}^{i-n+1} \mid M_{\text {sinal }}\right)}{P\left(X_{i}^{i-n+1}=x_{i}^{i-n+1} \mid N\right)}\right)
$$

Quando este valor é maior que um certo limiar arbitrário, a posição da sequência é classificada como candidato a ter um sinal. O conjunto de sinais candidatos encontrados representa um conjunto de estruturas, com o qual o algoritmo irá trabalhar. Contudo, esta filtragem não garante que encontremos um $\phi^{*}$ com o valor máximo de probabilidade, já que muitos caminhos não serão considerados, por esse motivo, vamos chamar o caminho encontrado por essa versão de $\phi^{\prime *}$.

O cálculo do caminho $\phi^{*}$ precisa da construção de uma lista $L_{j}$ em cada posição $j$ da sequência, representando o conjunto de estados com duração explícita que podem terminar na posição $j$. Cada estado $k$ de duração explícita da lista tem as seguintes propriedades:

- $s_{k}$ é o estado de duração constante que é anterior ao estado $k$;

- $z_{k}$ é o estado de duração constante que aparece depois do estado $k$;

- $\lambda_{k}$ indica o comprimento do estado $k$;

- $a_{k}$ indica o começo do estado $k$;

- $b_{k}=a_{k}+\lambda_{k}-1$ indica o fim do estado $k$;

- $c_{k}=j$ indica o fim do estado $z_{k}$;

A variável $\gamma_{i}(j)$ armazena a probabilidade conjunta da subsequência $x_{j}^{1}$ e do caminho ótimo, restrito aos sinais candidatos, que termina no estado $i$ na posição $j$. Esta variável é calculada recursivamente para uma sequência de tamanho $\ell$ da seguinte forma: 
- Inicialização: Seja $E$ o conjunto de estados de duração explícita:

$$
\gamma_{i}(1)=\pi(i) m\left(x_{1}^{1}, i\right) d(1, i) \text { para } i \in\{Q-E\}
$$

- Recursão: Para todo $i \in Q-E$ e $1<j<\ell$ faça

- Se $i$ for de duração constante:

$$
\gamma_{i}(j)=\max _{k \in L_{j}}\left\{\gamma_{s_{k}}\left(a_{k}-1\right) p\left(k \mid s_{k}\right) m\left(x_{b_{k}}^{a_{k}}, k\right) d\left(\lambda_{k}\right) p(i \mid k) m\left(x_{j}^{b_{k}+1}, i\right)\right\}
$$

- Se $i$ for de duração geométrica:

$$
\gamma_{i}(j)=\max _{k \in Q}\left\{\gamma_{k}(j-1) p(i \mid k) m\left(x_{j}^{j}, i\right)\right\} \text { para } k \in Q
$$

\section{- Terminação:}

- Se $i$ for de duração constante:

$$
\gamma_{i}(\ell)=\max _{k \in L_{\ell-1}}\left\{\gamma_{s_{k}}\left(a_{k}-1\right) p\left(k \mid s_{k}\right) m\left(x_{b_{k}}^{a_{k}}, k\right) d\left(\lambda_{k}\right) p(i \mid k) m\left(x_{\ell-1}^{b_{k}+1}, i\right)\right\}
$$

- Se $i$ for de duração geométrica:

$$
\gamma_{i}(\ell)=\max _{k \in Q}\left\{\gamma_{k}(\ell-1) p(i \mid k)\right\} \text { para } k \in Q
$$

A complexidade deste algoritmo depende de como cada valor de emissão $m(\cdot, k)$ é calculado. Se esta função for fatorável, então é possível calcular o valor da probabilidade de emissão em tempo $O(1)$ após um pré-processamento em tempo $O(L)$ (Majoros et al., 2007). Burge (1997) mostrou que considerando sequências genômicas de H. sapiens na média a quantidade de sinais candidatos cresce linearmente com o tamanho da sequência, fazendo com que esta versão do algoritmo de Viterbi execute em tempo médio $O\left(|Q|^{2} \times L\right)$.

O algoritmo descrito por Burge (1997) e Majoros et al. (2005b) assume uma arquitetura em que cada emissão de um estado de duração explícita esta flanqueada por emissões de estados de duração constante. O ToPS em suas primeiras versões implementava esse algoritmo o que impedia a construção de uma GHMM mais geral. Além disso, a filtragem dos sinais candidatos não garante que o caminho mais provável verdadeiro seja encontrado.

\subsection{GHMMs com decodificação eficiente}

O ToPS deve fornecer uma implementação do algoritmo de Viterbi que aceite uma arquitetura arbitrária de GHMM, mas que também funcione de forma eficiente quando for 
possível. Existem três propriedades que podemos explorar e que permitem uma execução do processo de decodificação em tempo $O(|Q| \times L)$ (Majoros et al., 2007):

- A GHMM é esparsa, ou seja, a quantidade de transições de um dado estado está limitada a uma constante $C$. Esta constante limita a quantidade de estados anteriores que o algoritmo deve buscar, permitindo que o algoritmo rode em tempo $O(C \times|Q| \times$ $\left.L^{3}\right)$.

- Os estados tem durações limitadas por uma constante $M$ que limita a quantidade de posições anteriores que o algoritmo busca. Esta constante permite executar o algoritmo em tempo $O\left(C \times|Q| \times M \times L^{2}\right)$.

- A verossimilhança de uma sequência dado um modelo de emissão é fatorável, isto é, ela é calculada como um produto de fatores, um fator para cada posição da sequência. Todos os modelos de Markov que já vimos em 2.3.2, e 2.3.2 possuem esta propriedade. Utilizando a técnica chamada prefix sum array, descrita por Majoros et al. (2005b), é possível calcular a verosimilhança de uma subsequência em tempo constante depois de um preprocessamento que consome tempo linear. Com essa restrição, o algoritmo executa em tempo $O(C \times|Q| \times M \times L) \subseteq O(|Q| \times L)$.

Em predição de genes a GHMM satisfaz todas as três condições. Cada estado tem no máximo quatro transições de saída, podemos definir o tamanho máximo de duração de cada estado, e todos os modelos de emissão utilizados podem ser calculados como um produto de fatores. A primeira propriedade é explorada através do utilização da lista de adjacência que representa o grafo da arquitetura da GHMM, a segunda propriedade simplesmente limita o comprimento máximo da emissão de um estado com o qual o algoritmo Viterbi precisa analisar. Finalmente, a última propriedade é explorada através de um pre-processamento em tempo linear aplicando o modelo de emissão de cada estado.

Embora o consumo de tempo seja linear no comprimento da sequência, o algoritmo que explora essas três propriedades ainda não é eficiente o bastante. Mesmo quando a GHMM satisfaz essas três propriedades, ainda teremos casos que o valor do comprimento máximo da emissão, embora constante, é muito alto (> 2000). O ToPS explora ainda outras pequenas otimizações que serão discutidas na próxima Seção.

\subsubsection{Outras otimizações}

Em alguns casos, podemos ter GHMMs com submodelos que fornecem probabilidade zero de emissão para algumas subsequências. Em predição de genes a maioria dos submodelos tem essa propriedade. Por exemplo, o submodelo do sítio doador sempre emite a subsequência "GT" na mesma posição, o submodelo de início de tradução sempre emite "ATG", o submodelo de fim de tradução emite "TAA", "TAG", ou "TGA", o sítio aceitador emite "AG", e o submodelo de região codificadora não emite o códon de terminação na fase 0 de leitura. 
Como consequência, a maioria dos caminhos dada uma sequência fica com probabilidade zero, ou seja, a maioria das entradas da matriz $\gamma_{i}(j)$ é igual a zero.

Podemos explorar dinamicamente a esparsidade de $\gamma_{i}(j)$ para economizar mais tempo durante a execução do algoritmo. Como o algoritmo de Viterbi preenche a matriz $\gamma_{i}(j)$ da esquerda (de $j=1$ ) para a direita (até $j=L$ ), é possível prever quando o valor de $\gamma_{i}(j$ ) será zero antes de buscar pelo estado anterior mais provável e pela duração mais provável. O algoritmo de Viterbi do ToPS matém uma lista para cada estado com todas as posições que fornece uma probabilidade diferente de zero para algum estado anterior e duração anterior, assim em cada passo do Viterbi basta percorrer esta lista. Ela é atualizada de acordo com as probabilidades de emissão, e probabilidades de duração. Todas as vezes que o algoritmo encontrar valores zero de probabilidade ele remove da lista o conjunto de todas as posições correspondentes, ou quando há probabilidade maior que zero ele adiciona elementos na lista. Adicionar e remover elementos na lista ligada é computacionalmente eficiente (consumo de tempo $O(1))$. Esta estratégia se mostrou eficiente para aplicabilidade em predição de genes, como mostraremos nos nossos resultados.

A nossa implementação consome $2 \mathrm{~Gb}$ para uma sequência de entrada de $1 \mathrm{Mb}$ e o consumo de memória cresce linearmente com o tamanho da sequência. Assim, para processar uma sequência de um cromossomo é necessário dividir a sequência em pequenas partes e processar cada parte individualmente. Esse passo de dividir a sequência não é muito problemático ao considerar que o preditor é formado por diversos modelos de GHMM específico de isochore. Considerando esse fato, o processo de divisão é vantajoso em termos de precisão e sensibilidade. Em nosso experimento, dividindo a sequência em segmentos de 1Mb foi necessário $64 \mathrm{~min}$ para processar uma sequência de $50 \mathrm{Mb}$ utilizando dois processos paralelos em uma máquina com dois Intel Xeon CPU E5410 e 16Gb de memória RAM.

\subsection{Tempo médio empírico de execução}

O gráfico da Figura 3.1 mostra o tempo consumido pelo nosso algoritmo de Viterbi em relação ao tamanho da sequência de entrada utilizando o processador Intel Xeon CPU E5410. Durante a análise de tempo empírico é importante fazer uma suposição sobre a distribuição da entrada, nesse caso assumimos que as sequências de entrada seguem a mesma distribuição dada pelo modelo GHMM. Assim, utilizamos sequências de diversos tamanhos obtidas pela simulação de uma GHMM para predição de genes e executamos o algoritmo de Viterbi utilizando o mesmo modelo GHMM. Como esperado, obervamos que o tempo no caso médio segue um padrão linear com relação ao tamanho da sequência. 


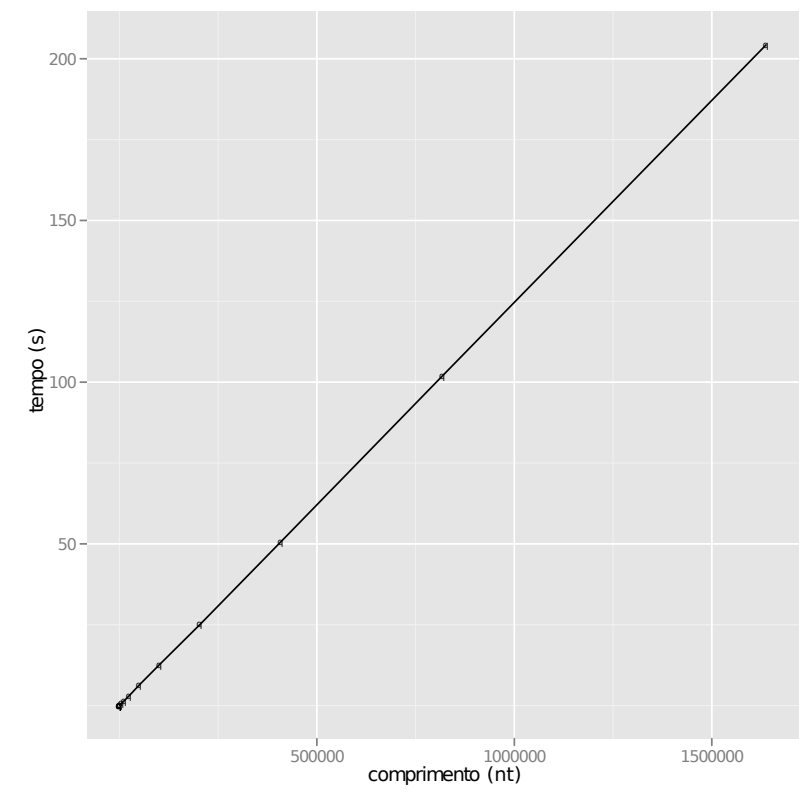

Figura 3.1: Tempo de execução do algoritmo de Viterbi 


\section{Capítulo 4}

\section{ToPS: um arcabouço para manipular modelos probabilísticos}

Modelos probabilísticos representando sequências discretas têm aplicações em muitas áreas de pesquisa tais como processamento de linguagens naturais (Manning e Schütze, 1999), computação musical (Klapuri e Davy, 2006), e Bioinformática (Durbin et al., 1998). Exemplos de tais modelos incluem modelos de Markov ocultos (Hidden Markov Models - HMM) (Rabiner, 1989), modelos ocultos semi-Markovianos (Hidden semi-Markov model (Guédon, 2003)), e cadeias de Markov de alcance variável (Rissanen, 1983) (Variable Length Markov Chain - VLMC).

Existem muitas implementações específicas, mas não encontramos na literatura nenhuma que oferece uma ampla variedade de modelos em um único arcabouço. Elas não são suficientes quando queremos representar sequências heterogeneas em domínios onde distintos modelos probabilísticos são necessários para uma boa representação, ou para construirmos classificadores onde diferentes famílias de sequências são caracterizadas por tipos de modelos distintos. Uma alternativa é o uso de sistemas de uso geral tal como o R ( R Development Core Team, 2008) que contém um grande número de pacotes para utilizar esses modelos. Contudo, nenhum pacote oferece uma variedade de modelos probabilísticos, forçando o uso de diferentes interfaces e pacotes, tarefa que dificulta o uso combinado de modelos.

Programas que fornecem uma grande variedade de modelos são comuns em predição de genes. Sistemas de predição de genes tal como o Tigrscan (Majoros et al., 2004), e o Twinscan (Korf et al., 2001) implementam modelos ocultos generalizados de Markov (Generalized Hidden Markov Model - HMM) (Burge, 1997; Kulp. et al., 1996) que combinam muitos submodelos para representar as sequências de genes. No entanto, esses programas são específicos para o domínio de predição de genes e não permitem o uso individual de cada submodelo.

Neste capítulo descreremos ToPS (Toolkit of Probabilistic Model of Sequence) implementa atualmente mecanismos que possibilitam o uso de diferentes tipos de modelos incluindo:

- processo independente e identicamente distribuído

- cadeias de alcance variável de Markov (VLMC - variable length Markov chain) 
- cadeias ocultas de Markov (HMM - hidden Markov model)

- cadeias não-homogêneas de Markov (IHMC - Inhomogeneous-Markov-Chain)

- cadeias generalizadas ocultas de Markov (GHMM - generalized hidden Markov chain)

- cadeias de pares ocultos de Markov (GPHMM - generalized pair hidden Markov chain) ${ }^{1}$.

O ToPS foi implementado em linguagem $\mathbf{C}++$ que possibilita o uso em diferentes plataformas e também possibilita a criação dos chamados wrappers para acessar os algoritmos do ToPS em outras linguagens de programação. Atualmente, fornecemos com a distribuição do ToPS um pacote para o uso no R. ToPS foi testado nos ambientes Linux, Mac OS X, e Windows.

ToPS tem seu código aberto e é distribuído sob a licença GPL versão 3.0. Ele está hospedado em http://tops.sourceforge.net/, onde há um repositório Git² o qual podem ser encontrados versões em desenvolvimento.

\subsection{Utilização do ToPS}

ToPS pode ser utilizado para criar amostradores de sequências, classificadores bayesianos, ou decodificadores de sequências. De qualquer forma, o usuário precisa primeiro especificar os parâmetros do modelo, descrevendo cada um manualmente, ou utilizando algum algoritmo de treinamento. A Figura 4.1 mostra o uso do ToPS em diferentes contextos.

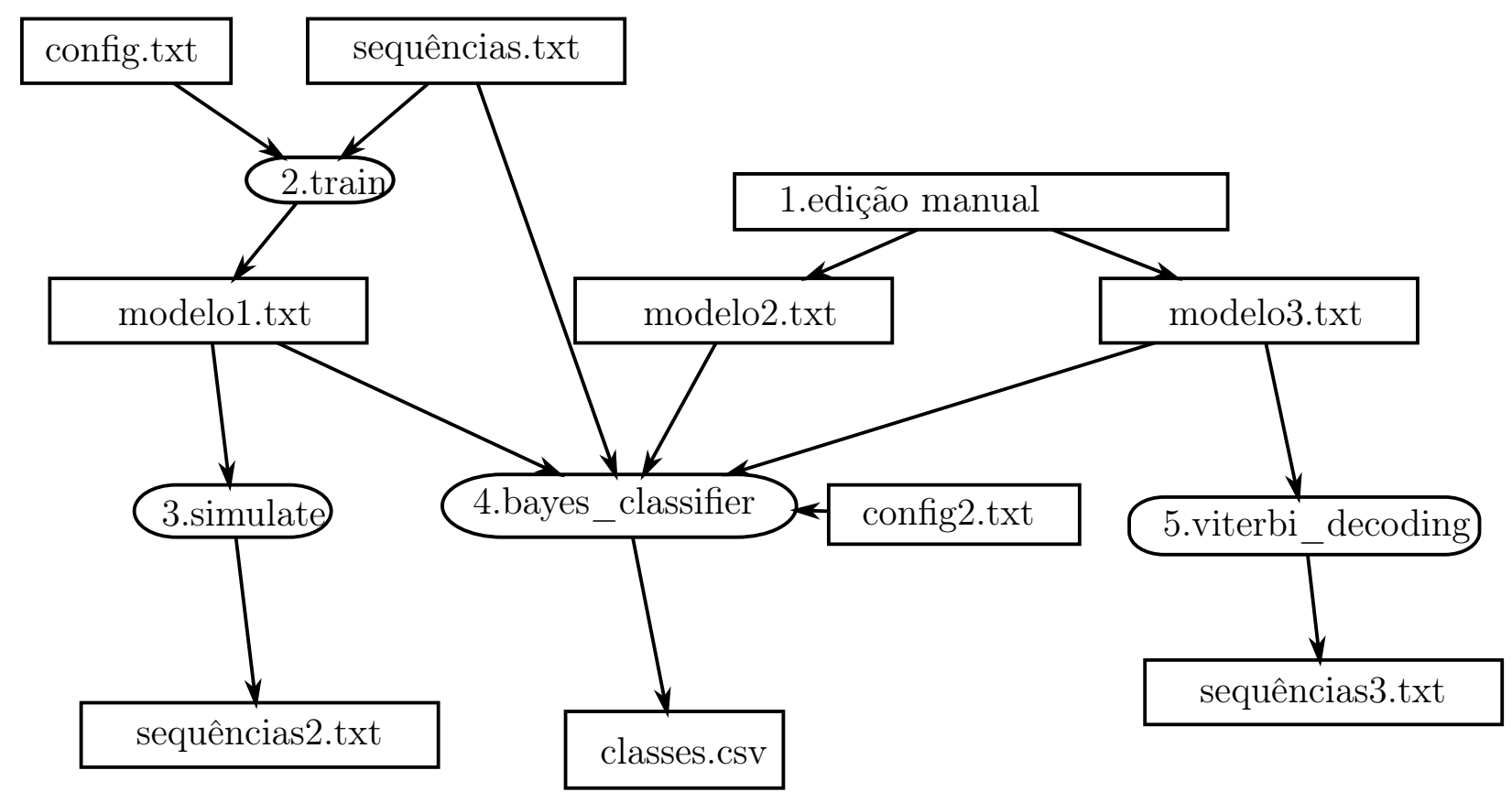

Figura 4.1: Diagrama com o uso do ToPS. Caixas retangulares representam arquivos com os dados ou processos manuais, caixas arredondadas representam programas.

\footnotetext{
${ }^{1}$ Implementado pelo Vitor Onuchic, mestrando em Bioinformática da Universidade de São Paulo

${ }^{2}$ http://git-scm.com
} 
Nesta seção, vamos utilizar o exemplo do cassino desonesto (Durbin et al., 1998) para ilustrar o uso das aplicações do arcabouço ToPS.

\subsubsection{Descrevendo um modelo probabilístico}

O cassino desonesto utiliza dois dados, um dado honesto, e um outro dado desonesto. $\mathrm{O}$ cassino troca de dados frequentemente sem avisar. Um jogador mais esperto pretende obter mais conhecimento sobre o dado desonesto e sobre a frequência de uso de cada tipo de dado.

Um modelo HMM vai ser utilizado para representar esta situação. Precisamos especificar:

- um conjunto de estados

- um conjunto de símbolos observados

- a distribuição de estados iniciais

- a função de transição de estados

- a probabilidade de emissão

Vamos utilizar uma HMM de dois estados:

- um estado para representar o dado honesto

- outro estado para representar o dado desonesto

Inicialmente, vamos assumir que a probabilidade de troca dos dados é igual a 0.1 , e que a probabilidade de observar o número 1 quando o cassino utiliza o dado desonesto é 0.5 . Na Figura 4.2, mostramos o modelo HMM para o cassino desonesto.

Um arquivo texto descreve os parâmetros deste modelo. $\mathrm{O}$ arquivo cassino.model define:

- state_name é lista de rótulos associados aos estados

- observation_symbols é uma lista que descreve os símbolos observados

- transitions especifica as probabilidades de transições

- emission_probabilities especifica as probabilidades de emissões

- initial_probabilities especifica as probabilidades iniciais dos estados

O símbolo "\#" indica que o resto da linha é para ser ignorado, pois é apenas um comentário. 


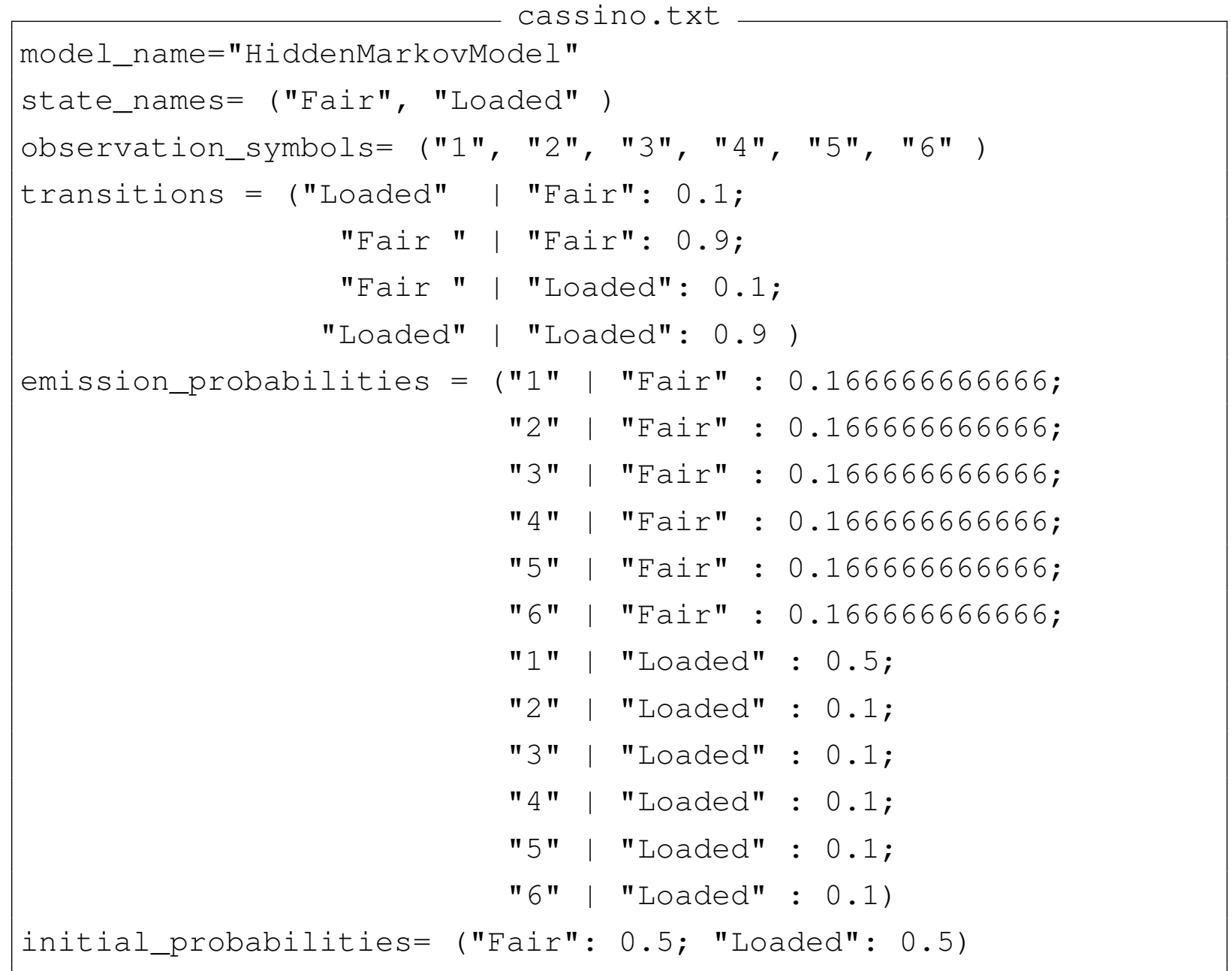

A partir do momento que definimos os parâmetros do modelo, podemos utilizar o arquivo cassino.txt como entrada para outros aplicativos do ToPS.

\subsubsection{Inferência dos parâmetros}

Se o jogador observou a sequência de números escolhidos pelo cassino desonesto, então o jogador pode tentar melhorar os parâmetros do modelo inicial utilizando um procedimento de re-estimação. Uma opção disponível para HMMs no ToPS é o algoritmo BaumWelch (Rabiner, 1989) (também conhecido como algoritmo forward-backward), que utilizaremos neste nosso exemplo. O algoritmo Baum-Welch descreve um procedimento iterativo

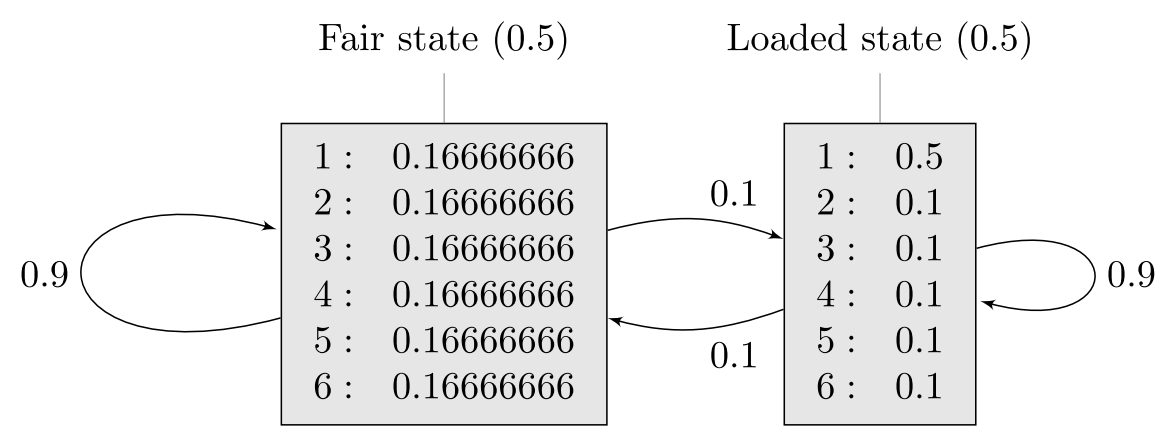

Figura 4.2: HMM para o cassino desonesto 
que tenta encontrar o estimador de máxima verossimilhança dos parâmetros utilizando tanto um modelo de HMM pré-definido como um modelo inicial, quanto um conjunto de sequências de entrada. Como modelo inicial, vamos utilizar os parâmetros especificados na seção anterior.

O arquivo de configuração, cassino_bw_train.cfg, especifica o procedimento de treinamento:

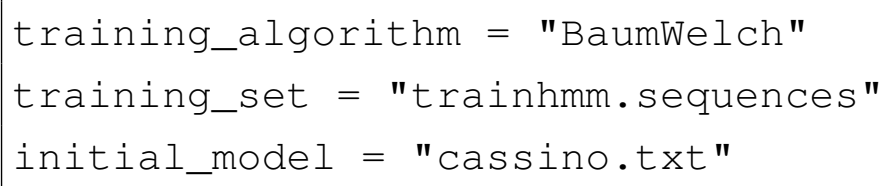

O programa train devolve na saída padrão os parâmetros do modelo em um formato fácil de ler. O seguinte comando criará um arquivo, cassino_bw.model, que podemos utilizar em outros aplicativos do arcabouço.

Linha de comando

train -c cassino_bw_train.cfg > cassino_reestimado_bw.model

\subsubsection{Gerando sequências simuladas}

Simulação de modelos probabilísticos é um procedimento para validar a implementação do modelo. O programa simulate realiza amostragens dado um modelo probabilístico. O usuário pode especificar o comprimento da sequência, a quantidade de sequências geradas.

O comando abaixo, por exemplo, gera 10 sequências de comprimento 1000, utilizando o modelo no arquivo cassino.txt. Nesse caso, como estamos utilizando uma HMM, geramos um arquivo com 10 cadeias com rótulos correspondentes aos estados ocultos de cada símbolo da sequência.

Linha de comando

simulate -m casino.txt -n $10-11000$-h states.sequences

$>$ output.txt

Os parâmetros do simulate são:

- -m especifica o nome do modelo.

- -n especifica a quantidade de sequências a serem geradas.

- -l especifica o comprimento de cada sequência.

- -h especifica o arquivo de saída que irá ter as sequências de estados ocultos. 


\subsubsection{Decodificando uma sequência}

O processo de rotular uma sequência é chamado de decodificação e é uma parte essencial para problemas de reconhecimento. No ToPS, a decodificação é realizada utilizando o algoritmo Viterbi (Rabiner, 1989), acessado no programa viterbi_decoding. Neste caso, a entrada do modelo pode ser uma HMM ou uma GHMM. Com o comando abaixo, o programa lê um arquivo de entrada input.txt e, utilizando o modelo especificado no arquivo casino.txt gera a sequência de estados visitados no caminho mais provável do modelo para cada sequência. O resultado é armazenado no arquivo output .txt.

Command line

viterbi_decoding - m casino.txt $<$ input.txt $>$ output.txt

O comando utiliza o seguinte parâmetro:

- -m especifica o arquivo contendo o modelo.

\subsubsection{Utilizando outros modelos}

O arcabouço implementa outros modelos, e a forma de uso é similar ao que vimos com o exemplo do cassino. A Tabela 4.1 mostra uma descrição de cada modelo implementado. Fornecemos mais exemplos no Apêndice A.

Tabela 4.1: Lista de modelos implementados utilizando o ToPS.

\begin{tabular}{ll}
\hline Nome do Modelo & Algoritmo de Treinamento \\
\hline DiscretelidModel & SmoothedHistogramkernelDensity \\
& SmoothedHistogramStanke \\
& SmoothedHistogramBurge \\
& DiscreteIIDModel \\
\hline VariableLengthMarkovChain & ContextAlgorithm \\
& FixedLengthMarkovChain \\
\hline InhomogeneousMarkovChain & FixedLengthInhomogeneousMarkovChain \\
& VariableLengthInhomogeneousMarkovChair \\
& WeigthArrayModel \\
& PhasedMarkovChain \\
\hline HiddenMarkovModel & BaumWelch \\
\hline GeneralizedHiddenMarkovModel & GHMMTransition \\
\hline
\end{tabular}




\subsubsection{Integrando os modelos}

\section{Classificador bayesiano}

Uma forma útil de combinar modelos é utilizando um classificador bayesiano. Cada modelo representa uma família de sequências. O classificador tenta decidir a família de uma dada sequência comparando as probabilidades a posteriori dos modelos. ToPS oferece o programa bayes_classifier que implementa classificadores bayesianos. Baseado no arquivo de configuração contendo uma lista de modelos probabilísticos e suas probabilidades a priori, o programa lê um conjunto de sequências e devolve, para cada sequência, a probabilidade a posteriori de cada modelo. Um exemplo de arquivo de configuração está na caixa bayes.cfg.

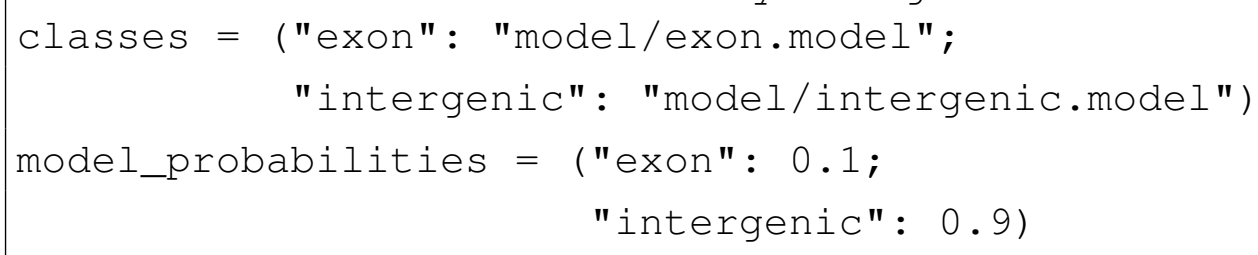

O programa lê as sequências utilizando a entrada padrão e devolve na saída padrão a classe de cada sequência.

Linha de comando

bayes_classifier $-c$ bayes.cfg < sequence.in > classification.out

\section{GHMMs}

Uma outra situação quando queremos combinar modelos probabilísticos é quando queremos segmentar e rotular a sequência em que diferentes partes da sequência são melhores representadas por modelos diferentes. Podemos alcançar este objetivo através do uso do modelo GHMM. Cada estado de uma GHMM emite palavras com probabilidades fornecidas por dois submodelos: (i) o modelo dos símbolos observados; e (ii) a distribuição do comprimento. Com ToPS, o usuário pode selecionar e implementar modelos probabilísticos para caracterizar o modelo observado, e utilizar a distribuição para o processo independente identicamente distrbuída ou uma distribuição geométrica para representar a distribuição do comprimento. Utilizando o conjunto de ferramentas descritos, o usuário pode treinar cada submodelo e combinar eles em uma arquitetura de GHMM.

Os modelos GHMMs são amplamente utilizados na Bioinformática para representar a estrutura dos genes. Para ilustrar, vamos utilizar um modelo simplificado de genes de bactéria. Na bactéria, genes são sequências do genoma com uma composição diferente com sinais específicos de início e fim. O conteúdo dos modelos dos genes são geralmente modelados por uma cadeia não-homogênea de Markov, e o comprimento do gene não segue uma distribuição geométrica. Genes distintos são separados por regiões não-codificadoras. Figura 4.3 ilustra um modelo de gene com 4 estados. O estado Noncoding tem uma distribuição geométrica no comprimento representada por uma transição para ele mesmo. Os estados Start 
e Stop são estados que emitem palavras de comprimento fixos: as regiões fronteiriças da região codificadora. O estado Coding tem uma distribuição iid na duração, e emite palavras de comprimento gerado no modelo "coding_run_length.txt". A descrição do modelo correspondente está mostrado na caixa ghmm.txt.

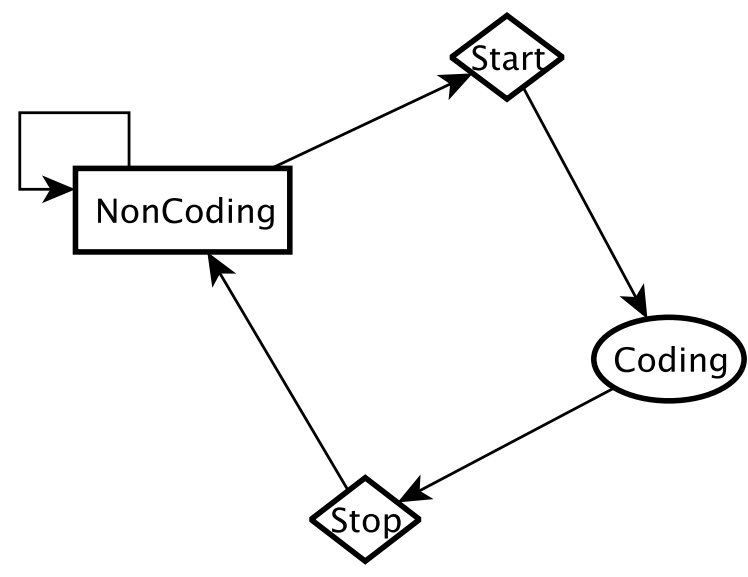

Figura 4.3: GHMM que representa regiões codificadoras em bacterias.

Os parâmetros state_names, observation_symbols, initial_probabilities, e transitions são configurados da mesma forma quando estamos especificando um modelo HMM.

Quando queremos especificar modelos que um modelo GHMM irá utilizar. No nosso exemplo, o modelo GHMM utiliza cinco submodelos: (i) noncoding_model (uma distribuição iid); (ii) coding_model (no arquivo "coding.txt"); (iii) start_model (no arquivo "start.txt"); (iv) stop_model (no arquivo "stop.txt"); (v) coding_duration_model (no arquivo "coding_duration.txt").

Depois de especificar os submodelos, descrevemos a configuração de cada estado. TOPS assume que as GHMMs tem dois tipos de estados: (i) estados de comprimento fixo, que emitem palavras de comprimento fixo; e (ii) estados de comprimento variável, que emitem palavras com comprimentos dado por uma distribuição de probabilidade. Existem dois tipos de estados de comprimento variável: estados com comprimento geometricamente distribuídos; e estados com comprimentos não geometricamente distribuídos. Quando especificado um estado, o usuário deve especificar o modelo observado utilizando o parâmetro observation. Para estados de comprimento variável o usuário deve especificar o parâmetro duration.

No arquivo ghmm.txt, temos dois estados de comprimentos fixo (Start, e Stop) e dois com comprimento variável ( NonCoding, e Coding). O estado Start utiliza o start_model como modelo de observação, e o estado Stop utiliza o modelo stop_modele como modelo da observação. O estado NoCoding emite palavras dado pelo modelo non_coding com comprimentos dado por uma distribuição geométrica em que a probabilidade de manter no mesmo estado é igual a 0.999. Finalmente, o estado Coding tem comprimento dado pelo modelo coding_duration_model e a observação é dado pelo coding_model. 


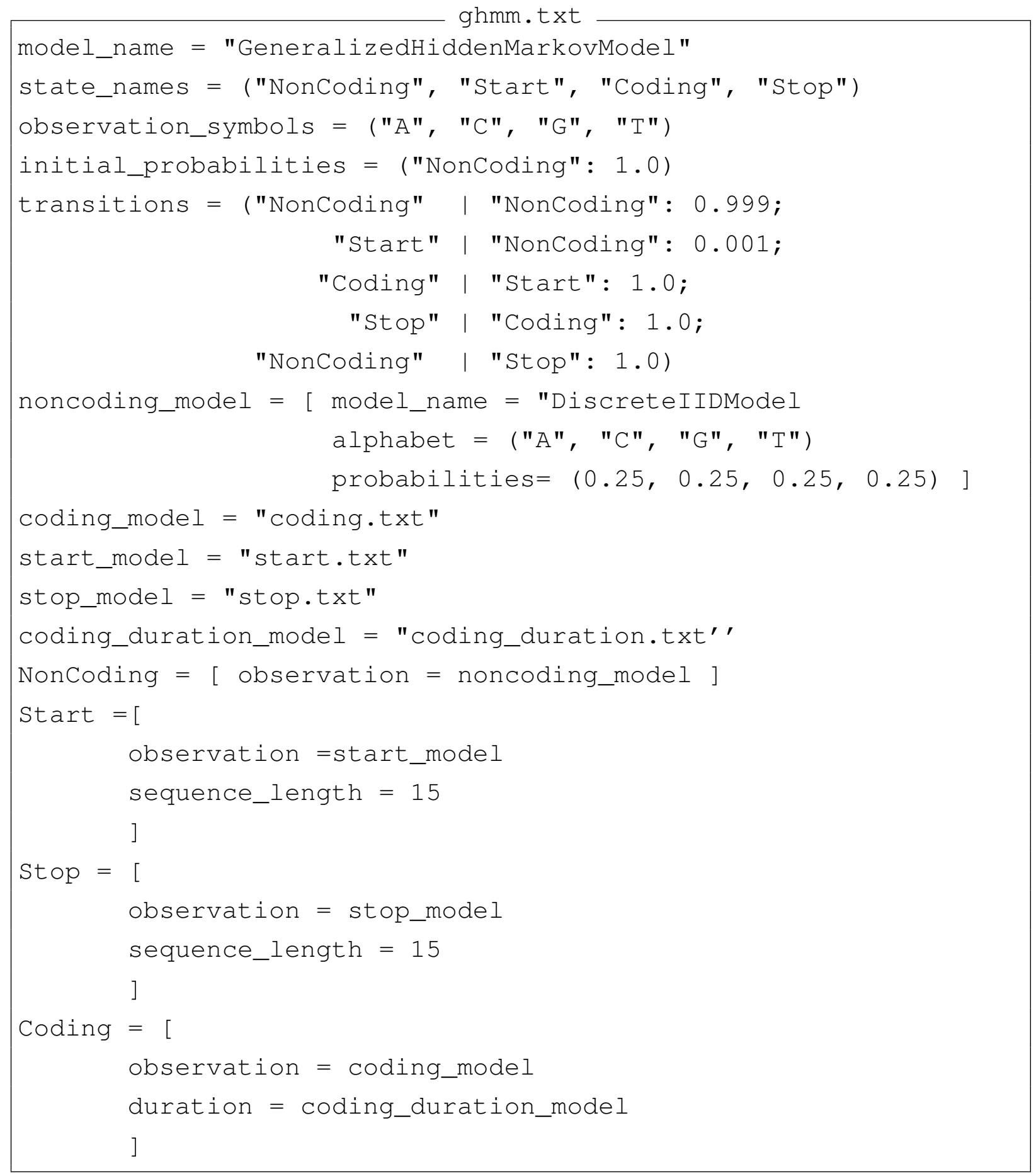

\subsection{Implementação}

A implementação dos diferentes tipos de modelos e os algoritmos associados a eles não é uma tarefa trivial. Combinar tais modelos em modelos mais complexos é ainda mais difícil já que as ferramentas atuais são geralmente independentes com interfaces distintas impossilitando a combinação de modelos. O desafio que enfrentamos consistiu em simplificar o processo de uso desse grande universo de modelos, diminuindo a superfície de conhecimento necessária para que o usuário consiga compor submodelos em modelos mais complexos. 
Exploramos no nosso sistema o fato de que todos os modelos que consideramos na versão atual do ToPs representam a distribuição de probabilidades de um conjunto de sequências, assim eles podem ser utilizados tanto para simulação, quanto para reconhecimento. Ou seja, para cada modelo que tem parâmetros $M$, implementamos o algoritmo que amostra uma sequência $S$ com probabilidade $P(S \mid M)$ e o algoritmo que dado uma sequência ele devolve o valor de $P(S \mid M)$.

Escrevemos também um conjunto de algoritmos que estimam os parâmetros de cada modelo. A Bioinformática fornece exemplos em que variações de modelos de cadeias de Markov ocorrem apenas no algoritmo de treinamento dos mesmos. Por exemplo, WAM (weight array model) é na verdade um modelo para representar cadeias não-homogêneas de Markov de ordem maior que zero treinados com um conjunto de sequências de tamanho fixo. Um outro exemplo é o modelo de cadeias interpoladas de Markov o qual é facilmente representado utilizando um modelo para cadeia de alcance variável. O ToPS desacopla o algoritmo de treinamento da implementação de cada modelo utilizando padrão de projeto Factory Method (Gamma et al., 1994).

Nesta Seção, descreveremos detalhes técnicos da implementação do nosso arcabouço.

\subsubsection{A classe ProbabilisticModel}

O núcleo do ToPS consiste numa hierarquia de três níveis, como mostrado na Figura 4.4. Na raiz, a classe abstrata ProbabilisticModel que fornece uma interface para possibilitar o uso individual dos modelos de forma intercambiável. No secundo nível, há três classes abstratas:

- FactorableModel representa modelos em que a verossimilhança de uma sequência é fatorável em um produto de termos, um termo para cada posição da sequência. Os métodos choosePosition e evaluatePosition são abstratos.

- InhomogeneousFactorableModel representa modelos que são não homogenêos. Os métodos choosePosition, evaluatePosition, maxTimeValue, isPhased são abstratos.

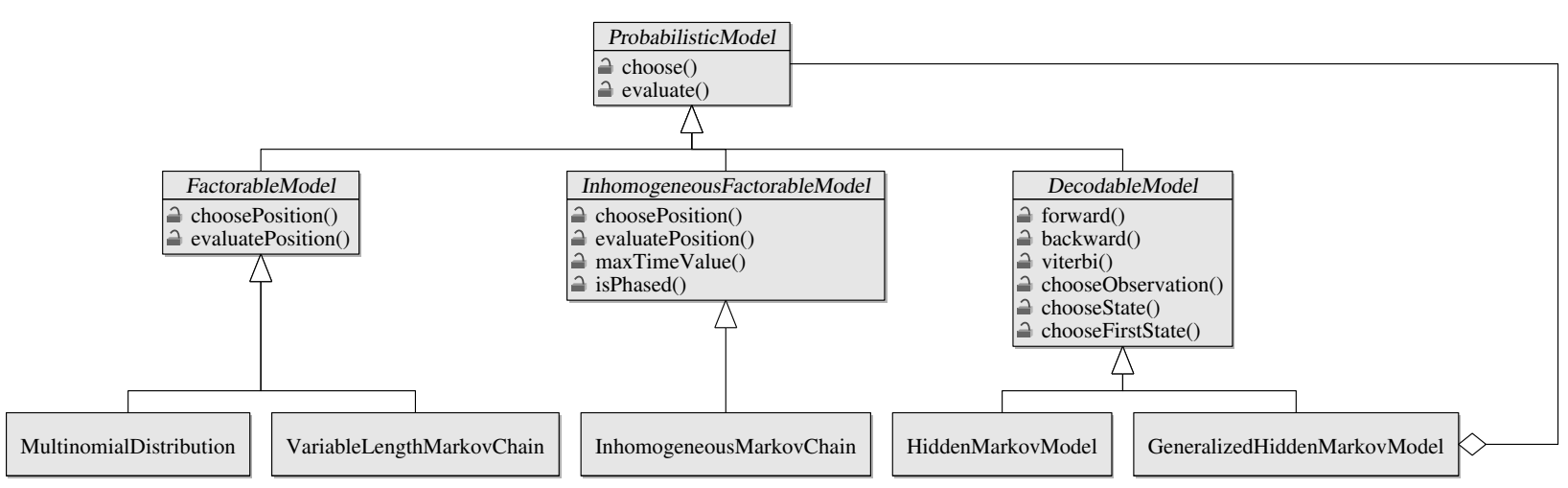

Figura 4.4: Diagrama de classes da hierarquia ProbabilisticModel. 
- DecodableModel representa modelos decodificadores. Os métodos forward, backward, viterbi, chooseobservation, choosestate, e choosefirststate são abstratos.

O último nível da hierarquia contém classes concretas e atualmente implementados pelo ToPS:

- DiscreteIIDModel.

- InhomogeneousMarkovChain.

- VariableLengthMarkovChain.

- HiddenMarkovModel.

- GeneralizedHiddenMarkovModel.

A implementação de outros modelos envolve estender esta hierarquia, dependendo da característica do modelo a ser implementado. Utilizando esta hierarquia é garantido que novos modelos funcionarão com outras componentes do arcabouço.

\subsubsection{Fábricas de modelos}

Uma instância de algum modelo pode ser obtida a partir de muitos algoritmos distintos. O padrão de projeto Factory Method fornece meios de implementar tal característica. Ele define uma interface de criação de objetos, permitindo que subclasses escolham qual classe instanciar (Gamma et al., 1994).

Possuímos em nosso arcabouço a classe abstrata ProbabilisticModelcreator que fornece o método abstrato create (parameters).

Para a criação de uma instância de um modelo, existem implementações das classes derivadas de ProbabilisticModelCreator. Por exemplo, podemos utilizar quatro algoritmos de criação para gerar objetos do tipo VariableLengthMarkovChain:

- TrainInterpolatedMarkovChain treina um modelo interpolado de Markov.

- TrainfixedLengthMarkovChain treina uma modelo de ordem fixa de Markov

- TrainVariableLengthMarkovChain treina um modelo de alcance variável de Markov utilizando o algoritmo Contexto.

- VariableLengthMarkovChain cria uma instância a partir de um conjunto de parâmetros. 


\subsection{Testando a implementação}

Uma vez implementado algoritmos de treinamento, e algoritmos para a simulação de cada modelo, precisamos ainda testar a nossa implementação. Esta validação foi realizada utilizando os próprios aplicativos do ToPS. Aplicamos o programa simulate para amostrar sequências de um conjunto de modelos, e o train para produzir modelos estimados. Os parâmetros estimados foram comparados com os valores originais. Quando relevante, comparamos o ToPS com outras implementações fornecidas pelo R. Em particular, comparamos a nossa implementação de HMM com o pacote HiddenMarkov (Harte, 2008) e a implementação cadeias de alcance variável com o pacote VLMC (Machler e Buhlmann, 2004).

\subsubsection{Processo discreto independente identicamente distribuído}

Para validar a implementação do modelo para representar processos discretos independentes identicamentes distribuídos, geramos uma sequência de tamanho 10000 utilizando o DiscreteIIDModel. Utilizando as sequências simuladas como conjunto de treinamento, estimamos um novo modelo. A Tabela 4.2 mostra que os valores dos parâmetros estimados estão próximos dos valores reais.

\subsubsection{Cadeia oculta de Markov}

Para validar a implementação da HMM, comparamos o ToPS com o HiddenMarkov (Harte, 2008) do R. Novamente, utilizamos o programa simulate para gerarmos uma sequência de tamanho 10000 utilizando um modelo HMM pré-especificado. Utilizando a sequência simulada como treinamento, estimamos uma HMM utilizando o ToPS e o HiddenMarkov. A Tabela 4.3 mostra que os parâmetros estimados foram equivalentes em ambas as implementações.

\section{Cadeia de alcance variável de Markov}

Para validar a implementação da cadeia de alcance variável de Markov, comparamos o ToPS com o pacote VLMC (Machler e Buhlmann, 2004). Utilizamos o programa simulate para gerar uma sequência de tamanho 1000000 utilizando uma dada VLMC. Este comprimento é grande o suficiente para gerarmos uma boa estimativa dos valores reais, tal como

Tabela 4.2: Valores estimados

\begin{tabular}{ccccc}
\hline & $p_{1}$ & $p_{2}$ & $p_{3}$ & $p_{4}$ \\
\hline Valores originais & 0.1 & 0.2 & 0.3 & 0.4 \\
Valores estimados & 0.1001 & 0.1970 & 0.3039 & 0.3990 \\
\hline
\end{tabular}


Tabela 4.3: Parâmetros estimados para uma HMM de dois estados

\begin{tabular}{cccccc}
\hline & \multicolumn{2}{c}{ Transições } & & \multicolumn{2}{c}{ Observações } \\
\cline { 2 - 3 } \cline { 5 - 6 } & $p_{1}$ & $p_{2}$ & & $p_{3}$ & $p_{4}$ \\
\hline Estimado pelo ToPS & 0.524255 & 0.43373 & & 0.915369 & 0.980938 \\
Estimado pelo HiddenMarkov & 0.524255 & 0.43373 & & 0.915369 & 0.980938 \\
Valores originais & 0.1 & 0.05 & & 0.95 & 0.95 \\
\hline
\end{tabular}

Tabela 4.4: Parâmetros estimados para uma cadeia de alcance variável de Markov

\begin{tabular}{cccc}
\hline & Valores originais & VLMC & ToPS \\
\hline $\operatorname{Pr}\left(X_{n}=0 \mid X_{n-1}=0\right)$ & 0.1 & 0.100294 & 0.100297 \\
$\operatorname{Pr}\left(X_{n}=0 \mid X_{n-1}=1, X_{n-1}=0\right)$ & 0.7 & 0.699360 & 0.699362 \\
$\operatorname{Pr}\left(X_{n}=0 \mid X_{n-1}=1, X_{n-1}=1\right)$ & 0.4 & 0.400774 & 0.400773 \\
\hline
\end{tabular}

Tabela 4.5: Parâmetros estimados de uma WAM

\begin{tabular}{cccc}
\hline & $p_{0}$ & $p_{1}$ & $p_{2}$ \\
\hline Valores originais & 0.9 & 0.5 & 0.1 \\
Valores estimados & 0.903 & 0.4974 & 0.1004 \\
\hline
\end{tabular}

mostrada na Tabela 4.4, ambos os sistemas forneceram estimativas próximas ao valor original.

\section{Inhomogeneous Markov chain}

Para validar a implementação da cadeia não-homegênea de Markov, utilizamos novamente o programa simulate para gerar um conjunto com 10000 sequências a partir de uma WAM especificada manualmente. Utilizando o conjunto de sequências, estimamos uma nova WAM. A Tabela 4.5 mostra que os valores estimados estão próximas dos valores originais.

\section{Cadeia oculta generalizada de Markov}

A GHMM é construída a partir da composição de submodelos da mesma forma como foi explicado na Seção 4.1. Uma vez que já validamos o treinamento dos submodelos, precisamos apenas validar o algoritmo de simulação e o Viterbi.

Para testarmos a exatidão do algoritmo Viterbi, utilizamos um modelo simples de GHMM (arquivo ghmm.txt da Seção 4.1). Geramos 10 sequências de tamanho 100000 utilizando o programa simulate, estimamos e construimos uma nova GHMM utilizando as sequências simuladas. Utilizando a nova GHMM, executamos o programa viterbi_decoding e comparamos a rotulação (dado pelo programa viterbi_decoding) com a rotulação real (dado pelo programa simulate). A rotulação devolvida pelo Viterbi e a rotulação real ficaram $92.6 \%$ idênticos. 
Finalmente, a nossa implementação de GHMM também foi amplamente avaliada no Capítulo 7 em que construímos preditores de gene com performance comparável com o preditor AUGUSTUS para diversos genomas. 


\section{Capítulo 5}

\section{MYOP: desenvolvendo preditores de}

\section{genes}

Um preditor de genes é formado por um ou mais modelos de GHMM treinados e é utilizado para prever a localização e a estrutura dos genes em uma dada sequência genômica. Arquiteturas de preditores fornecem a descrição dos modelos de GHMM com o conjunto de estados, transições, e os submodelos associados a cada estado. MYOP (Make Your Own Predictor) é um sistema para implementar preditores de genes, e pode ser utilizado tanto para desenvolver novas arquiteturas, quanto para implementar preditores para um dado genoma em arquiteturas predefinidas. Como ele foi criado utilizando o ToPS, conseguimos dar flexibilidade para combinar numa GHMM diferentes submodelos probabilísticos em arquiteturas arbitrárias. A principal diferença em relação a outras implementações existentes é que o ToPS conseguiu desacoplar a descrição da GHMM do código-fonte, fornecendo mais liberdade para o usuário. MYOP é distribuído utilizando a licença GPL, permitindo que outras pessoas desenvolvam novas funcionalidades para este sistema.

\subsection{Introdução}

Muitos programas de predição de genes nos mostraram diversos problemas recorrentes no desenvolvimento dos mesmos. Eles apresentam dificuldades durante o processo de treinamento, e além disso as arquiteturas dos modelos de GHMMs estão fortemente acopladas com a implementação do programa de predição. Um bom indicativo destes problemas é o fato de que vários preditores disponibilizam apenas um conjunto de modelos treinados e o binário do executável do programa, mas não fornecem as ferramentas utilizadas para realizar o treinamento. Observamos essa decisão, por exemplo, com os programas Genscan (Burge, 1997), Genemark.hmm (Lomsadze et al., 2005), e FGENESH ${ }^{1}$ os quais utilizam licenças que limitam a distribuição e a forma com que esses programas podem ser utilizados. A experimentação de novas arquiteturas de GHMM é complicada, pois era necessário escrever um

\footnotetext{
${ }^{1}$ http://linux1.softberry.com/berry.phtml
} 
novo programa do início.

Mesmo quando a configuração de preditores é possível, processo de treinamento de um preditor é bastante trabalhoso. Por exemplo, o preditor Genezilla (Majoros et al., 2004) fornece um conjunto de ferramentas, mas o próprio autor precisa investir 5 horas/homem com 500 comandos para obter um modelo completo de GHMM². O programa Twinscan fornece a ferramenta iParameterEstimation o qual possui um manual de 126 páginas.

Todos os programas de predição que estudamos possuem um conjunto de arquiteturas fixadas que são difíceis de serem alteradas por que elas estão engessadas no código-fonte. O programa AUGUSTUS é o único que fornece 4 arquiteturas diferentes (partial, complete, atleastone, exactlyone), os outros fornecem uma arquitetura similar a arquitetura partial do AUGUSTUS. O Genezilla (Majoros et al., 2007) permite ao usuário escolher submodelos para cada estado, mas ele implementa um algoritmo de Viterbi que não funciona quando existem transições entre estados com distribuição de duração explícita. Em outras palavras, a modularidade natural da GHMM não foi explorada pelas implementações existentes.

\subsection{Utilização do MYOP}

O MYOP pode ser utilizado para o treinamento de novos preditores, para previsão das localizações dos genes em uma dada sequência, e para facilitar no desenvolvimento de novas arquiteturas de preditores. Para realizar o treinamento, MYOP recebe um arquivo no formato FASTA com as sequências dos genes e um arquivo no formato GTF com as anotações associadas a esses mesmos genes. O processo de treinamento gera um diretório cujo conteúdo é transparente para o usuário que irá realizar apenas o treinamento ou a previsão de genes. Além disso, deixamos pronto um conjunto de modelos pre-treinados para diferentes genomas de organismos modelo que estão prontos para a tarefa de predição de genes.

A especificação de cada preditor envolve inúmeros arquivos numa estrutura de diretórios pré-fixada, porém, a estrutura de diretórios deve ser conhecida apenas para quem irá desenvolver ou modificar uma arquitetura de predição. Usuários que estão interessados em apenas prever as estruturas ou em treinar um modelo para novos dados precisam saber apenas a localização do diretório que contém o preditor.

A tarefa de desenvolver novos preditores não é trivial, pois requer um amplo conhecimento dos modelos probabilísticos. No ToPS, os modelos estão implementados e organizados para facilitar o uso. O MYOP facilita o processo de construir modelos de GHMMs específicos para a tarefa de predição de genes. Com este ambiente flexível o processo de realizar validações de novas ideias é também facilitada, permitindo a escolha de preditores mais precisos.

A Figura 5.1 mostra as tarefas que usuários finais, que não pretendem especificar novas arquiteturas de predição, podem realizar com o MYOP. Durante o treinamento, é comum

\footnotetext{
${ }^{2}$ http://www.genezilla.org/history.html
} 
encontrar duas situações diferentes: quando conhecemos genes bem anotados do genoma de interesse, ou quando não conhecemos genes bem anotados do genoma. No primeiro caso, utilizamos o programa myop-train.pl que recebe as sequências e as anotações para realizar o treinamento (1) este processo gera um diretório que contém os modelos probabílisticos treinados. Quando estamos considerando um novo genoma com poucos genes bem anotados, podemos tentar utilizar a estratégia de treinamento iterativo (2) que recebe apenas um modelo inicial, treinado com genes de um genoma próximo, e um conjunto de sequências do novo genoma. O treinamento iterativo consiste em utilizar as predições encontradas pelo modelo anterior para treinar um novo modelo e repetindo-se este processo de predição e treinamento por um número dado de vezes (Korf, 2004). Assim como ocorre com o processo de treinamento do myop-train.pl, o processo de treinamento iterativo também gera um diretório com os modelos treinados. Finalmente, quando já temos um diretório com os modelos treinados, é possível realizar a previsão das localizações dos genes e as respectivas estruturas com o uso do programa myop-predict.pl.

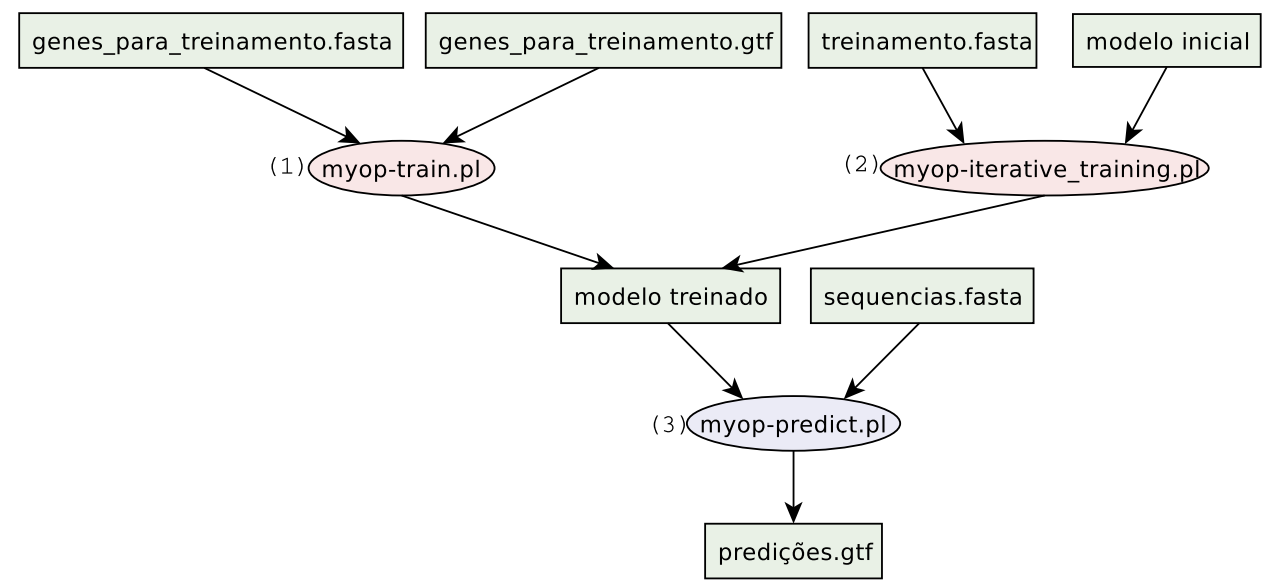

Figura 5.1: Diagrama com o uso do MYOP.

Os programas myop-train.pl e myop-iterative_training.pl realizam automaticamente o treinamento e não requerem conhecimento do usuário sobre os modelos probabilísticos que o preditor está utilizando.

A linha de comando abaixo mostra como fazemos para treinar um modelo novo.

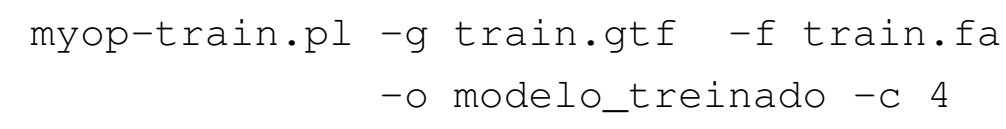

Os parâmetros do myop-train.pl são:

- -g especifica o arquivo no formato GTF que contém as anotações

- -f especifica o arquivo com as sequências

- - o especifica o diretório do modelo treinado 
- -c especifica a quantidade de processos paralelos disparados para treinar os modelos.

Para prever genes, utilizamos a linha de comando abaixo:

$$
\text { Linha de comando }
$$

myop-predict.pl -p modelo_treinado -c 4 -f sequencias.fasta

$>$ predicoes.gtf

Os parâmetros do myop-predict.pl são:

- -p especifica o diretório em que o modelo de GHMM está.

- -c especifica o número de processos viterbi_decoding.

- -f especifica a sequência de entrada

No Apêndice B, fornecemos mais detalhes de como utilizar o MYOP.

MYOP possui um conjunto de outras características que inclue a possibilidade de executar diversas tarefas em parelelo com o objetivo de economizar tempo tanto durante a predição, quanto durante o treinamento dos preditores. As configurações de cada submodelo podem ser modificadas facilmente, e além disso construímos um repositório de arquiteturas pre-montadas. Utilizando este repositório o usuário pode selecionar qualquer modelo préimplementado a partir da linha de comando. Se não especificado este repositório, o MYOP realiza o treinamento utilizando uma arquitetura padrão. As arquiteturas desenvolvidas possuem um controle de versão para facilitar a reprodutibilidade de experimentos. O MYOP foi desenvolvido para ser flexivel e ao mesmo tempo ele deve ser fácil de ser utilizado para as tarefas de treinamento e predição.

\subsection{Implementação}

Além dos programas utilizados para treinar e prever genes, MYOP é formado por outros programas de suporte em linguagem Perl que implementam um fluxo de trabalho para o treinamento. Estes programas são utilizados para preparar todos os modelos de predição de genes, e devem ser conhecidos pelos usuários que pretendem desenvolver novas arquiteturas. Esses programas são:

- myop-setup.pl inicializa todos os arquivos de configurações de cada submodelo.

- myop-generate_training_set.pl gera os conjuntos de treinamento de cada submodelo.

- myop-train_submodels.pl treina cada submodelo.

- myop-build_ghmm.pl monta os modelos de GHMMs utilizando os submodelos treinados. 
Para saber sobre o uso dos programas auxiliares, veja o Apêndice B.

A Figura 5.2 mostra o fluxo que é executado automaticamente para treinar um preditor de genes. A primeira etapa consiste em inicializar os arquivos de configurações de cada submodelo de acordo com os parâmetros de treinamento. O segundo passo gera um conjunto de treinamento para cada submodelo. Com os parâmetros e o conjunto de treinamento, o treinamento dos submodelos é realizado no terceiro passo. Finalmente, utilizando os submodelos treinados o MYOP constrói os modelos de GHMM que formam o preditor.

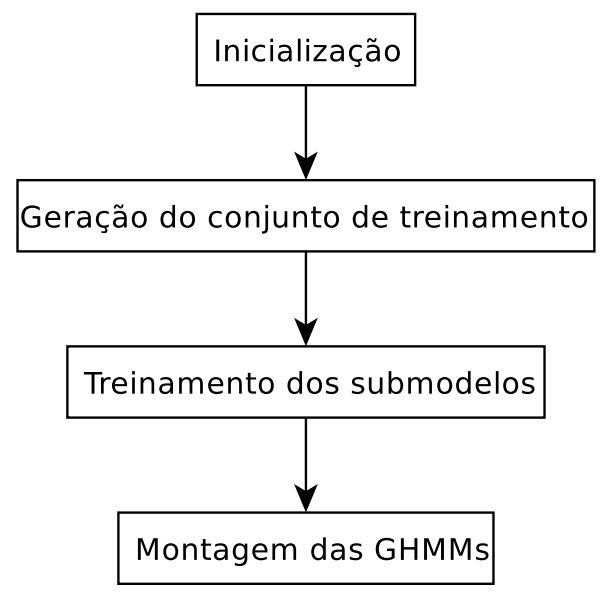

Figura 5.2: $M Y O P$ passos para treinamento

O resultado de um treinamento fica em um diretório que contém a especificação completa do modelo GHMM, incluindo, para fins de documentação e reprodutibilidade, a cópia de todos os arquivos que foram utilizados para estimar o modelo: arquivos de configuração; e a amostra de treinamento utilizada. 


\section{Capítulo 6}

\section{SGEval: calculando a exatidão dos preditores de genes}

Durante a implementação de um programa de predição é fundamental medir a exatidão do mesmo. É comum avaliar o preditor de genes usando medidas de exatidão (precisão (precision) e revocação (recall)) para diferentes pontos de vista. Em Burset e Guigò (1996), foram desenvolvidas medidas de exatidão para verificar quantas estruturas éxons/íntrons foram corretamente preditas, quantos éxons foram corretamente preditos, e quantos nucleotídeos foram corretamente preditos. Do ponto de vista de estrutura do gene, uma variante de um gene é considerada corretamente predita somente quando todos os éxons dessa variante foram corretamente preditos. Do ponto de vista de éxons, um éxon predito é considerado como corretamente predito se todos os nucleotídeos desse éxon foram corretamente preditos. Finalmente, um nucleotídeo predito como éxon é um positivo verdadeiro se ele faz parte de algum éxon real. As medidas de Burset e Guigò (1996) se tornaram padrão e são tradicionalmente usadas por todas as avaliações.

Existem dois programas que calculam tais medidas: (i) Eval (Keibler e Brent, 2003); (ii) GFPE (Wang, 2003). Eval fornece um conjunto de outras medidas de exatidão incluindo medidas relacionadas com sítios de splicing preditos, sítios de início e fim de tradução preditos, introns preditos, éxons iniciais preditos, éxons finais preditos, éxons terminais preditos, e éxons únicos preditos. Ele também gera diagramas de Venn para éxons e genes. GFPE é um arcabouço na linguagem Java e fornece apenas as medidas tradicionais de exatidão.

Os programas Eval e GFPE possuem limitações importantes. O Eval devolve apenas a quantidade de elementos de cada subconjunto do diagrama de Venn, sem fornecer a lista de identificadores dos elementos de cada subconjunto. Conhecer os elementos de cada subconjunto do diagrama de Venn é importante para realizarmos análises exploratórias que possam indicar direções para melhorar o preditor. Eval também mostrou problemas frente a eventos de splicing alternativo, quando as variantes do mesmo gene não estavam anotados com o mesmo identificador de gene. Finalmente, não encontramos uma discussão clara nos artigos de como o Eval ou o GFPE contabilizam as medidas nessa situação. 
Devido a essas limitações, implementamos uma nova ferramenta de comparação de anotações que chamamos de SGEval (Splicing Graph Evaluation) que aproveita uma estrutura de dados chamada de grafos de splicing (Sammeth et al., 2008). Esses grafos representam todos os possíveis eventos de splicing alternativos de uma dada anotação. Desenvolvemos algoritmos para manipulação desses grafos para contabilizar medidas de exatidão e diagramas de Venn. Todos os grafos de splicing gerados pelo SGEval são visualizáveis através de programas de visualização de grafos. SGEval fornece as posições dos elementos de cada subconjunto do diagrama de Venn, facilitando análises exploratórias mais detalhadas. Em particular, o SGEval teve importância durante a comparação entre um preditor desenvolvido com o MYOP e o preditor AUGUSTUS em experimentos com o genoma de cana-de-açúcar, veja Capítulo 10. Mostramos que os preditores apresentaram medidas similares, mas o diagrama de Venn mostrou algumas vantagens do MYOP que não eram visualizáveis apenas com medidas de exatidão.

\subsection{Uso do SGEval}

SGEval pode ser utilizado para calcular as medidas de exatidão, diagramas de Venn, e grafos de splicing. O uso está ilustrado na Figura 6.1. Ao receber uma anotação de referência

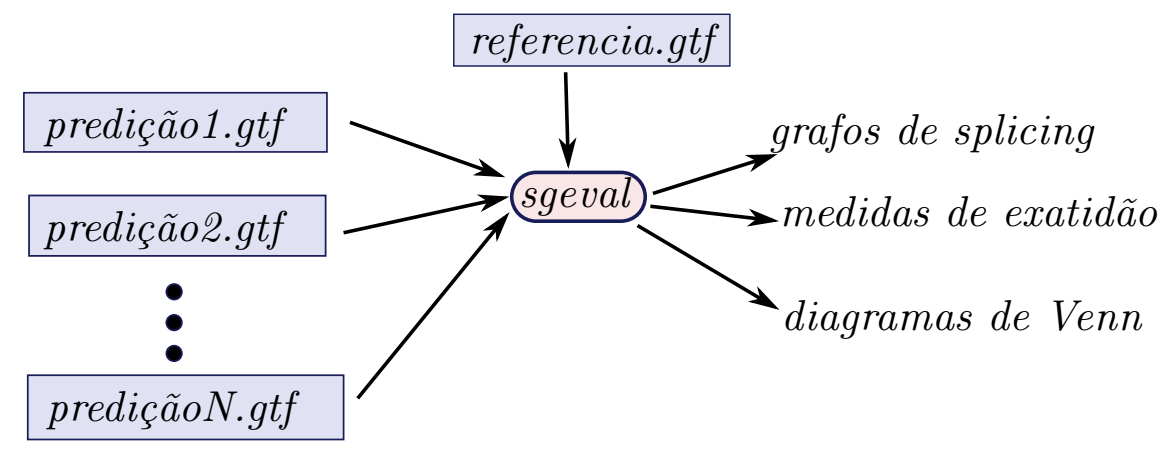

Figura 6.1: Diagrama com o uso do SGEval.

e um conjunto de anotações obtidas por predição, SGEval calcula medidas de precisão e revocação para vários pontos de vista incluindo: estrutura do gene; éxons iniciais; éxons internos; éxons finais; íntrons; sítios aceitadores; sítios doadores; sítio de início de tradução; sítio de fim de tradução; nucleotídeos de éxons; e nucleotídeos de íntrons. Para cada um desses pontos de vista, SGEval devolve os elementos de cada subconjunto do diagrama de Venn e também devolve as contagens necessárias para se calcular as medidas de exatidão. Do ponto de vista de "estrutura de gene", um positivo verdadeiro é contabilizado quando existe uma estrutura verdadeira que é exatamente igual a uma estrutura predita, um falso positivo é contabilizado quando uma estrutura predita não é igual a nenhuma estrutura verdadeira, e um falso negativo ocorre quando uma estrutura verdadeira não foi corretamente predita. A contagem para os outros pontos de vista é feita de forma análoga. 


\subsection{Grafos de splicing}

Grafo de splicing permite representar todos os eventos de splicing alternativo que ocorrem em uma dada anotação (Sammeth et al., 2008). Um exemplo ilustrativo está na Figura 6.2 em que apresentamos quatro tipos de splicing alternativos: (i) exclusão de éxon; (ii) sítio doador alternativo; (iii) sítio aceitador alternativo; e (iv) retenção de íntron. O respectivo grafo de splicing está na Figura 6.2. Para construir-lo, transformamos cada sítio em um nó e utilizamos as sequências de sítios de cada variante para formar as arestas. A aresta correspondente a variante é rotulada com o identificador da mesma.

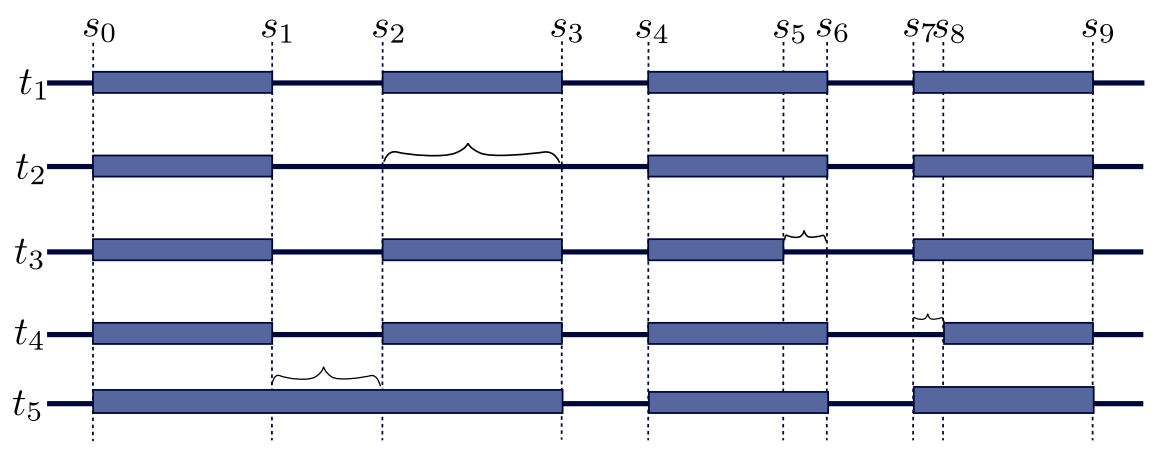

Figura 6.2: Exemplos ilustrativos de eventos de splicing alternativos. Exclusão de éxon (transcrito $t_{2}$ ); sítio doador alternativo (transcrito $t_{3}$ ); sítio aceitador alternativo (transcrito $t_{4}$ ), e retenção de intron (transcrito $t_{5}$ )

O programa SGEval constrói um conjunto de grafos de splicing a partir do conjunto de todas as anotações. Uma variante é representada por um caminho o qual forma uma sequência de sítios. A variante $t_{1}$ é representada pela sequência de sítios $\left(s_{0}, s_{1}, s_{2}, s_{3}, s_{4}, s_{6}, s_{7}, s_{9}\right)$, e a variante $t_{5}$ é representada pela sequência $\left(s_{0}, s_{3}, s_{4}, s_{6}, s_{7}, s_{9}\right)$. Ou seja, cada sítio é representado por um nó no grafo, e cada aresta indica pares de sítios consecutivos associados a uma variante.

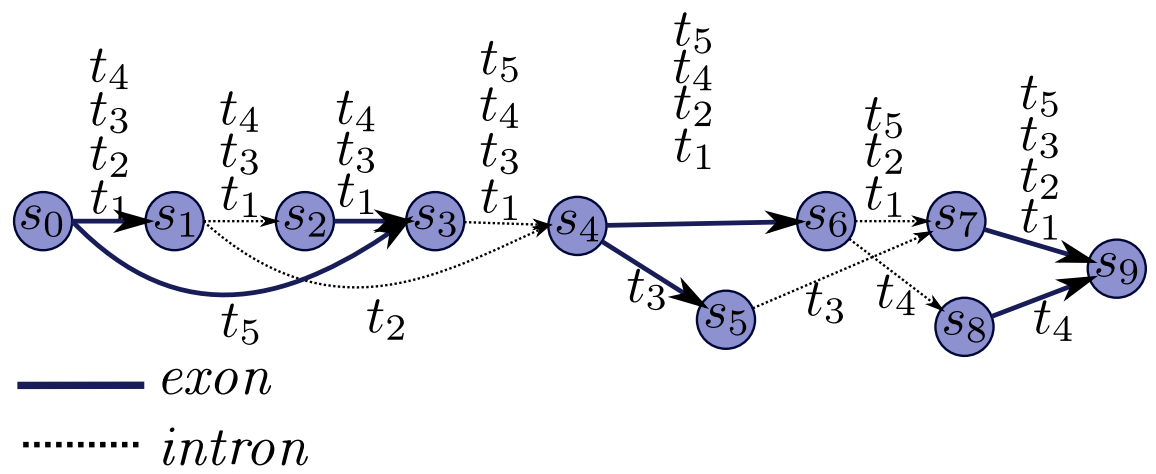

Figura 6.3: Grafo de splicing obtido a partir do exemplo da Figura 6.2

A representação da anotação através de grafos é compacta, remove redundância, e facilita a construção dos diagramas de Venn. O SGEval adiciona no grafo de splicing as estruturas preditas por programas de predição, permitindo a comparação das diferentes fontes de anotação. Na Figura 6.4, ilustramos a adição de duas predições $\left(p_{1}\right.$ e $\left.p_{2}\right)$. A contagem do erro 
com respeito a um dado gene é feito facilmente. No exemplo, a predição $p_{2}$ foi completamente suportada pela variante $t_{1}$ e a predição $p_{1}$ tem erros de predição representados pelas arestas $s_{4} \rightarrow s_{10}$ e $s_{10} \rightarrow s_{8}$.

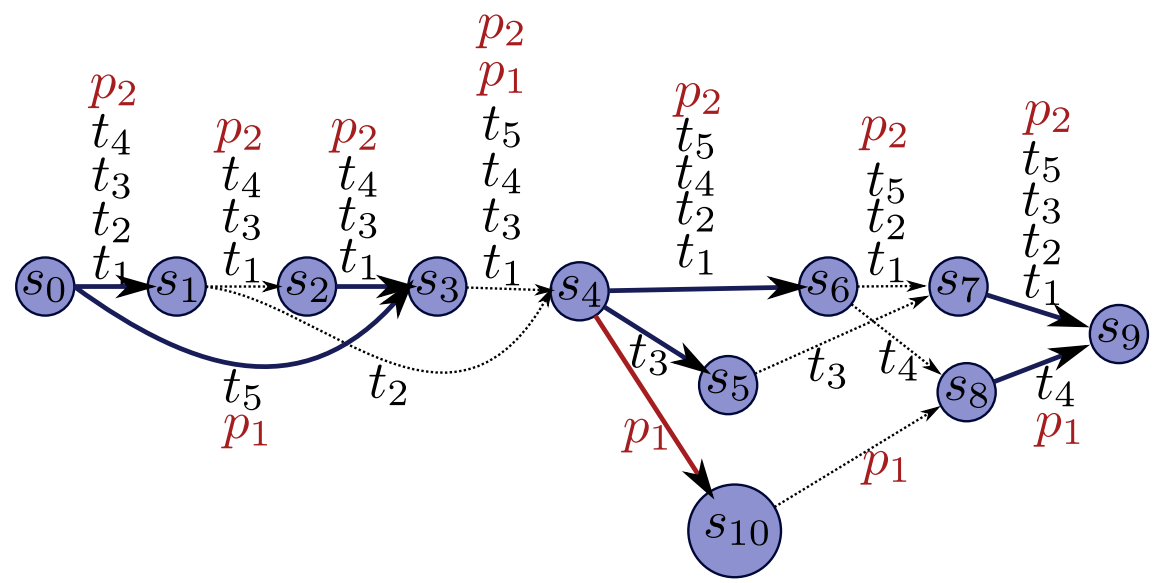

Figura 6.4: Grafo com as predições $p_{1}$ e $p_{2}$

\subsection{Medidas de exatidão}

SGEval calcula os valores de precisão e revocação (sensibilidade) para cada um dos pontos de vista. Por exemplo, a Figura 6.5 ilustra como o SGEval contabiliza os valores de exatidão para as estruturas preditas e éxons preditos. Com as contagens de falsos positivos $(F P)$, verdadeiros positivos $(T P)$, e falsos negativos $(F N)$, a precisão e revocação são fornecidas pelas fórmulas:

$$
\begin{aligned}
\text { Precisão } & =\frac{T P}{T P+F P} \\
\text { Revocação } & =\frac{T P}{T P+F N}
\end{aligned}
$$

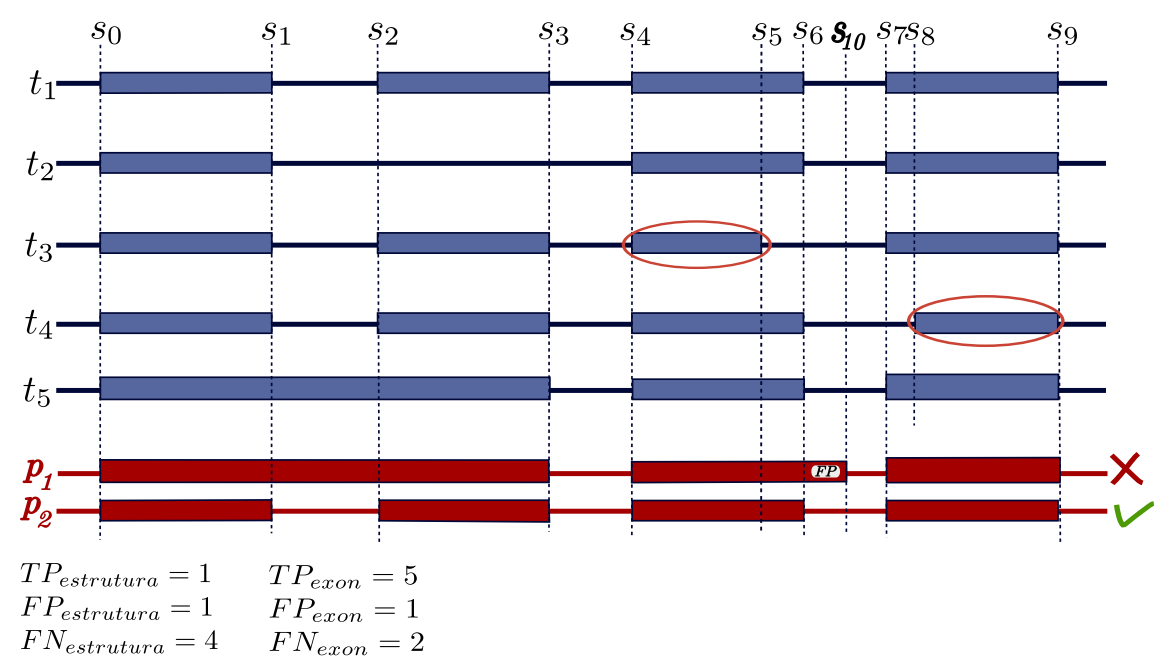

Figura 6.5: Contagem feita para dois pontos de vista: estruturas, e éxons. 
Ao considerar apenas os éxons, observamos que dois éxons (marcados por elipses) não foram encontrados, e um éxon foi incorretamente predito. Devido ao éxon incorretamente predito, obtemos uma estrutura que é falsa. A outra estrutura foi corretamente predita. Assim, temos precisão de $\frac{1}{1+1}=0.5$ com revocação de $\frac{1}{1+4}=0.2$ para estruturas preditas, e temos precisão de $\frac{5}{5+1}=0.83$ com revocação de $\frac{5}{5+2}=0.71$ para éxons preditos.

\subsection{Diagramas de Venn}

Os diagramas de Venn para éxons são facilmente computados utilizando a estrutura de grafos, simplesmente precisamos olhar todas as arestas do tipo éxon e verificar o rótulo que este éxon possui. O rótulo automaticamente fornece em qual subconjunto do diagrama cada éxon pertence. Por exemplo, o éxon flanqueado pelos sítios $s_{0}$ e $s_{3}$ está presente nas estruturas $\left\{t_{5}, p_{1}\right\}$, e o éxon $s_{4} \rightarrow s_{6}$ é está presente nas estruturas $\left\{t_{1}, t_{2}, t_{4}, t_{5}, p_{2}\right\}$. Se o conjunto de estruturas $\left\{t_{1}, t_{2}, t_{3}, t_{4}, t_{5}\right\}$ é da anotação de referência $R$, e $\left\{p_{1}\right\}$ é do preditor $A$, e $\left\{p_{2}\right\}$ é do preditor $B$, temos que o éxon $s_{0} \rightarrow s_{3}$ é do subconjunto $R \cap A$, e o éxon $s_{4} \rightarrow s_{6}$ é pertencente ao subconjunto $R \cap B$.

Podemos aplicar variações desse algoritmo não apenas para éxons, mas também para íntrons. Para contabilizar as estruturas de cada subconjunto, basta verificar para cada estrutura quais anotações a suportam. Fazer a medição de quantos íntrons foram corretamente previstos é útil para verificarmos se ambas as regiões fronteiriças entre éxon e íntron foram corretamente previstas simultaneamente. A medida que considera éxons corretamente previstos inclui além dos sítios de splicing os éxons iniciais e éxons finais, que fazem fronteira com as regiões não-traduzidas das pontas $5^{\prime}$ e $3^{\prime}$ do gene.

Os sítios fornecem os intervalos de cada região, e assim SGEval também constrói diagramas de Venn considerando contagens do ponto de vista de nucleotídeos.

\subsection{Implementação}

SGEval foi implementado em linguagem Perl. Na Figura 6.6, mostramos o fluxograma de como ele gera os relatórios. Ao receber as anotações o SGEval constrói o grafo de splicing. Assumimos que os genes formam componentes conexas, com o conjunto de todas as componentes conexas o SGEval constrói diagramas de Venn. A partir dos diagramas de Venn é possível calcular as medidas de precisão e revocação de cada um dos pontos de vista. 


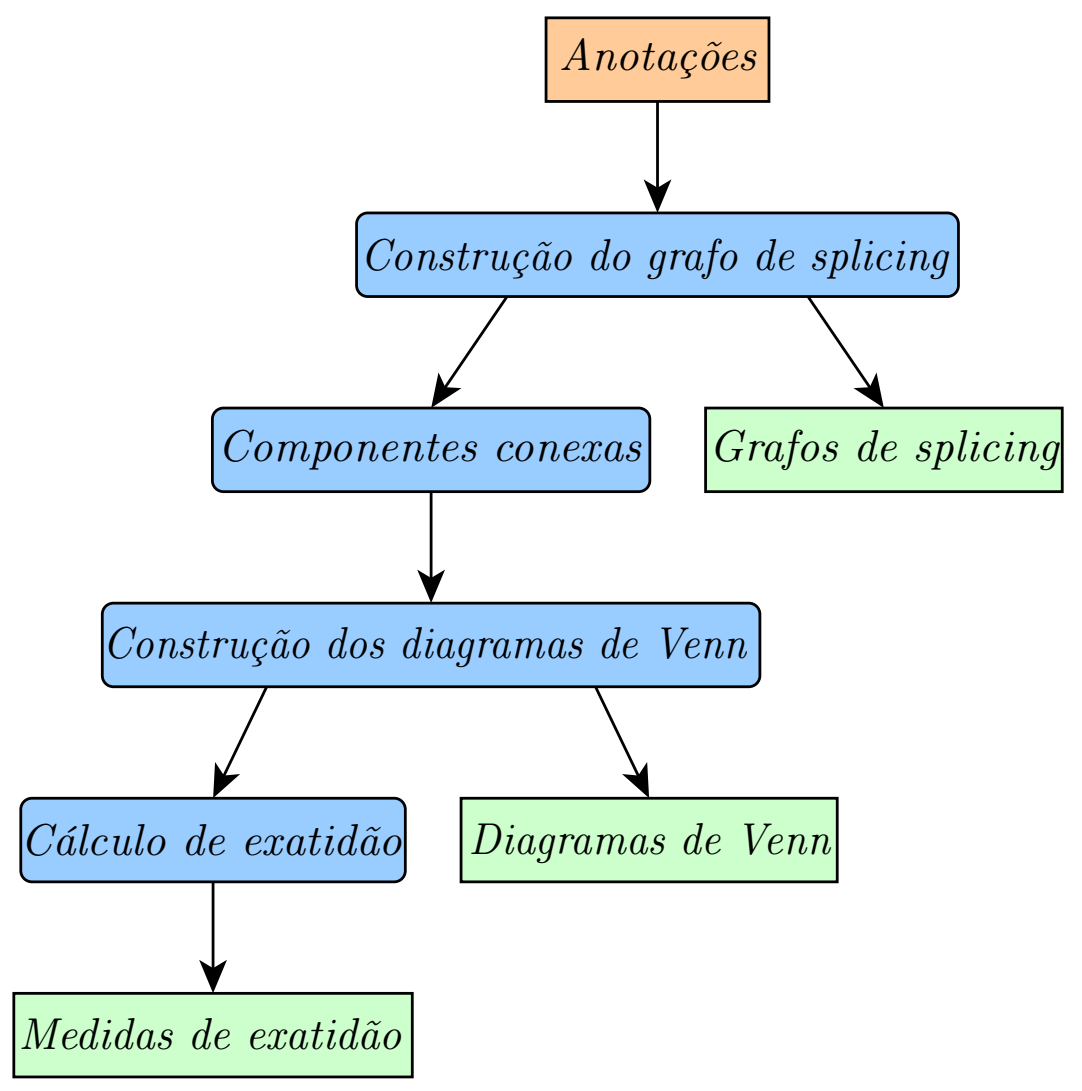

Figura 6.6: Fluxograma do SGEval 


\section{Capítulo 7}

\section{Avaliando preditores de genes}

O objetivo principal de um programa de predição de genes consiste em fornecer corretamente as localizações e as estruturas dos genes em uma dada sequência genômica. Para ajudar a escolher os melhores, muitas publicações fornecem diversas estimativas de medidas de exatidão que compararam os diferentes programas. Embora tais avaliações consigam mostrar as principais deficiencias existentes, elas não são suficientes para determinar os méritos de cada nova modelagem.

Existem competições, tal como o GASP (Genome Annotation Assessment Project) (Guigo, 2000), que tentam avaliar o atual estado da arte de métodos de predição de sítios funcionais numa dada sequência. Estes estudos não são suficientes para determinar quais são os méritos de cada algoritmo ou abordagem, mas apontaram deficiências que são comuns em preditores ab initio de genes:

- Fraca detecção de múltiplos genes. Quando a sequência de entrada tem apenas um único gene, os programas produzem resultados aceitáveis. Na avaliação GASP, o programa Genscan obteve especificidade de $75 \%$ e sensibilidade de $78 \%$ em relação aos éxons preditos. Por outro lado, os programas não reconhecem precisamente a estrutura dos genes quando a sequência de entrada contém mais de um gene. Nesse caso, o Genscan obteve sensibilidade de $64 \%$ e especificidade de $44 \%$ em relação aos éxons preditos.

- Reconhecimento pobre de sítios de splicing. Todos os programas ab initio são deficientes em relação ao reconhecimento de sinais de splicing, isso é um problema importante já que esses sinais definem fronteiras entre éxons e íntrons.

Para realizar comparações justas entre programas é necessário que todos sejam analisados de forma mais parecida possível. Muitos pesquisadores concordam que esta tarefa é considerada difícil (Majoros et al., 2007; Zhang, 2002): "a truly fair comparison of the prediction programs is impossible as their performance depends crucially on the specific TRAINING DATA that are used to develop them" (Zhang, 2002). Além disso, é comum que 
programa de predição tenha modelos treinados sem fornecer a lista dos genes utilizada para o treinamento.

De fato, a reprodução de um resultado exatamente identico ao obtido utilizando um preditor a partir de uma outra implementação independente é praticamente impossível. Embora o arcabouço matemático aplicado pelos programas de predição é o mesmo, implementações distintas apresentam muitas diferenças. Por exemplo, o programa Genezilla possui 17805 linhas de código em $\mathrm{C}++$, o programa Phat tem apenas 8495 linhas em $\mathrm{C}$, e o MYOP tem 1453 linhas em Perl (ToPS tem 14903 linhas em $\mathrm{C}++$ ). As diferenças de exatidão estão relacionadas a diversos fatores incluindo erros de implementação, uso de diferentes estimadores de parâmetros, diferenças na implementação do algoritmo Viterbi, diferenças na implementação dos submodelos, escolha de parâmetros arbitrários, e outros. Em outras palavras, não é possível entender sobre os méritos dos diferentes métodos de predição através da comparação de diferentes programas.

Assim como descrito em Majoros et al. (2007), defendemos para fins de estudo dos métodos de predições um ambiente de código único e integrado em que possamos avaliar mais uniformemente cada variação na modelagem. Como estamos comparando as modelagens e não os programas, defendemos também experimentos com a validação cruzada, em vez de utilizar apenas uma única amostra de teste. O protocolo de avaliação aqui apresentado permite comparações controladas entre as variações na modelagem com a finalidade de ajudar a escolher qual variação apresenta melhor resultado.

\subsection{Amostras de genes}

O primeiro passo para avaliar preditores de genes consiste em obter conjuntos de genes bem anotados. Muitas vezes apenas um genoma ou família de genomas é utilizado para avaliação. Em Rogic et al. (2001) e em Burset e Guigò (1996), apenas uma família de genomas (Mamíferos e Vertebrados) foi utilizada na comparação dos preditores. Em Pavy et al. (1999), apenas o genoma de A thaliana foi utilizado como modelo de avaliação e não fica claro como foi feito o treinamento dos programas avaliados. Mesmo nas competições "GASP" são utilizados apenas um genoma em cada (EGASP - H. sapiens (Guigó et al., 2006), nGASP - C. elegans (Coghlan et al., 2008), GASP - D. melanogaster ). Atualmente, há um grande número de genomas bem anotados, possibilitando a construção de nossas próprias amostras de validação.

O protocolo que desenvolvemos para a avaliação consiste em selecionar apenas genes com evidência de expressão e sem nenhum erro aparente na anotação. Genes com sítios de splicing não canônicos também foram removidos, já que os preditores avaliados não modelam esses tipos de sítio. A Tabela 7.1 mostra a quantidade de genes que selecionamos em cada organismo. Disponibilizamos a lista de genes em http://www.vision.ime.usp.br/ yoshiaki/ www/geneset/. 
Tabela 7.1: Genomas e genes selecionados

\begin{tabular}{lccc}
\hline Organismo & Montagem & Página Web & Genes \\
\hline A. thaliana & TAIR10 & http://www.arabidopsis.org & 20688 \\
C.elegans & ce6 & http://genome.ucsc.edu & 17937 \\
Z.mays & ZmB73_5b & http://www.plantgdb.org & 24954 \\
P. falciparum & PlasmoDB-7.1 & http://plasmodb.org & 4078 \\
D.melanogaster & $\mathrm{dm3}$ & $\mathrm{http}: / /$ genome.ucsc.edu & 13373 \\
H.sapiens & hg18 & http://genome.ucsc.edu & 11570 \\
O. sativa & OSgenomeV6.1 & http://www.plantgdb.org & 57663 \\
D. rerio & WUGC $3.2 .4 /$ taeGut1 & http://genome.ucsc.edu & 7986 \\
G. max & Gmax_109 & http://www.plantgdb.org & 36451 \\
M. musculus & NCBI37/mm9 & http://genome.ucsc.edu & 16385 \\
R. norvegicus & Baylor $3.4 / \mathrm{rn} 4$ & http://genome.ucsc.edu & 13501 \\
\hline
\end{tabular}

\subsection{Validação cruzada}

A principal vantagem dos preditores ab initio de genes é que eles são capazes de reconhecer genes que não estavam na amostra de treinamento e que são difíceis de serem encontrados por métodos que utilizam comparações entre sequências. Esta habilidade de reconhecer novos elementos é conhecida como capacidade de generalização. Uma técnica amplamente utilizada, na área de reconhecimento de padrões, para medir o erro de generalização é a validação cruzada (Duda et al., 2001). Para aplicar esta técnica, obrigatoriamente treinamos e testamos várias vezes o programa de predição de genes. Infelizmente, a realização de experimentos com algum tipo de validação cruzada não é trivial: o processo de treinamento de muitos preditores de sucesso (por exemplo Genscan) é feito somente com a ajuda do autor do programa. Em particular, o CONTRAST (Gross et al., 2007) deixa explícito em seu sítio na Internet que não é recomendável que o preditor seja executado pelo usuário ${ }^{1}$. Os preditores são difíceis de serem treinados por vários motivos: (i) grande número de estados envolvidos; (ii) a grande quantidade de parâmetros arbitrários; e (iii) a falta de ferramentas automáticas para realizar o treinamento. Além disso, a exatidão das predições é influenciada de forma significativa pela qualidade da amostra de treinamento. Esses motivos impedem aplicar validação cruzada na maior parte das avaliações.

Para tentar estimar o erro de generalização, algumas avaliações fazem a comparação de preditores previamente treinados, além de usar um conjunto de teste com genes que foram adicionados no Genbank depois da data de publicação do preditor mais recente (Pavy et al., 1999; Rogic et al., 2001). Um problema importante com esta abordagem é que não fica claro a relação do conjunto de treinamento com o conjunto de validação. Além disso, os preditores de genes fornecem resultados diferentes apenas alterando parâmetros arbitrários e assim não podemos concluir, com este tipo de análise, se um novo método realmente trouxe uma

\footnotetext{
1 "CONTRAST is distributed as open source, free software. Please note that we do not recommend running CONTRAST yourself if you are simply interested in generating predictions for a specific genome. Instead, please send us a request." (http:// contra.stanford.edu)
} 
melhoria consistente na exatidão. Podemos observar casos em que o preditor foi treinado com genes de um genoma distinto no qual ele foi avaliado. Quando o preditor é treinado para um genoma muito distante do genoma de interesse, claramente ele vai apresentar resultado muito inferior em relação ao que ele poderia alcançar caso os parâmetros fossem mais específicos.

As avaliações de preditores de genes descritas em (Burset e Guigò, 1996; Guigo, 2000; Pavy et al., 1999; Rogic et al., 2001) analisam um conjunto de programas de predição com apenas um conjunto limitado de genes, além disso foram aplicados modelos pre-treinados dos preditores avaliados. Existem pelo menos duas desvantagens nessas avaliações, não conhecemos a amostra de treinamento de cada programa e o uso de um conjunto de genes para o teste não fornece uma boa estimativa do erro de generalização. Além disso, a exatidão varia significativamente com o tamanho da amostra de treinamento que foi utilizada para a avaliação. Em particular, a primeira versão do Genscan para H. sapiens foi treinado com apenas 380 genes (Burge, 1997), tendo portanto uma performance inferior em relação aos preditores mais recentes que foram treinados com amostras maiores. A nossa idéia consiste em avaliar o preditor em situações diferentes e não apenas com uma única amostra pré-fixada. Assim, considerando esses fatos, desenvolvemos o seguinte protocolo:

- Como queremos verificar a curva de aprendizado dos preditores, criamos uma sequência crescente de conjuntos de genes. A lista de nomes dos genes selecionados de cada organismo foi embaralhada uniformemente para diminuirmos dependências relativas a localização desses genes no genoma. Cada lista serviu para construirmos uma série de conjuntos de genes, $G_{1} \subset G_{2} \subset \cdots \subset G_{15}$, em que o primeiro conjunto é subconjunto do segundo, que é subconjunto do terceiro, etc. Para construir esta sequência de conjuntos, selecionamos os 125 primeiros elementos para construir $G_{1}$, os elementos de $G_{1}$ e os 125 próximos elementos para construirmos $G_{2}$, e sucessivamente até construirmos o último conjunto.

- A quantidade 125 foi escolhida para possuirmos conjuntos de treinamento cada vez maiores começando com 100 elementos de treinamento e 25 de validação indo até 1500 de treinamento e 375 de validação, nos testes de validação cruzada com fator de estratificação igual a 5. Assim, para cada organismo, preparamos 15 testes de validação cruzada de tamanho crescente, particionando cada conjunto $G_{k}$ em 5 partes iguais, ou seja, partes de tamanho $k \times 25$. Cada parte foi indexada com um número de 1 até 5 . Para cada índice $i \in\{1,2,3,4,5\}$, os genes da parte $i$ foram utilizados como amostra de teste e todos os outros elementos das partes indexados por $j \neq i$ como amostras de treinamento. Assim, para cada conjunto $G_{k}$ executamos 5 experimentos utilizando $k \times 100$ elementos para o treinamento e $k \times 25$ elementos para teste. No total, para cada organismo teremos 75 resultados com diversas medidas de exatidão calculadas pelo nosso programa de comparação de anotações, SGEval. 


\subsection{Critério de avaliação}

Os valores de exatidão consideram três pontos de vista: sítios codificadores preditos, éxons preditos, e variantes de estruturas de genes preditos (Burset e Guigò, 1996; Keibler e Brent, 2004; Pavy et al., 1999; Rogic et al., 2001). Embora existam medidas de exatidão para diferentes pontos de vista, utilizar apenas essas medidas não é suficiente para decidir qual programa é melhor quando observamos resultados muito similares, já que as medidas escondem muitos detalhes. Nestes casos, diagramas de Venn nos mostram que preditores com medidas similares de exatidão fornecem anotações complementares e que não deixam de ser evidências válidas de genes codificadores de proteínas. Em particular, o diagrama foi útil durante a avaliação dos preditores AUGUSTUS e MYOP em cana de açúcar (Capítulo 10) e ajudou também para direcionar algumas outras análises exploratórias neste mesmo genoma.

\subsection{Splicing alternativo nas avaliações}

Ainda são poucas as publicações que mostram comparações de preditores levando também em consideração eventos de splicing alternativo. Geralmente, o preditor de gene devolve no máximo uma única predição da estrutura para cada gene predito e por esse motivo é comum excluir aqueles genes que apresentam splicing alternativo da amostra de validação. Contudo, incluímos também tais genes, pois foi demonstrado que a maior parte dos genes com múltiplos éxons apresentam splicing alternativos (Nilsen e Graveley, 2010) em H. sapiens. A ferramenta SGEval constrói grafos de splicing, permitindo utilizar todas as variantes anotadas para avaliar o preditor.

O problema de considerar variações de splicing na modelagem do preditor é um desafio e são raros os programas que as consideram. Alguns preditores devolvem estruturas sub-ótimas em que cada éxon possui um valor de probabilidade (Stanke et al., 2006), mas a modelagem em si não foi preparada para representar tais eventos. Não encontramos nenhuma avaliação que compara preditores frente a eventos de splicing alternativos. 


\section{Capítulo 8}

\section{Implementando arquiteturas de preditores de genes}

Programas desenvolvidos para uma mesma tarefa possuem diversas características que são recorrentes e possuem também algumas pequenas variações que os diferenciam. Este fato é evidente em predição de genes onde, por exemplo, muitos programas de predição utilizam um modelo GHMM como modelo integrador, mas com importantes variações de implementação e modelagem. Utilizamos as características que são comuns para direcionar o desenvolvimento de um novo protocolo para implementação de predição de genes. As variações nas modelagens serão apresentadas e indicaremos algumas das ideias que, embora pareçam intuitivas não fornecem melhorias ou até pioram a exatidão. Assim, iremos descrever os passos gerais para a implementação de preditores de genes e em seguida explicaremos os detalhes de algumas das variações importantes que devem ser consideradas.

\subsection{Passos gerais para construir preditores de genes}

Para desenvolver um novo preditor de genes, é preciso definir todos os elementos do modelo GHMM. É fundamental especificar a arquitetura, os submodelos de emissão e os submodelos de duração, além de tratar a variabilidade do conteúdo GC.

O primeiro passo consiste em definir a arquitetura da GHMM (conjunto de estados e conjunto de transições) que definirá o conjunto de estruturas éxon/íntron que o preditor irá reconhecer. Um aspecto comum a todos os preditores é que eles fornecem estruturas de gene consistentes com a fase de leitura da proteína, que acarreta ocorrência de muitos estados o tipo éxons. Esta modelagem está presente em várias implementações independentes (Seção 2.4). Existem pequenas variações que iremos discutir a seguir, mas em todas as variações há o cuidado de tratar a fase de leitura dos éxons.

Em seguida, definimos os modelos probabílisticos de emissão e os submodelos probabilísticos de duração de cada estado. Embora existam uma grande quantidade de estados numa arquitetura de GHMM, muitos dos submodelos de emissão são reaproveitados em dois ou 
mais estados que representam o mesmo tipo de sequência. Por exemplo, o mesmo submodelo de emissão da região codificadora é geralmente utilizado por todos os estados do tipo éxon, e o submodelo de emissão da região não-codificadora é utilizado pelo estado da região intergência e pelos estados de íntrons. Além disso, existem diferentes estados para representar sítios de splicing, mas é suficiente a utilização de um único modelo para o sítio aceitor, e um único modelo para o sítio doador. Desta forma, um mesmo submodelo treinado é amplamente reaproveitado por vários estados diferentes em uma dada arquitetura de GHMM.

Finalmente, para tratar a variabilidade do conteúdo GC, precisamos de uma metodologia de treinamento de modelos específicos de conteúdo GC. Utilizar um preditor com uma única GHMM treinada com todos os genes da amostra de treinamento não é recomendado quando o genoma alvo possui muitas regiões distintas de isochore (regiões com alta uniformidade na composição GC). Burge (1997) mostrou que genes em diferentes isochores possuem características diferentes, e assim, ele utilizou diversos modelos de GHMM para composições GC específicas. Discutiremos ainda neste Capítulo quais as estratégias aplicadas por diferentes preditores para tratar este problema. Apresentaremos uma nova estratégia que chamamos de Target GHMM e que foi inspirada em um artigo nosso que discute sobre modelos nulos (Machado-Lima et al., 2010).

Inicialmente analisaremos as possíveis arquiteturas da GHMM, em seguida analisaremos quais os melhores submodelos para cada estado, e finalmente descreveremos metodologias para tratar a variação na composição GC. É importante ressaltar que o MYOP é uma ferramenta que facilita utilizar esse protocolo, e assim podemos rapidamente desenvolver preditores arbitrários e comparar quais preditores fornecem melhores resultados.

\subsection{Arquiteturas da GHMM}

Uma arquitetura consiste de um conjunto de estados e suas possíveis transições, e define quais estruturas de genes podem ser previstas.

Embora exista uma infinidade de variações na arquitetura da GHMM, existem quatro tipos básicos voltados para predição de genes (Stanke e Waack, 2003):

1. múltiplos genes completos: permite predições de vários genes completos na mesma sequência. Esta arquitetura é também utilizada para estimar o número de genes presentes em um dado genoma.

2. múltiplos genes parciais: permite predições parciais nas extremidades da sequência. Genes que aparecem entre os genes das extremidades são sempre completos, e por isso que não observamos muitas vantagens dessa arquitetura com relação a arquitetura "múltiplos genes completos". A diferença entre as duas abordagens estará na caracterização dos estados de término da GHMM.

3. exatamente um gene na sequência: permite apenas um gene na sequência de entrada. 
Esta arquitetura é utilizada quando sabemos que existe apenas um gene na sequência independente da fita.

4. exatamente uma única região codificadora (sem íntron): é útil para prever a região codificadora em sequências de mRNA.

Essas arquiteturas podem ser implementadas para prever genes em uma única fita, ou em ambas as fitas. No segundo, caso evitamos previsões conflitantes em fitas diferentes e permitimos a previsão de genes em apenas um passo.

A Figura 8.1 mostra um exemplo de uma arquitetura que representa genes completos. Esta arquitetura evita predições que sobrepõe em fitas opostas, em ambas as fitas simultaneamente. Note a simetria do modelo, onde uma parte é quase o reverso da outra. Para prever apenas genes completos, definimos o estado da região intergênica, "N", como sendo tanto o estado inicial, quanto o estado terminal da nossa GHMM.

Muitas outras variações são facilmente implementadas a partir desta arquitetura mais completa. Por exemplo, para modelar a arquitetura de genes parciais a partir da arquitetura de genes completos, podemos adicionar um novo estado, $F$, que é final e absorvente $(p(F \mid F)=1)$ e criar para cada estado uma transição para este novo estado final. Esta arquitetura permite que um gene parcial seja reconhecido no final da sequência. Podemos também permitir que a sequência tenha um gene parcial no começo da sequência, para isso podemos adicionar uma probabilidade positiva da GHMM começar também a partir de outros estados.

Uma idéia que é intuitiva consiste em estimar as probabilidades de transições da GHMM, opção que foi adotada por Cawley et al. (2001) no genoma de P. falciparum. Neste genoma, eles observaram que íntrons na fase de leitura 2 são raros fazendo com que a opção de estimar as probabilidades de transições seja a mais natural. Fizemos experimentos que indicam que ocorre perda de exatidão quando utilizamos estimadores de máxima verossimilhança obtidas a partir das estruturas de genes observadas na amostra de treinamento (veja Seção 9.5).

A Figura 8.1 mostra um exemplo de arquitetura que assume distribuição uniforme nas fases de leituras dos éxons e que por isso chamamos esta arquitetura de fixed. Ela foi utilizada como base para a construção de diversos preditores MYOP e possui um conjunto de estados, $Q$, com um total de 67 elementos:

$$
\begin{array}{r}
Q=\{N, \text { start, stop, rstart, rstop, ES,rES }\} \cup A \cup B \\
A=\bigcup_{i \in\{0,1,2\}}\left\{E I_{i}, r E I_{i}, E T_{i}, r E T_{i}, \text { don }_{i}, \text { acc }_{i}, r d o n_{i}, \text { racc }_{i}, I_{i}, r I_{i}, r I s_{i}, I s_{i}, I f_{i}, r I f_{i}\right\} \\
B=\bigcup_{i \in\{0,1,2\}, j \in\{0,1,2\}}\left\{E_{i j}, r E_{i j}\right\}
\end{array}
$$

Considerando apenas a fita direta, utilizamos três estados para os éxons iniciais $\left(E I_{i}\right)$, três 
estados para os éxons terminais $\left(E T_{i}\right)$, nove estados para éxons internos $\left(E_{i j}\right)$, três estados para sítio doador $\left(d_{0} n_{i}\right)$, três estados para sítio aceitador $\left(a c c_{i}\right)$, três estados para íntron curtos $\left(I s_{i}\right)$, e mais três estados para representar íntrons longos $\left(I_{i}\right)$ e estados auxiliares $\left(I f_{i}\right)$ que resolve um problema técnico para a modelagem do comprimento do intron, explicado na Seção 8.4. A arquitetura para genes da fita reversa é apenas um "espelho" da fita direta e os nomes desses estados começam com a letra $r$.

$\mathrm{Na}$ implementação do programa Genscan, observaram que a arquitetura de GHMM deste mesmo preditor apresenta ambiguidade semântica, ou seja, existem muitos caminhos diferentes que mapeam para uma mesma anotação (Stanke e Waack, 2003). A ambiguidade semântica para gramáticas probabilísticas livres de contexto e para modelos decodificadores, incluindo GHMM e HMM, pode falhar em fornecer a anotação mais verosímil (Giegerich e zu Siederdissen). Para evitar este problema, a arquitetura implementada em fixed fornece predições de genes completos e assim cada caminho nesta arquitetura está associada a uma única anotação. Infelizmente, não encontramos nenhum estudo, na bibliografia pesquisada, sobre os efeitos da ambiguidade semântica para a predição de genes codificadores os quais utilizam HMM e GHMM.

\subsection{Submodelos de emissão}

Durante a especificação dos submodelos de emissão, é necessário especificar qual é a amostra de treinamento associado a cada submodelo e qual é o tipo do modelo que será aplicado. Nesta etapa, há muitas variações que podemos escolher, iremos descrever algumas delas.

\subsubsection{Uso do método BIC}

O MYOP é a primeira ferramenta de predição de genes que fornece a implementação do método BIC (Schwarz, 1978) para seleção de modelos. Este critério serve para escolhermos, de forma objetiva parâmetros relacionados com a dimensão do modelo, que antes eram arbitrários. Um exemplo de parâmetro arbitrário é a escolha da ordem do modelo da cadeia de Markov. AUGUSTUS usa cadeias de ordem 4 tanto no modelo de região codificadora, quanto no modelo de região não-codificadora. Genscan usa modelos de cadeia de Markov com ordem 5 os quais deveriam intuitivamente facilitar a discriminação entre região codificadora e não-codificadora, pois quanto maior a ordem da cadeia, melhor deveria ser a modelagem das depedências entre as posições da sequência. Contudo, Stanke (2003) explica que o uso de uma ordem maior do que 4 piora a predição do AUGUSTUS e ele fornece a seguinte explicação:

"A higher order Markov chain may more often correctly classify sequences as coding or non-coding but if it misclassifies a sequence it tends to be wider off the 
correct classification. This means that when using a higher order Markov chain the decisions are made to a greater extent by the content models than by the signal models and errors of the content models have a lower chance of being corrected

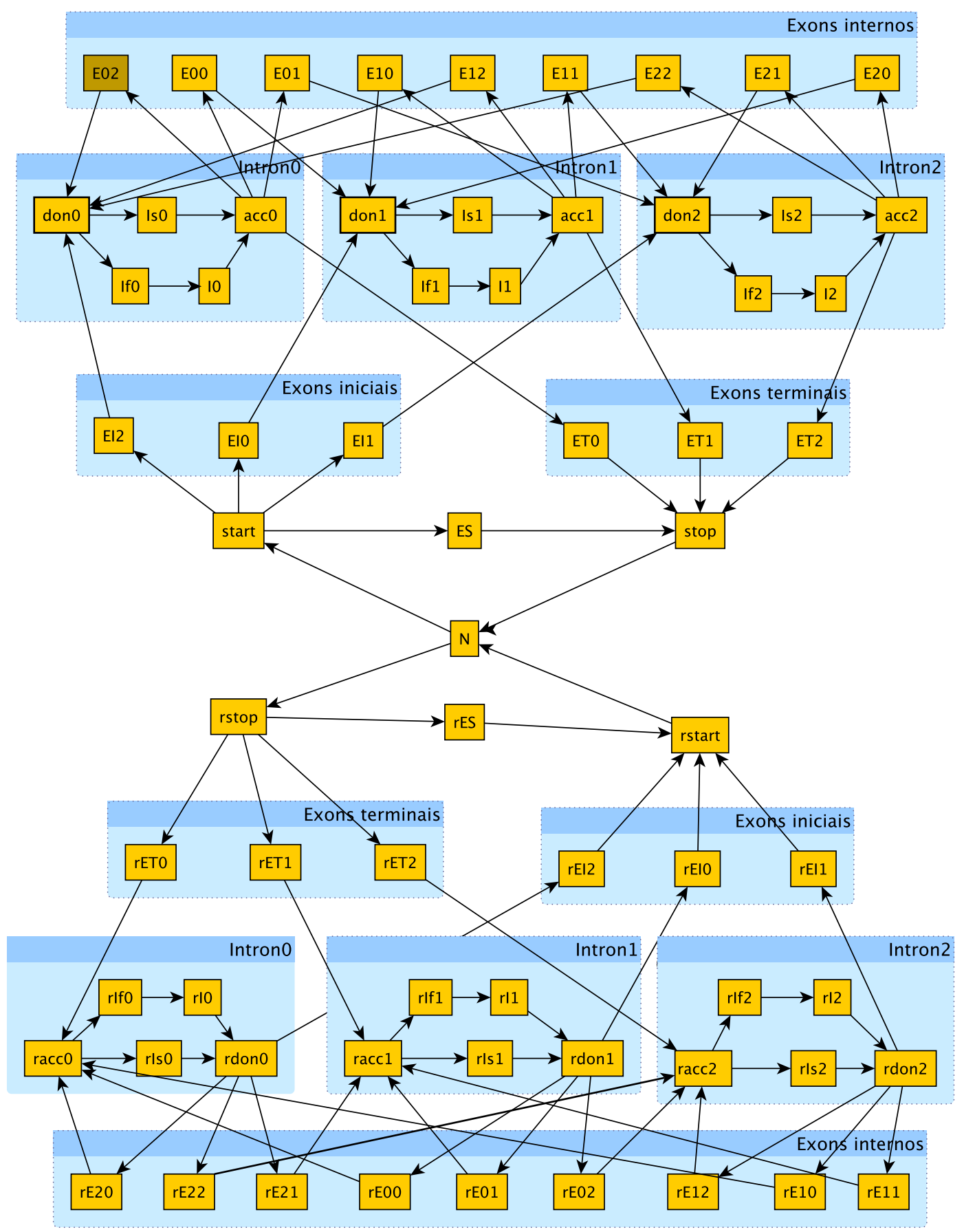

Figura 8.1: GHMM implementado na arquitetura fixed do MYOP 
by the signal models."

Possuimos uma outra explicação que complementa a usada acima. O número de parâmetros de uma cadeia de Markov cresce exponencialmente com a ordem da mesma. Assim, quanto maior a ordem da cadeia maior deve ser a amostra de treinamento. Observamos que a quantidade de genes usados no treinamento do preditor AUGUSTUS não é suficiente para estimar modelos com ordens maiores do que 4. O BIC fornece um critério para escolher o melhor modelo considerando também o tamanho da amostra de treinamento. Aplicamos o BIC no mesmo conjunto de treinamento do AUGUSTUS que tem cerca de 1284 genes $^{1}$ a ordem selecionada por esse critério foi igual a 4 tanto para o modelo da região codificadora, quanto para o modelo da região não-codificadora, indicando que o conjunto de genes para o treinamento usado pelo AUGUSTUS não fornece um modelo de cadeia de Markov com ordem maior que quatro.

\subsubsection{Sensores de conteúdo}

Em predição de genes, os estados do tipo éxon representam regiões que codificam proteínas, e os estados do tipo íntron e estados do tipo região intergênica representam regiões não codificadoras. Desse modo, precisamos de pelo menos dois submodelos de emissão:

- modelo para a região codificadora: treinado com todas as regiões codificadoras.

- modelo para a região não-codificadora: treinado com regiões não codificadoras, removendo também as sequências de íntrons.

Existe uma infinidade de variações a serem exploradas, mas nem sempre elas melhoram a exatidão. Por exemplo, é possível utilizar um modelo treinado com sequências de íntrons para representar estados do tipo íntron. Embora esta ideia seja intuitiva, ela não funciona para $H$. sapiens em que observamos perda de exatidão com esta variação na modelagem (veja o experimento na Seção 9.4). Podemos também treinar um modelo diferente para cada estado do tipo éxon usando as respectivas sequências observadas no treinamento, mas o livro escrito por Majoros et al. (2007) mostra que esta ideia também não fornece uma melhora na exatidão, o que foi confirmado pelos nossos experimentos. De qualquer maneira, é importante que novas variações sejam cuidadosamente avaliadas utilizando vários genomas e com o uso de validação cruzada.

Podemos também escolher quais os tipos de submodelos podemos utilizar. O ToPS possui a implementação de dois modelos importantes que são comumente utilizado para regiões codificadoras: (1) modelo para a cadeia iterpolada de três fases de Markov (3PIMM); (2) e o modelo para a cadeia de três fases de Markov (3PMC). O preditor GENSCAN adota uma 3PMC com ordem 5, enquanto que o AUGUSTUS utiliza um modelo 3PIMM com ordem 4.

\footnotetext{
${ }^{1}$ http://augustus.gobics.de/datasets/
} 
Testamos ambas as abordagens e o modelo adotado pelo AUGUSTUS forneceu os melhores resultados.

Em particular, os submodelos abaixo foram utilizados para construir preditores MYOP e obtiveram uma exatidão bastante competitiva:

- Região codificadora caracterizada utilizando um modelo interpolado de três fases de Markov com ordem selecionada pelo BIC e treinado com todas as sequências codificadora do conjunto de treinamento. Este modelo representa a emissão dos estados do tipo éxon.

- Região não-codificadora caracterizada utilizando um modelo interpolado de Markov de ordem selecionada pelo BIC com sequências da região intergênica. Este modelo representa a emissão dos estados que representam regiões não codificadoras de proteínas. Tentamos utilizar também sequências de íntrons para estimar este modelo, mas a exatidão quando há sequências de íntrons piora significativamente em $H$. sapiens. Especulamos que esta perda de exatidão esteja relacionada com eventos de splicing alternativo, por exemplo, retenção de íntrons. Tais eventos podem prejudicar a discriminação entre sequências codificadoras e não-codificadoras. Em C.elegans, que apresenta um genoma relativamente mais simples, não observamos perda de exatidão quando usamos seguências de íntron para o treinamento. (veja Seção 9.4).

\subsubsection{Sensores de sinais}

Sensores de sinais representam sequências de comprimento fixo que correspondem a sinais biológicos utilizados pelo maquinário celular no processo de transcrição e edição do RNA mensageiro. Exemplos de sensores de sinais incluem modelos para o sítio de início de tradução, sítio de fim de tradução, e os sítios de splicing. Muitos programas utilizam modelos de cadeias não-homogêneas de Markov, onde cada posição da sequência é representada por uma distribuição de probabilidade distinta.

Além dos modelos para cadeias de Markov, existem outros modelos que conseguem capturar as depedências entre posições não adjacentes e que são utilizados para representar o sítio doador. O modelo similiarity based weighting (Stanke e Waack, 2003) é um exemplo.

Podemos observar que a maioria das regiões fronteiriças entre regiões codificadoras e regiões não-codificadoras têm alguma sequência conservada. O sítio de início de tradução possui a sequência ATG, o sítio de fim de tradução pode ser $\{T A G, T G A, T A A\}$, o sítio aceitador apresenta a sequência conservada $\mathrm{AG}$, e finalmente, o sítio doador possuí a sequência GT. Para caracterizar essas fronteiras utilizamos modelos que representam a vizinhança dessas sequências conservadas. Podemos definir dois parâmetros: o comprimento do sinal, e o deslocamento, que é a quantidade de nucleotídeos antes da sequência conservada, veja Figura 8.2. 


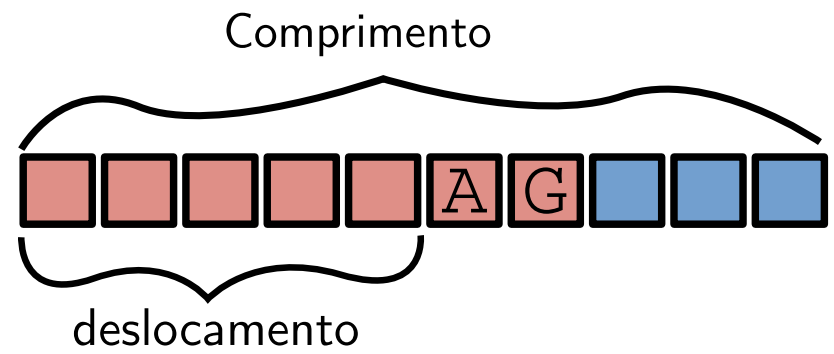

Figura 8.2: Representação de um sítio aceitador. A parte em vermelho indica uma região nãocodificadora (intron) e a parte em azul é a região codificadora (éxon). O deslocamento é a quantidade de nucleotídeos antes da sequência conservada, neste caso, deslocamento é de 5nt. O comprimento é a quantidade de nucleotídeos que o modelo representa, neste caso, o comprimento é de 10nt.

A escolha do comprimento da vizinhança em relação as sequências conservadas é importante para conseguirmos um bom preditor de genes. Existem várias formas de decidir o comprimento do sensor de sinal. Uma delas é utilizar a entropia de Shannon, a qual fornece uma idéia de quais posições do sinal tem entropia baixa e quais posições tem entropia alta. À medida que aumenta a distância entre a sequência conservada e a posição do sinal, a entropia estimada para esta posição tende a aumentar. Assim, um limiar na entropia pode ser utilizado para definir o comprimento do sinal. Uma outra alternativa, que leva em consideração o modelo de predição inteiro, é o de selecionar um comprimento que fornece a melhor GHMM em testes de validação cruzada.

Em particular, os submodelos abaixo foram utilizados para construir preditores MYOP e obtiveram uma exatidão competitiva:

- Sítio aceitador de íntron: O sítio aceitador é formado pela composição de três modelos em sequência:

- ponto de ramificação: Uma WAM de ordem selecionado pelo BIC treinado com os 32 nucleotídeos que começam a 36 nucleotídeos anteriores a sequência conservada AG.

- sítio aceitador: Uma WAM de ordem 1 treinado com sequências, (iiiAGe), de tamanho 6 com 3 nucleotídeos antes do AG e mais um nucleotídeo depois do AG.

- padrão de tamanho 4: Frequência dos padrões de tamanho 4 que aparecem na posição correspondente. O comprimento 4 é uma solução puramente técnica adotada por Stanke (2003) para resolver um problema relativo a ordem da cadeia do sensor de conteúdo, o comprimento foi escolhido de tal forma a evitar que a sequência conservada AG do sítio aceitador seja usada como contexto do modelo da região codificadora.

- Sítio doador de íntron: Similarity Based Weighting (Stanke, 2003) treinado com a sequência de tamanho 9 (eeeGTiiii) com 3 nucleotídeos antes do GT e mais quatro nucleotídeos depois do GT. 
- Sítio de início de tradução: O sítio de início de tradução foi formado pela composição de três modelos em sequência:

- motivo inicial: WAM de ordem 3 treinado com os 20 nucleotídeos anteriores ao códon de iniciação;

- ATG: emite ATG com probabilidade um;

- padrão de tamanho 4: emite 4 nucleotídeos com probabilidade estimada usando a frequência relativa desses 4 nucleotídeos nessa região;

- Sítio de fim de tradução: emite TAG, TGA, ou TAG com probabilidade estimada com a frequência do uso desses três tipos de códon de terminação.

\subsection{Submodelos de duração}

A grande maioria dos programas de predição assume que o comprimento do íntron é dado por uma distribuição geométrica. No Capítulo 7, mostramos que este tipo de modelagem dimimui a sensibilidade em prever íntrons longos e diminue também a precisão em prever códons de terminação (precisão de $64.24 \%$ foi para 42.66\%) e códons de iniciação (precisão de $54.97 \%$ foi para $36.32 \%$ ). Este comportamento ocorre porque íntrons longos são previstos como região intergênica, ou seja, os genes com introns longos ficam repartidos em duas ou mais estruturas preditas com introns curtos.

Em D. melanogaster, Reese et al. (2000) perceberam o mesmo comportamento com o preditor Geneid o qual dividia genes com íntrons longos em genes pequenos com íntrons curtos. Stanke (2003) forneceu uma solução para este problema que consiste em modelar separadamente a duração dos íntrons curtos através de estados de duração explícita com distribuição dada por um histograma suavizado estimado com introns de tamanho no máximo 584. O valor 584 foi cuidadosamente escolhido de tal forma a não afetar o tempo de execução do preditor e ao mesmo tempo fornecer uma melhora na predição em relação aos íntrons longos.

Cada estado do tipo $I f_{i}$ (Íntron tamanho fixo) emite palavras de tamanho 584 e serve para fornecer dois caminhos distintos: se um íntron emitido tem tamanho menor que 584, temos certeza de que o íntron foi emitido por algum estado do tipo $I s_{i}$ (íntron curto), caso o íntron emitido for de tamanho maior que 584, temos certeza de que ele foi emitido pelos estados $I f_{i}$ seguido por iterações do estado $I_{i}$ (íntron duração geométrica).

Como o modelo de emissão dos estados do tipo íntron e estados do tipo região intergênica é o mesmo, a sensibilidade de predição de íntrons longos é também controlada pelo tamanho médio da região intergênica. Em nossos testes, a técnica do Augustus apresentou melhora apenas a partir do momento que o comprimento médio das emissões do estado da região intergênica foi diminuido de $10^{6}$ para $10^{4}$. Valores altos de comprimento médio de região 
intergênica fizeram com que o problema de predição de íntrons longos voltasse (dado não mostrado).

Ao estimar a distribuição do comprimento das regiões do tipo éxon, muitos comprimentos não serão observados e assim precisamos de alguma técnica de suavização para evitarmos overfitting. O MYOP fornece três métodos de suavização de histogramas: (1) Método descrito em Burge (1997); (2) Método descrito em Stanke (2003); (3) e o método de Sheather (2004). Para representar a duração de estados de duração explícita, usamos histogramas suavizados pela técnica descrita em Stanke (2003) o qual forneceu o melhor resultado.

Finalmente, os estados do tipo éxons emitem apenas palavras que tenham comprimentos compatíveis com as fases de leituras de entrada e fases de leitura de saída. Foi possível implementar a duração de éxons usando duas transformações nas distribuições suavizadas:

- Atribuímos probabilidade zero para durações que não são compatíveis com a fase de leitura de entrada e de saída e renormalizamos a distribuição.

- Os estados de sítios de splicing e estados de início e fim de tradução emitem regiões que são éxonicas, assim descontamos da distribuição de duração dos estados do tipo éxon o comprimento do segmento de éxon emitido por modelos dos estados de sinais biológicos. O mesmo processo foi feito considerando os estados de íntrons.

\subsection{Treinamento dependente de conteúdo GC}

Muitos preditores de genes adotam a estratégia de particionar o conjunto de treinamento de acordo com o conteúdo GC (quantidade das letras G e C na sequência). Esta estratégia melhora a exatidão média para genomas que apresentam regiões chamadas de isochore, que são grandes regiões (maiores que $3 K B$ ) com conteúdo GC homogêneo. Genscan, Genezilla, Genemark.hmm, e GlimmerHMM usam 4 modelos GHMM treinados com genes com composição dentro de um dos quatro intervalos ([0\%, 43\%], [43\%, 51\%], [51\%-57\%], e [57\%, 100\%]), ao analisar uma sequência o conteúdo GC é calculado e o modelo GHMM com conteúdo GC mais próximo é usado para a decodificação. A desvantagem desta abordagem é que o conjunto de treinamento para cada GHMM é bem menor. Para evitar isso, o Augustus usa todo o conjunto de treinamento para estimar uma GHMM com um conteúdo GC alvo. Ele fornece um peso para cada gene da amostra de treinamento. Enquanto genes com conteúdo GC mais próximos ao conteúdo GC alvo recebem pesos maiores, genes com conteúdo GC mais distantes recebem pesos menores. Este peso indica o número de vezes que um gene será usado para estimar uma GHMM com um dado conteúdo GC alvo. Se $\alpha$ é o conteúdo GC alvo, e $\beta$ o conteúdo GC do gene de treinamento, o peso do gene é calculado pela seguinte função (Stanke, 2003):

$$
w(\alpha, \beta)=\left\lceil 10 \exp \left(-200 *(\alpha-\beta)^{2}\right)\right\rceil
$$


Assim, o AUGUSTUS consegue aumentar a granularidade em relação ao espectro do conteúdo GC, usando, em vez de 4 modelos, 10 modelos específicos de composição GC. Apenas os submodelos de sítio de splicing, as distribuições da duração dos estados, e as probabilidades de transições da GHMM não são GC específico.

O número ideal de intervalos GC muda para genomas diferentes. Em nossas primeiras implementações usamos apenas um modelo GHMM treinado com toda amostra. Os nossos preditores que empregam apenas uma GHMM funcionaram muito bem para os genomas de A.thaliana e C.elegans. Observamos que nesses genomas há baixa variância na composição GC entre as sequencias dos genes: variância de 10\%, e 15.07\% respectivamente. Contudo, em genomas com alta variedade na composição GC, um preditor que usa apenas um modelo GHMM é menos sensível, ou seja, genes com grande viés composicional eram classificados como região não-codificadora. Em particular, observamos melhora significativa na exatidão para $H$. sapiens e Z. mays os quais apresentam uma variância bem maior na composição, $68 \%$ e $69 \%$, respectivamente.

Tentamos usar também a estratégia, que chamamos de "target GHMM", que consiste em treinar uma nova GHMM de acordo com o conteúdo GC da sequência de entrada. Nesta estratégia, quando o preditor recebe uma nova sequência de entrada, o conteúdo GC da sequência é calculado, os pesos dos genes de treinamento são recalculados, uma nova GHMM é estimada, e usando a nova GHMM realizamos a decodificação da sequência de entrada. Esta estratégia tem a desvantagem de ser computacionalmente intensivo, mas observamos uma melhora na exatidão em nossas testes de validação cruzada em H. sapiens (veja Seção 9.6). 


\section{Capítulo 9}

\section{Experimentos para construir uma biblioteca de preditores}

Durante o desenvolvimento de nossos preditores de genes, realizamos diversos experimentos exploratórios para nos ajudar a escolher arquiteturas mais relevantes. Neste Capítulo, mostraremos cinco experimentos. No primeiro experimento, comparamos duas arquiteturas de predição que são utilizadas como base para a construção da grande maioria dos preditores de sucesso. Mostramos que uma arquitetura similar ao que é utilizada pelo preditor AUGUSTUS (Stanke, 2003) tem grandes vantagens em relação aos outros preditores. Em seguida, implementamos uma arquitetura no MYOP, bastante similar ao que o preditor AUGUSTUS utiliza, e realizamos experimentos de validação cruzada comparando ambos os preditores. Embora o MYOP utilize modelos puros de GHMM, foi possível implementar preditores bastante competitivos. A maioria dos preditores MYOP apresentou performance superior ou similar ao preditor AUGUSTUS, que implementa algumas heurísticas no código-fonte. Além disso, realizamos experimentos que mostram a existência de ideias aparentemente intuitivas, mas que na verdade fornecem resultados visivelmente piores. Apresentamos uma nova estratégia promissora para lidar com a variação no conteúdo GC, que chamamos de Target GHMM, e que utiliza o mesmo princípio do artigo que descreve modelos nulos para classificação de sequências (Machado-Lima et al., 2010). Finalmente, como sequela dos experimentos de validação cruzada, obtemos preditores de genes para onze genomas distintos.

\subsection{Avaliando arquiteturas de preditores amplamente uti- lizadas}

Vimos na Seção 2.4 uma arquitetura de GHMM que é utilizada como base para a implementação da grande maioria dos preditores de genes. Nesta arquitetura de GHMM, as regiões não codificadoras de proteínas estão representadas por estados com duracão geometricamente distribuída. As diferenças entre diferentes implementações estão principalmente nos submodelos escolhidos para cada estado, para analisar a diferença utilizamos os mesmos 
submodelos em ambas arquiteturas. Uma variação dessa arquitetura foi desenvolvida pelo preditor AUGUSTUS, que fornece estados adicionais para modelar a distribuição do comprimento de íntrons curtos. Outras variações estão em estados adicionais para representar região promotora e região de poliadenilação. O objetivo deste experimento foi comparar dois dos principais tipos de arquiteturas de GHMM para predição de genes:

- geometric é uma arquitetura que assume que o comprimento do íntron é dado por uma distribuição geométrica, esta arquitetura é utilizada como base para muitos programas de predição, incluindo GlimmerHMM, GeneMark.hmm, Genscan, Phat, e Genezilla.

- fixed é a arquitetura similar ao do preditor AUGUSTUS em que fornece a mesma probabilidade de transição para as diferentes fases de leitura, esta arquitetura utiliza estados específicos para modelar íntrons curtos.

Por apresentar uma melhor modelagem dos íntrons curtos, a secunda arquitetura deve apresentar uma melhor exatidão. De fato, no diagrama de Venn de íntrons previstos para o conjunto apresentado em $G_{15}$, temos que 83 íntrons foram corretamente preditos apenas pela arquitetura geometric, e 132 íntrons preditos corretamente apenas pela arquitetura fixed. O histograma da Figura 9.1 mostra íntrons exclusivos que foram corretamente preditos. Podemos verificar neste histograma que a arquitetura fixed realmente melhora a exatidão em prever tanto os íntrons curtos, quanto em prever íntrons longos ( $\geq 40,000)$. Contudo, há um intervalo de comprimentos (de 600 até 4000) onde a arquitetura geometric forneceu uma revocação maior (50 íntrons corretamente preditos) do que a arquitetura fixed (32 íntrons corretamente preditos). Este é um exemplo em que a comparação utilizando o diagrama de Venn fornece mais informações para a identificação das vantagens de cada preditor.

A Tabela 9.1 e a Tabela 9.2 mostram a exatidão do ponto de vista de estruturas preditas e do ponto de vista de éxons preditos. Observamos uma melhora significativa de precisão ao utilizar a arquitetura fixed. A tabela também ilustra a importância de uma plataforma

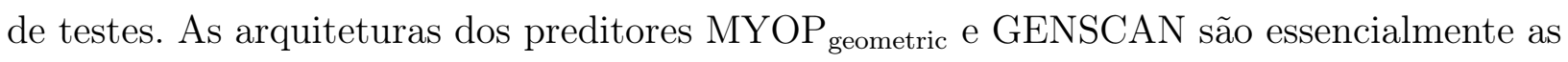
mesmas, mas a dificuldade de manipular vários preditores impede testes justos. Isso pode ser visto na diferença de performance entre o AUGUSTUS (arquitetura fixed) e o GENSCAN (arquitetura geometric), muito maior do que nas duas versões do MYOP. Esse fato se deve ao conjunto de treinamento do GENSCAN que não é controlável. Cabe ressaltar que a performance da arquitetura $\mathrm{MYOP}_{\text {fixed }}$ é comparável com a performance do AUGUSTUS, demonstrando que o uso de uma plataforma genérica não implica em perda de qualidade.

\subsection{Comparações com o AUGUSTUS}

Para testar a hipótese de que conseguimos, através da utilização do MYOP, exatidão competitiva com relação aos melhores programas ab initio, fizemos uma comparação com o AUGUSTUS (versão 2.5.5). Utilizamos este preditor por dois motivos: (i) o AUGUSTUS 


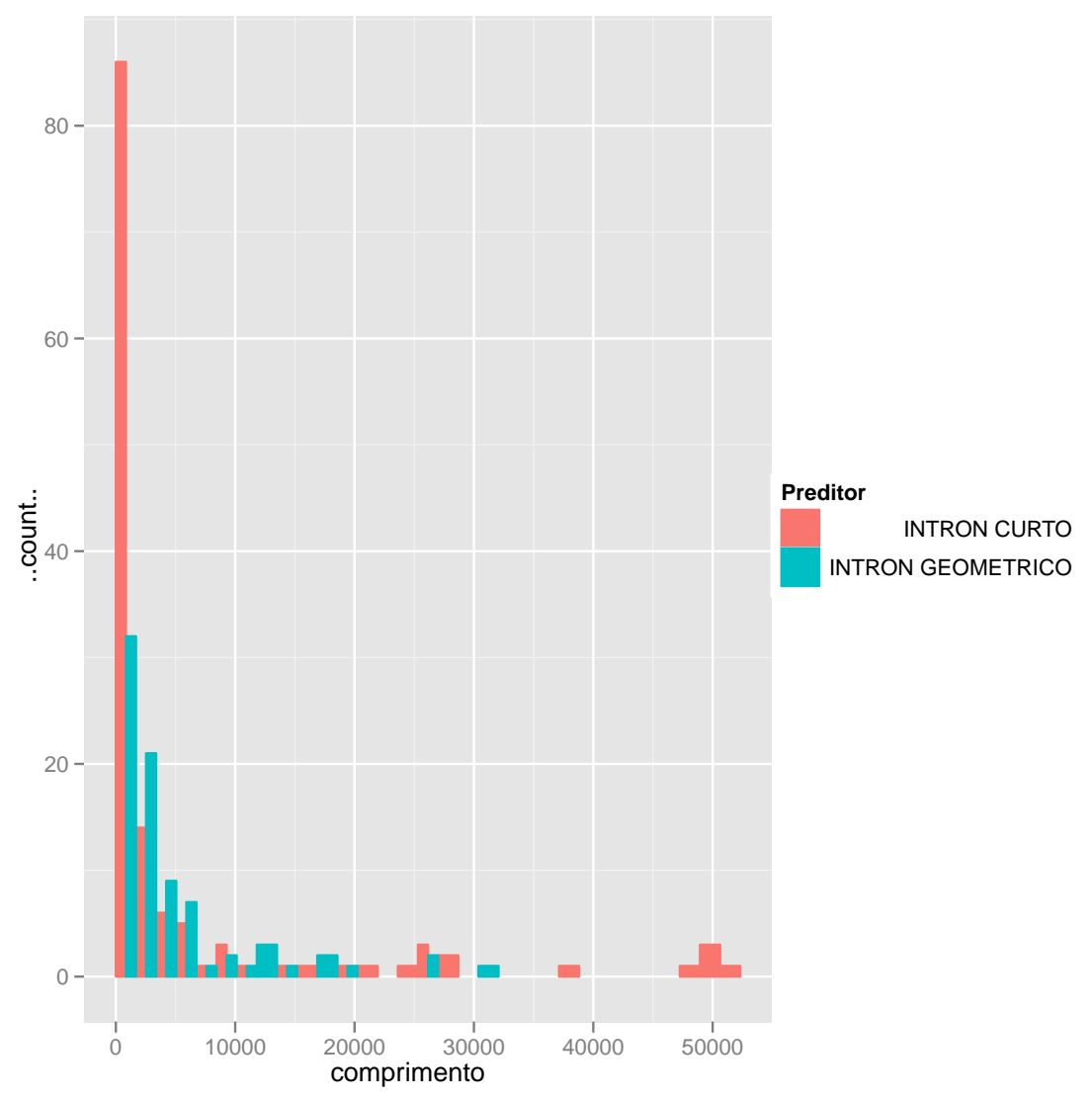

Figura 9.1: Comprimento de introns exclusivos corretamente preditos

Tabela 9.1: Estruturas de genes corretamente previstas em $H$. sapiens no conjunto $G_{15}$

\begin{tabular}{lccc}
\hline & \multicolumn{3}{c}{ Estruturas de genes } \\
Preditor & Precisão & Revocação & F \\
\hline MYOP $_{\text {geometric }}$ & $14.97 \pm 1.62$ & $26.13 \pm 2.40$ & $19.03 \pm 1.91$ \\
MYOP $_{\text {fixed }}$ & $\mathbf{2 2 . 9 6} \pm 1.76$ & $26.77 \pm 2.07$ & $\mathbf{2 4 . 7 2} \pm 1.90$ \\
AUGUSTUS (complete) & $20.22 \pm 1.99$ & $\mathbf{2 9 . 0 7} \pm 1.85$ & $23.84 \pm 1.97$ \\
GENSCAN (pré-treinado) & $6.99 \pm 1.53$ & $11.84 \pm 2.11$ & $8.79 \pm 1.79$ \\
\hline
\end{tabular}


Tabela 9.2: Éxons corretamente previstos em $H$. sapiens no conjunto $G_{15}$

\begin{tabular}{lccc}
\hline & & Éxons \\
Estratégia & Precisão & Revocação & $\mathrm{F}$ \\
\hline MYOP $_{\text {geometric }}$ & $67.29 \pm 1.65$ & $71.02 \pm 1.10$ & $69.10 \pm 1.36$ \\
MYOP $_{\text {fixed }}$ & $\mathbf{7 4 . 1 2} \pm 0.96$ & $72.32 \pm 1.29$ & $\mathbf{7 3 . 2 1} \pm 1.01$ \\
AUGUSTUS (complete) & $72.41 \pm 1.69$ & $71.99 \pm 0.54$ & $72.18 \pm 1.04$ \\
GENSCAN (pré-treinado) & $55.40 \pm 2.15$ & $\mathbf{7 3 . 6 2} \pm 1.02$ & $63.22 \pm 1.77$ \\
\hline
\end{tabular}

tem ferramentas automatizadas para realizarmos o treinamento permitindo o teste de validação cruzada; (ii) ele apresentou a melhor exatidão em duas competições internacionais importantes, no nGASP (Coghlan et al., 2008) (melhor entre 11 preditores de genes) e no EGASP (Guigó et al., 2006) (melhor entre 5 preditores).

Para esta comparação fizemos uma implementação do MYOP ( $\mathrm{MYOP}_{\text {fixed }}$ ) o mais próxima possível do AUGUSTUS ${ }^{1}$. Isso permite verificar se não há perda de performance introduzidas com a flexibilidade e modelagem do MYOP. As curvas de aprendizado desses dois preditores mostram que o $\mathrm{MYOP}_{\text {fixed }}$ consegue performance comparável com o AUGUSTUS. Em algumas situações, o MYOP fixed apresentou resultados mais exatos.

Ambas as medidas de exatidão ( precisão e revocação) foram combinadas em uma única medida utilizando o escore F, que é igual a média harmônica:

$$
F=\frac{2 \times \text { precisão } \times \text { revocação }}{\text { precisão }+ \text { revocação }}
$$

Escolhemos por utilizar a média harmônica, porque ela é a menor entre os três tipos de média (geométrica, aritmética, e harmônica), ou seja, ela tende a dar valores mais próximos ao menor valor entre a precisão e a revocação. Por exemplo, suponha que temos dois preditores, o primeiro com revocação igual a $100 \%$ e precisão igual a $10 \%$, e o segundo com revocação de $55 \%$ e a precisão de $55 \%$. Enquanto a média aritmética fornece o mesmo valor para ambos os casos (55\%), o escore $\mathrm{F}$ do primeiro preditor é igual a $18.55 \%$ e do segundo preditor é igual a 55\%. A média aritmética falha em fornecer a idéia de que o primeiro preditor é pior que o segundo, já que o primeiro preditor tem uma quantidade relativamente mais alta de falsos positivos do que o segundo.

Os gráficos das curvas de aprendizado mostram que tanto o $\mathbf{M Y O P}$ fixed quanto o AUGUSTUS convergem para um escore $F$ similar. Além disso, as curvas indicam que a partir de 600 genes na amostra de treinamento o preditor apresenta exatidão similar em relação a preditores treinados com um número maior de genes.

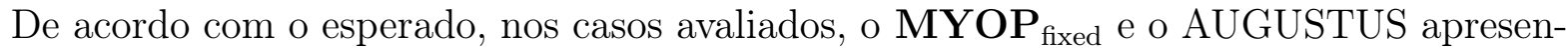
taram resultados de exatidão similar. Contudo, o diagrama de Venn mostra que os preditores costumam fornecer resultados que se complementam. Em particular, a Figura 9.2 apresenta uma média dos diagramas de Venn para éxons da validação cruzada no conjunto $G_{15}$ para

\footnotetext{
${ }^{1}$ augustus - genemodel=complete -noInframeStop=false
} 
seis genomas. Por essa razão, é sugerido utilizar a combinação de múltiplos preditores de genes para realizar a anotação de um novo genoma (Allen e Salzberg, 2005).

A. thaliana

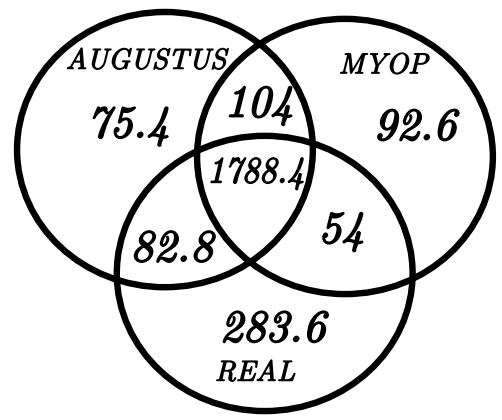

H. sapiens

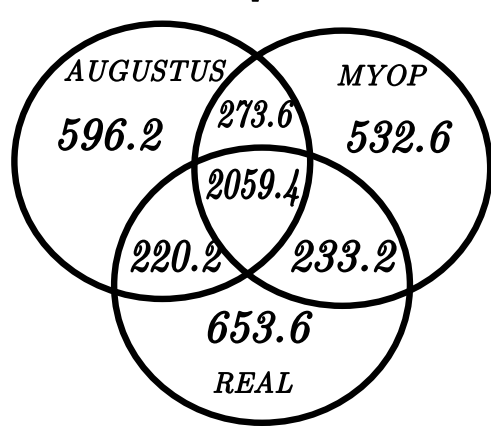

C. elegans

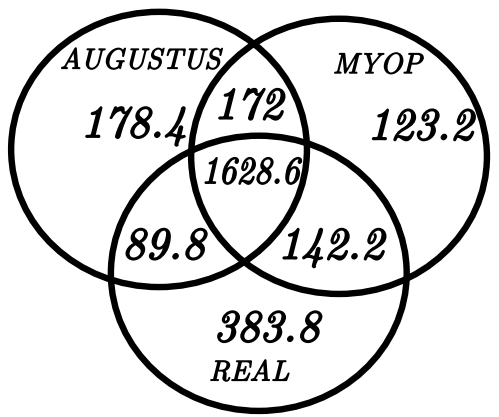

P. falciparum

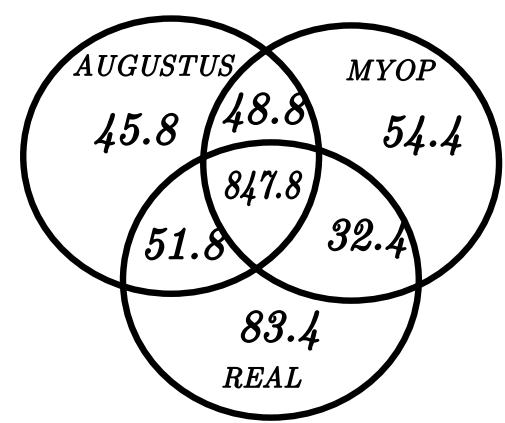

Z. mays

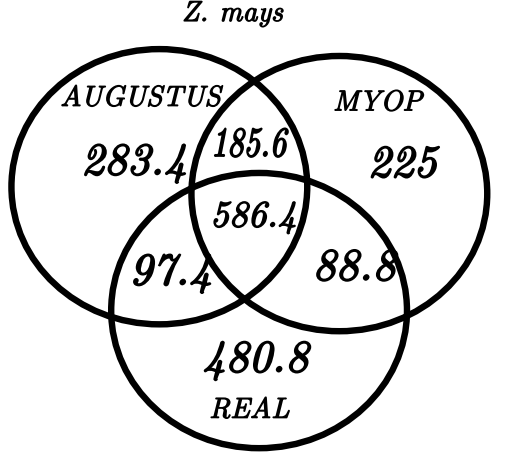

D. melanogaster

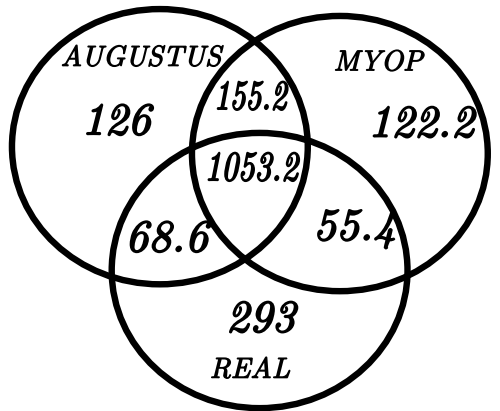

Figura 9.2: Diagrama de Venn para éxons corretamente preditos. Os diagramas mostram resultados que se complementam.

Para cada um dos genomas, fizemos uma curva de aprendizado comparando o $\mathrm{MYOP}_{\text {fixed }}$ com o AUGUSTUS, mostramos abaixo as curvas mais relevantes e as outras curvas estão no Apêndice C.

- Predição em A. thaliana (Figura 9.3): Em A. thaliana, as curvas de aprendizados de ambos os preditores são similares e se sobrepõe ao considerarmos também a variância. Neste caso, o AUGUSTUS alcançou uma performance superior em prever a estrutura do genes.

- Predição em C. elegans (Figura 9.4): Em C.elegans as curvas de aprendizado de ambos os preditores são similares com o $\mathrm{MYOP}_{\text {fixed }}$ levemente superior para prever a estrutura do gene.

- Predição em D.melonogaster (Figura 9.5): Em D. melanogaster, as curvas de aprendizados do MYOP e do AUGUSTUS são parecidas, exceto na medida de nucleotídeos íntronicos preditos. Esta medida de exatidão não é utilizada por outras avaliações e nesse caso específico apontou uma diferença entre os dois preditores a qual não seria visível se usássemos apenas as medidas de exatidão de Burset e Guigò (1996). Embora a quantidade de íntrons corretamente preditos em ambos os preditores foi similar, o $\mathrm{MYOP}_{\text {fixed }}$ conseguiu uma revocação maior ( $75 \%$ versos $68 \%$ ) com a 
especificidade parecida ( $81 \%$ versos $79.33 \%$ ) em nucleotídeos de íntrons indicando que

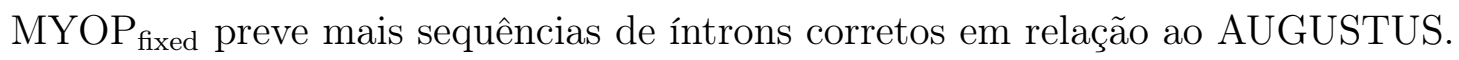

- Predição em H. sapiens (Figura 9.6): Em H.sapiens, o MYOP fixed $_{\text {apresentou }}$ resultados melhores do que o AUGUSTUS para prever o começo e fim dos genes.

- Predição em Z. mays (Figura 9.7): Em Z. mays, as curvas de aprendizados apresentaram uma dispersão maior (a margem em cinza no gráfico) do que em relação aos outros genomas. Identificar o porque dessa variação e implementar meios que consigam diminuir é um ponto a ser explorado. Esperamos que este comportamento apareça para outros genomas que possuem muitos genes com transferência horizontal. Precisamos analisar a hipótese de que genes obtidos por transferência horizontal são responsáveis em aumentar a variabilidade das estruturas do gene e assim dificultar a tarefa de prever o gene neste genoma.
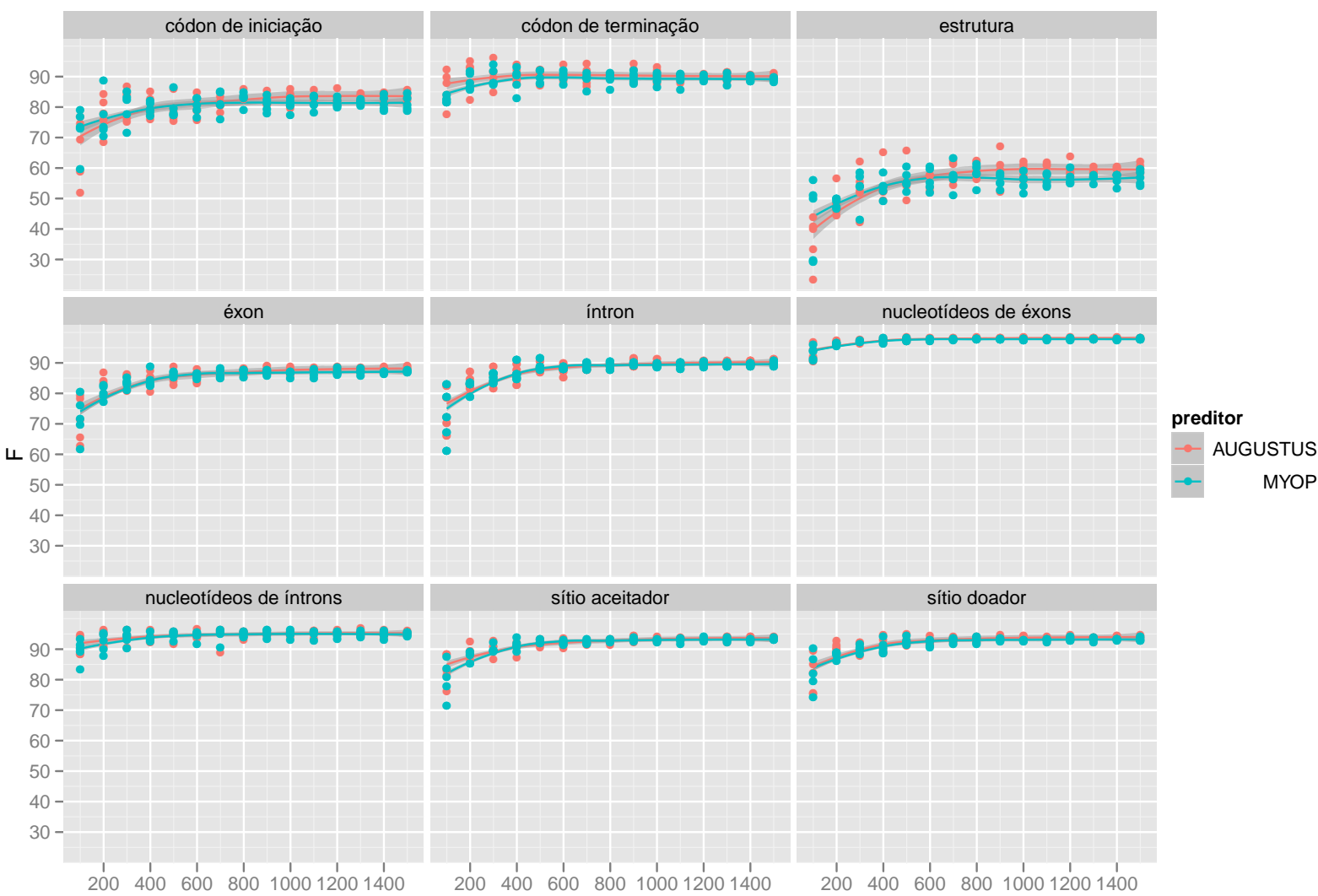

Figura 9.3: Exatidão dos preditores AUGUSTUS e MYOP fixed em A. thaliana em relação ao tamanho da amostra de treinamento 


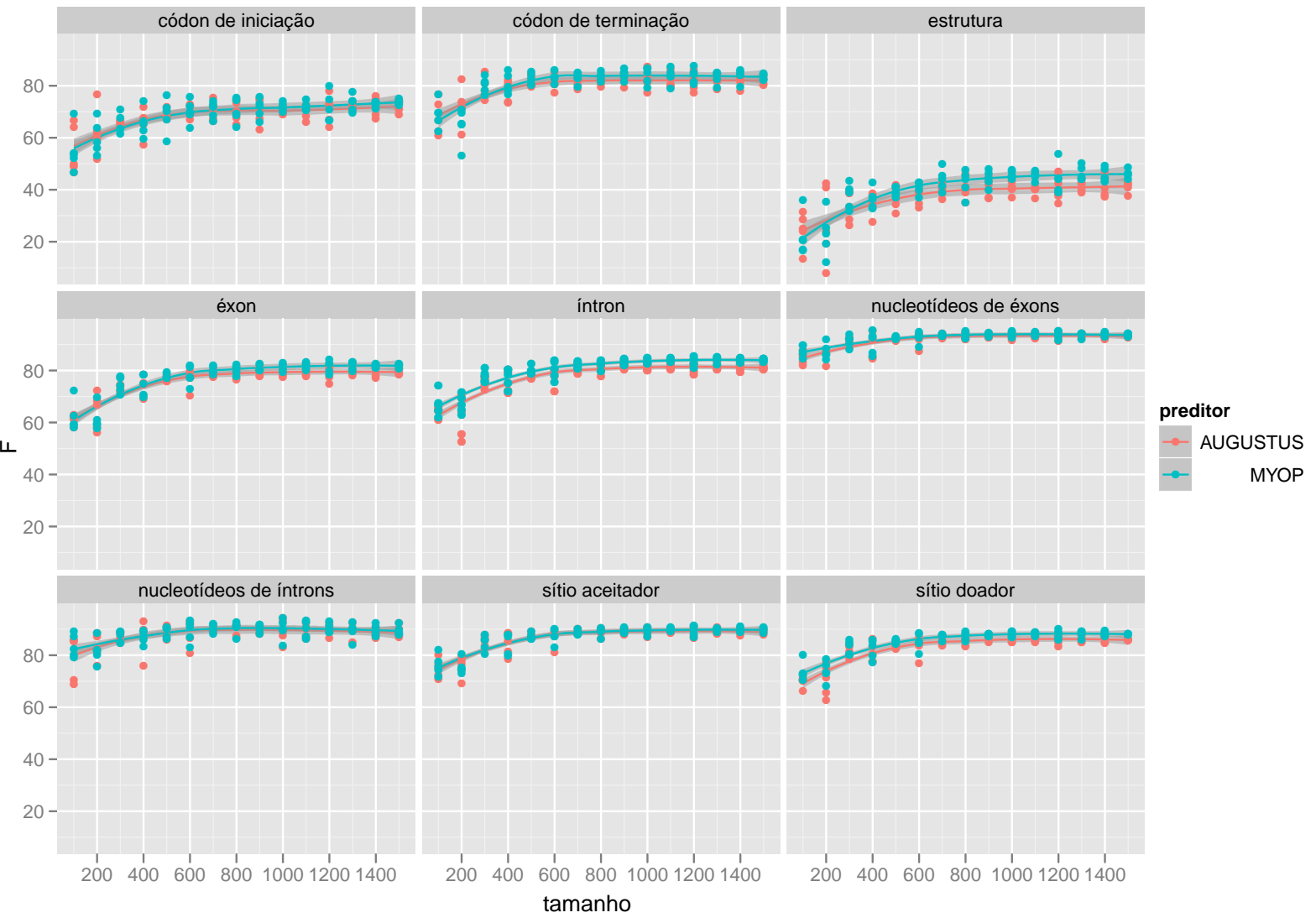

Figura 9.4: Exatidão dos preditores AUGUSTUS e MYOP fixed em C. elegans em relação ao tamanho da amostra de treinamento 

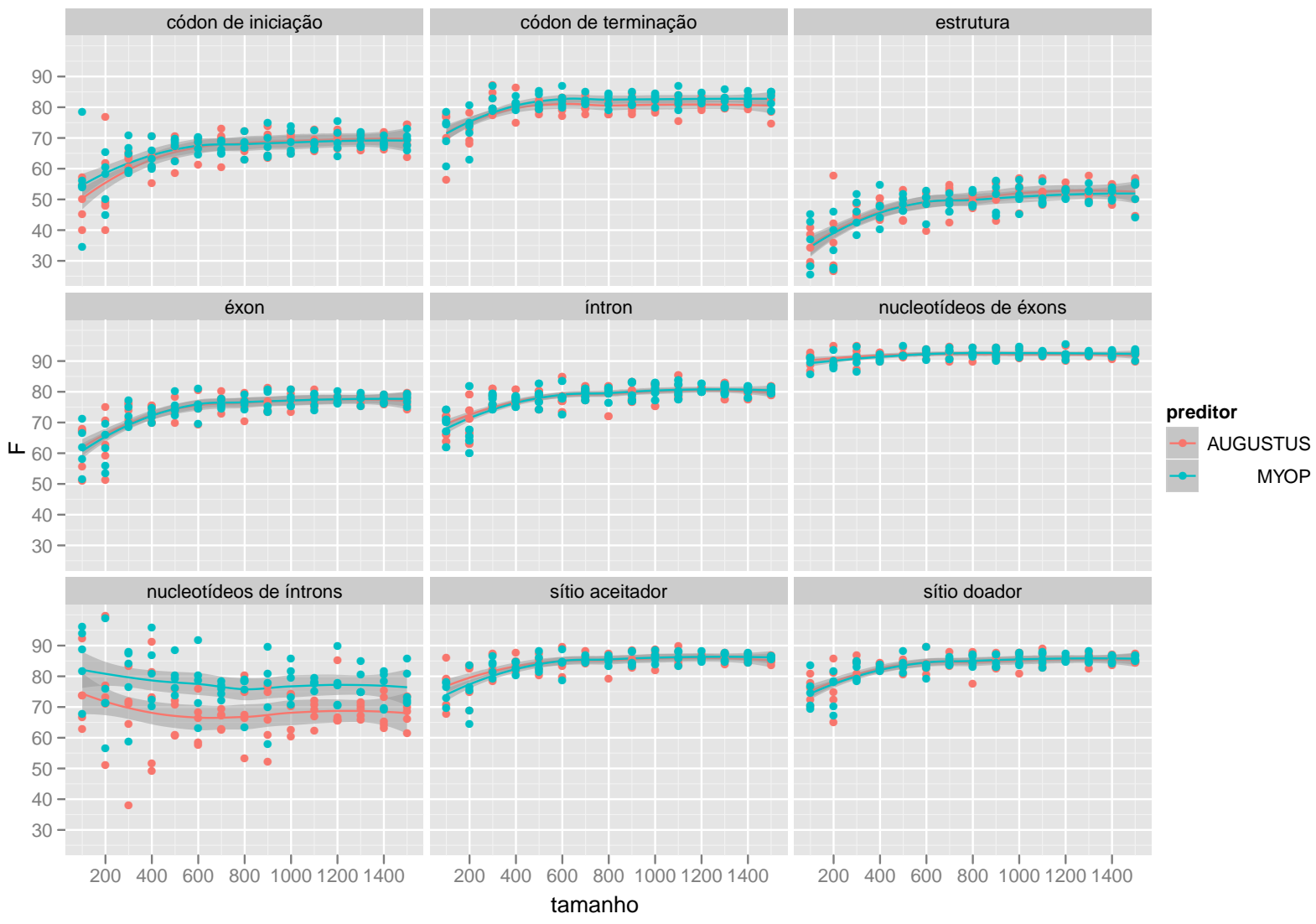

Figura 9.5: Exatidão dos preditores AUGUSTUS e MYOP fixed em D. melanogaster em relação ao tamanho da amostra de treinamento 


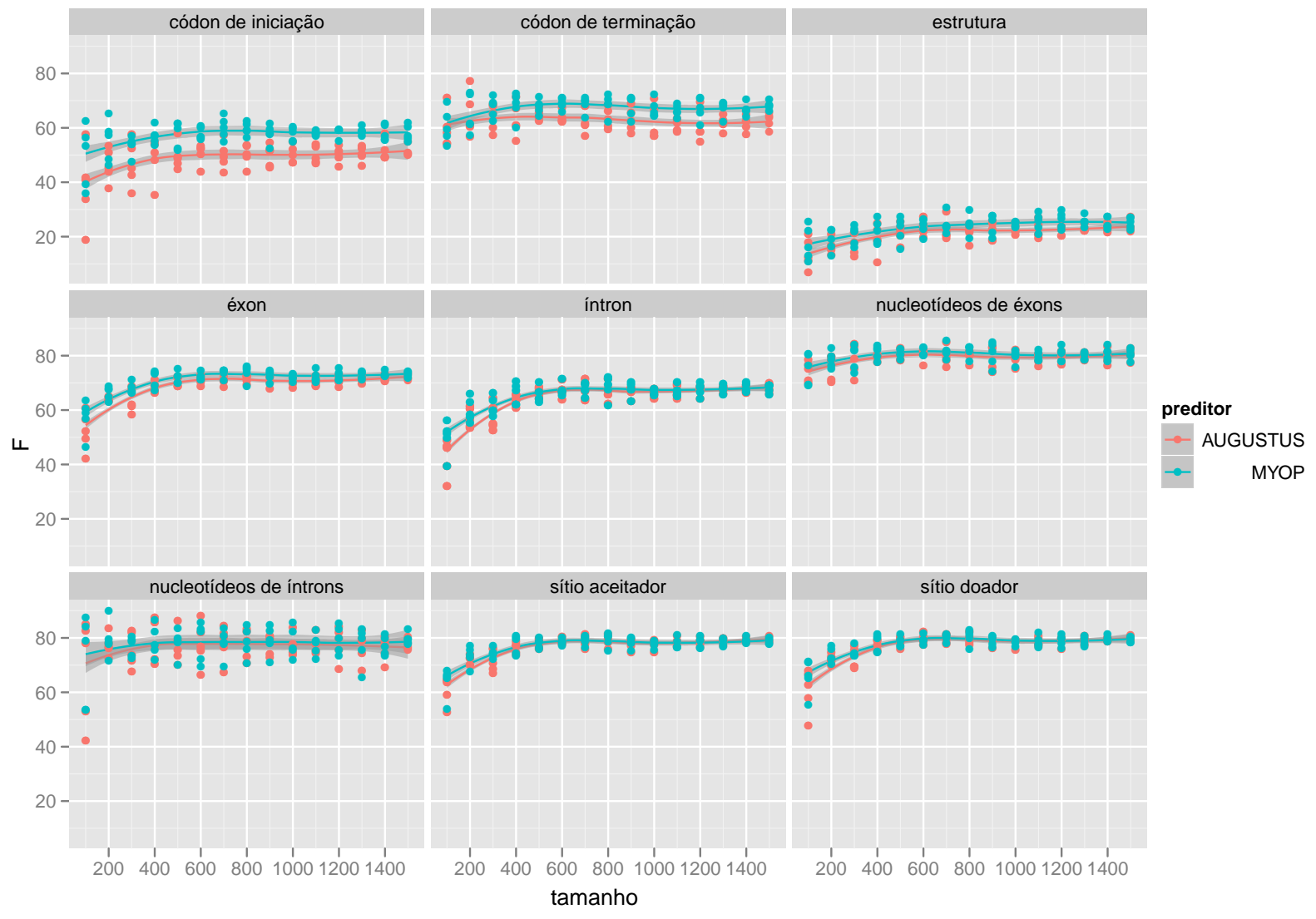

Figura 9.6: Exatidão dos preditores AUGUSTUS e MYOP fixed em H. sapiens em relação ao tamanho da amostra de treinamento 


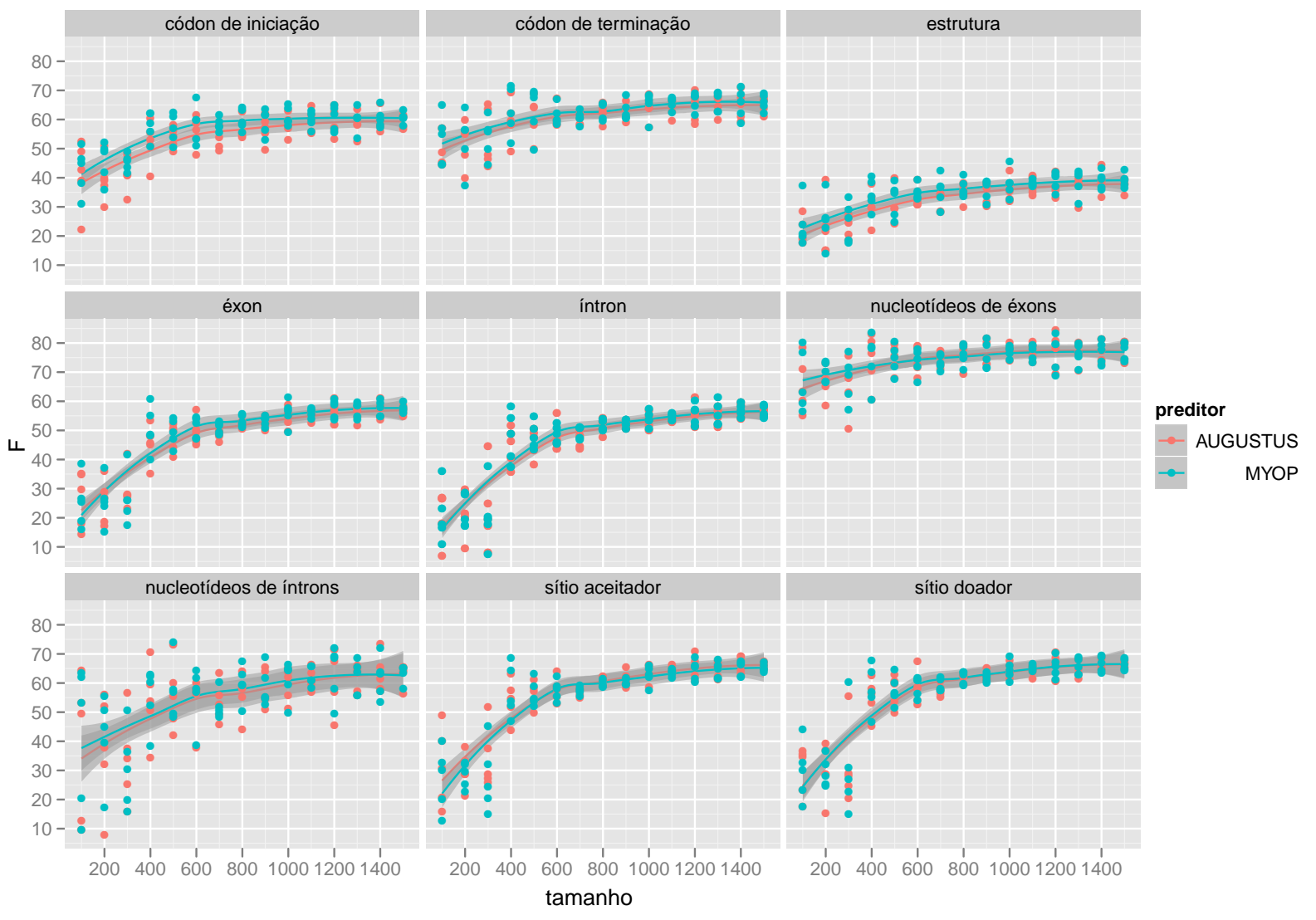

Figura 9.7: Exatidão dos preditores AUGUSTUS e $M Y O P_{\text {fixed }}$ em Z. mays em relação ao tamanho da amostra de treinamento 


\subsection{Eliminar códon de terminação conflitante na estru- tura predita melhora a predição}

Quando não especificado no arquivo de configuração, o MYOP utiliza modelo puro de GHMM o qual assume independência entre emissões de diferentes estados. A Figura 9.8 mostra uma limitação do modelo puro. Por causa da suposição de independência, duas emissões de regiões codificadoras que são vizinhas e que ocorrem em estados diferentes podem formar um códon de terminação que conflita com a fase de leitura. Existem duas situações possíveis para o aparecimento de códon de terminação conflitante: (1) códons de terminação que aparecem entre as fronteiras das emissões flanqueadoras da emissão do estado do tipo éxon; (2) códons de terminação que aparecem entre dois éxons separados por um íntron. Uma solução para manter o uso de uma GHMM pura consiste em criar novos estados na GHMM os quais fornecem apenas caminhos sem códon de terminação conflitante. Contudo, a modificação da arquitetura é um tarefa complicada e sujeita a muitos erros de implementação. Para eliminar predições com codon de terminação conflitantes, os preditores implementam uma modificação no algoritmo Viterbi que invalidam caminhos não desejados. Em Majoros et al. (2007) existe a demonstração de que o algoritmo de decodificação modificado encontra a estrutura de gene mais provável dentro do conjunto de estruturas válidas.

(1)

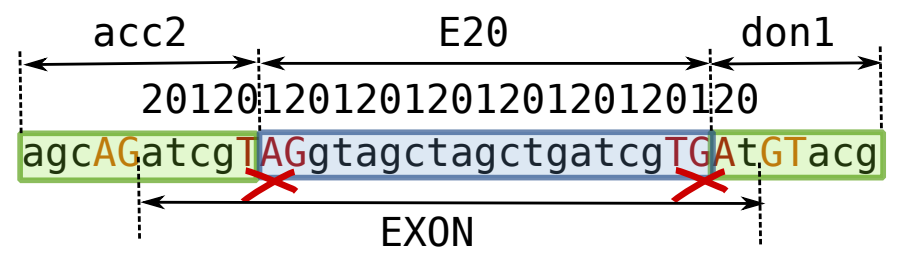

(2)

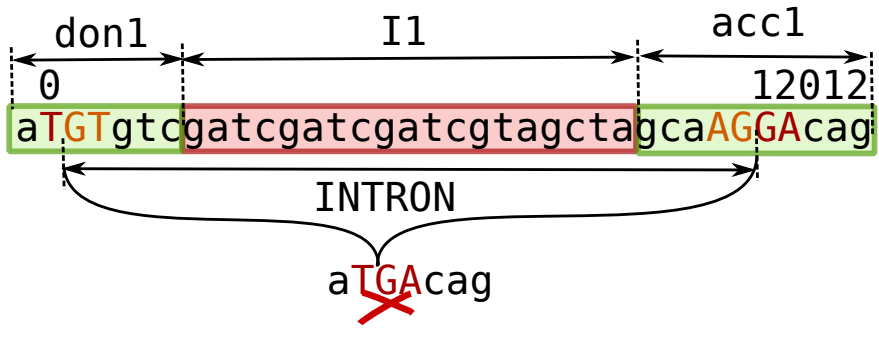

Figura 9.8: Códons de terminação conflitantes

Para o problema de predição de genes, implementar a heurística no Viterbi para evitar o aparecimento de códons de terminação conflitantes deve ser vantajoso. Em H. sapiens, observamos que cerca de 14\% dos genes preditos pela GHMM pura são estruturas que possuem codon de terminação na fase de leitura, enquanto que em P. falciparum apenas $1 \%$ das predições apresentam este problema.

Assim, a implementação que adotamos para evitar o primeiro caso consiste em verificar, se a sequência do éxon (incluindo as regiões que foram emitidos pelo sinal) pode ser gerada pelo modelo da região codificadora o qual não emite códon de terminação. Este comportamento deve ser especificado no arquivo de configuração. Observamos na Tabela 9.3 e na Tabela 9.4 
que tanto em $H$. sapiens quanto em $P$. falciparum a exatidão apresentou uma pequena melhora em relação ao modelo puro.

Tabela 9.3: Comparação entre a implementação pura de GHMM com a GHMM com heurística na validação cruzada em $G_{15}$ de H. sapiens

\begin{tabular}{lccc}
\hline & \multicolumn{3}{c}{ Éxons } \\
Preditor & Precisão & Revocação & F \\
\hline MYOP (puro) & $72.22 \pm 0.91$ & $72.24 \pm 1.14$ & $72.23 \pm 0.95$ \\
MYOP (com heurística) & $74.12 \pm 0.96$ & $72.32 \pm 1.29$ & $73.21 \pm 1.01$ \\
\hline
\end{tabular}

Tabela 9.4: Comparação entre a implementação pura de GHMM com a GHMM com heurística na validação cruzada em $G_{15}$ de P. falciparum

\begin{tabular}{lccc}
\hline & \multicolumn{3}{c}{ Éxons } \\
Preditor & Precisão & Revocação & F \\
\hline MYOP (puro) & $89.25 \pm 1.19$ & $86.66 \pm 0.85$ & $87.94 \pm 1.00$ \\
MYOP (com heurística) & $89.54 \pm 1.29$ & $86.71 \pm 0.96$ & $88.10 \pm 1.11$ \\
\hline
\end{tabular}

\subsection{Submodelo de íntron treinado com sequências de ín- trons podem piorar a exatidão}

Uma das primeiras ideias para definir um estado do tipo íntron consiste em utilizar sequências de íntrons para treinar um submodelo de emissão de íntron. Para verificar se é vantajoso o uso dessas sequências, fizemos um experimento de validação cruzada com o genoma de $C$. elegans e com o genoma de H. sapiens. Enquanto em C. elegans observamos uma leve melhora em prever regiões intrônicas, em H. sapiens observamos uma perda significativa de exatidão. Sabemos que em H. sapiens 90\%-100\% dos genes com múltiplos éxons apresentam algum tipo de evento de splicing alternativo (Nilsen e Graveley, 2010) o qual pode prejudicar o modelo de íntron através da inclusão de regiões codificadores na amostra de treinamento do submodelo de íntron, assim é mais vantajoso utilizar a região intergênica para o treinamento dessa região em $H$. sapiens. A perda de exatidão também está documentado no código-fonte do preditor AUGUSTUS, mas há um comentário que diz que ocorre perda por razões desconhecidas. Na Tabela 9.5 e na Tabela 9.6, apresentamos o resultado do experimento nos genomas de $C$. elegans e $H$. sapiens do ponto de vista de íntrons corretamente previstos. Neste experimento, utilizamos sequências de íntrons para treinar o submodelo na GHMM íntron, e utilizamos a região intergência para treinar submodelo de íntron na GHMM intergenic. 
ESTIMAR A PROBABILIDADE DE TRANSIÇÃO PODE PIORAR A EXATIDÃO DAS PREDIÇÕES 9.6

Tabela 9.5: Íntrons corretamente previstos em $H$. sapiens para a validação cruzada em $G_{15}$

\begin{tabular}{lccc}
\hline & & Íntrons & \\
Preditor & Precisão & Revocação & $\mathrm{F}$ \\
\hline MYOP (intron) & $58.09 \pm 3.34$ & $58.63 \pm 1.99$ & $58.35 \pm 2.63$ \\
MYOP (intergenic) & $68.26 \pm 1.60$ & $66.64 \pm 1.60$ & $68.26 \pm 1.60$ \\
\hline
\end{tabular}

Tabela 9.6: Íntrons corretamente previstos em C. elegans para a validação cruzada em $G_{15}$

\begin{tabular}{lccc}
\hline & & Introns & \\
Preditor & Precisão & Revocação & F \\
\hline MYOP (íntron) & $87.69 \pm 0.88$ & $81.02 \pm 0.87$ & $84.22 \pm 0.54$ \\
MYOP (intergenic) & $87.43 \pm 0.94$ & $81.01 \pm 0.70$ & $84.10 \pm 0.50$ \\
\hline
\end{tabular}

\subsection{Estimar a probabilidade de transição pode piorar a exatidão das predições}

Cawley et al. (2001) observaram que as fases de leitura de éxons em P. falciparum não estão uniformemente distribuídas. Este fato sugere que estimar a probabilidade de transição da GHMM pode ser vantajoso. Por outro lado, Stanke (2003) assumiu que a distribuição das fases de leitura é uniforme e decidiu por fornecer uma matriz de probabilidade fixada. O nosso protocolo de avaliação permite verificar qual das duas abordagens é a mais vantajosa. Ao avaliarmos uma arquitetura em que assumimos distribuição uniforme (fixed) e uma outra arquitetura em que estimamos a probabilidade de transição (estimated), não observamos melhora de exatidão com a arquitetura mais intuitiva. Na Tabela 9.7, mostramos a performance na validação cruzada de ambas as arquiteturas em $P$. falciparum para o conjunto $G_{15}$ e na Tabela 9.8 realizamos o mesmo experimento para $H$. sapiens. Para $H$. sapiens a perda de exatidão com a arquitetura estimated é significativo.

Tabela 9.7: Éxons corretamente previstos em P. falciparum para a validação cruzada em $G_{15}$

\begin{tabular}{lccc}
\hline & \multicolumn{3}{c}{ Estruturas de genes } \\
Preditor & Precisão (variância) & Revocação (variância) & F (variância) \\
\hline MYOP (estimated) & $89.28 \pm 1.53$ & $86.74 \pm 1.14$ & $88.00 \pm 1.30$ \\
MYOP (fixed) & $89.54 \pm 1.29$ & $86.71 \pm 0.97$ & $88.10 \pm 1.11$ \\
\hline
\end{tabular}

\subsection{Target GHMM e variação do conteúdo GC}

Estudamos uma estratégia para lidar com o problema da variação do conteúdo GC, chamamos esta nova estratégia de Target GHMM. Ela consiste em treinar uma GHMM diferente para cada nova sequência alvo. Quando o preditor recebe uma nova sequência para ser decodificada, o conteúdo GC é calculado e uma nova GHMM é treinada utilizando 
Tabela 9.8: Éxons corretamente previstos em H. sapiens para a validação cruzada em $G_{15}$

\begin{tabular}{lccc}
\hline & & Estruturas de exons & \\
Preditor & Precisão & Revocação & F \\
\hline MYOP (estimated) & $66.67 \pm 1.41$ & $72.75 \pm 1.22$ & $69.58 \pm 1.29$ \\
MYOP (fixed) & $\mathbf{7 3 . 9 9} \pm 0.99$ & $\mathbf{7 2 . 3 9} \pm 1.20$ & $\mathbf{7 3 . 1 8} \pm 1.01$ \\
\hline
\end{tabular}

Tabela 9.9: Target GHMM e variantes corretamente preditas

\begin{tabular}{lccc}
\hline Estratégia & Precisão & Revocação & F \\
\hline Target GHMM & $\mathbf{2 3 . 5 8} \pm \mathbf{0 . 4 0}$ & $\mathbf{2 6 . 4 0} \pm \mathbf{1 . 0 0}$ & $\mathbf{2 4 . 9 0} \pm \mathbf{0 . 4 0}$ \\
múltiplos GHMM & $20.95 \pm 1.10$ & $24.62 \pm 2.20$ & $22.62 \pm 1.52$ \\
\hline
\end{tabular}

o método do Seção 8.5 e a nova GHMM é utilizada para decodificar a sequência. Para o conjunto $G_{13}$ de H.sapiens, observamos uma melhora significativa na validação cruzada, veja Tabela 9.9 , a variância do escore $\mathrm{F}$ foi de 2.33 para 0.16 , observamos também um aumento de especificidade e um aumento de revocação. Embora a estratégia Target GHMM tenha um custo computacional relativamente alto, mostramos que ela serve para refinar a predição da estrutura do gene. 


\section{Capítulo 10}

\section{Preditores em novos genomas}

Encontrar estruturas de genes em novas sequências genômicas é uma tarefa desafiadora e importante. A falta de genes anotados dificulta o treinamento de preditores específicos e dificulta também no processo de avaliação dos mesmos. Neste caso, o processo de validação cruzada discutida no Capítulo 7 não se aplica diretamente, precisamos de uma outra estratégia para analisar as predições.

Para prever as estruturas, podemos usar um preditor treinado com genes de um genoma próximo ao do genoma novo de interesse (Korf, 2004). Baseados nas predições ab initio e também usando as evidências obtidas através do mapeamento das sequências de ESTs, desenvolvemos uma estratégia de predição para novos genomas. Esta estratégia consegue: (1) avaliar preditores ab initio para o novo genoma; (2) avaliar as montagens das sequências de ESTs; (3) e combinar as predições ab initio com o mapeamento dos ESTs gerando um conjunto de estrutura de genes com evidência de expressão. Como estudo de caso, aplicamos esta estratégia para prever as estruturas de genes nas sequências de 109 BACs de cana de açúcar, que foram geradas pelo BIOEN (FAPESP Bioenergy Program) ${ }^{1}$. Nessa tarefa, fizemos uma análise comparativa das predições do MYOP e do AUGUSTUS, realizando validações das predições com mapeamentos de ESTs. Posteriormente, o aluno Abdalla de Almeida (IQ-USP) fez uma análise das predições conflitantes entre os dois programas com proteínas do UNIPROT(Consortium et al., 2011).

\subsection{Fluxo de trabalho para análise em novos genomas}

A partir do momento que possuímos as sequências expressas e as sequências genômicas, é possível realizar o mapeamento das sequências expressas nas sequências genômicas na tentativa de inferir um conjunto de estruturas de gene. Este mapeamento é realizado por programas de alinhamento que tratam também o evento de splicing. BLAT (Kent, 2002), SIM4 (Florea et al., 1998), EXONERATE (Slater e Birney, 2005), GENESEQER (Schlueter et al., 2003), e GMAP (Wu e Watanabe, 2005) são exemplos de programas para

\footnotetext{
1 http://sugarcanegenome.org/
} 
esta tarefa. Usando o resultado do mapeamento dos transcritos, é possível construir um conjunto de estruturas (parciais ou completos) através do algoritmo que devolve as montagens maximais de alinhamentos de transcritos (maximal transcript alignment assemblies) (Haas et al., 2003). Esta mesma abordagem foi aplicada para melhorar a anotação do genoma de A. thaliana (Haas et al., 2003), e a ferramenta que implementa este fluxo de trabaho, PASA (Program to Assemble Spliced Alignments) ${ }^{2}$ é de código aberto. O PASA realiza o alinhamento usando o BLAT e o SIM4, valida os alinhamentos segundo critérios de identidade e cobertura, e realiza a montagem das estruturas a partir dos transcritos alinhados. Além disso, o PASA consegue corrigir anotações já existentes através do uso das montagens dos alinhamentos. A anotação das estruturas dos genes pode ser melhorada incrementalmente com a obtenção de novas sequências de ESTs.

O uso de um conjunto de preditores ab initio de genes é importante para rapidamente prever as estruturas iniciais de um conjunto de genes. Usando o SGEval, cada preditor pode ser avaliado comparando as montagens do PASA contra as estruturas preditas. Finalmente, o PASA também combina as evidências dos preditores ab initio com o resultado do mapeamento para compilar um conjunto de genes preditos e que tem evidência de expressão.

A Figura 10.1 mostra o fluxograma para a tarefa de predição que implementamos, usando 2200 genes de milho (1) geramos um preditor usando a ferramenta MYOP (2), este preditor foi aplicado para prever os genes nas sequências de BACs (3). Executamos nessas mesmas sequências de BACs o preditor AUGUSTUS (4). O PASA foi aplicado três vezes de forma independente: Para realizar apenas o mapeamento dos ESTs (SUCEST (Vettore et al., 2001)) (5), para realizar apenas o mapeamento das sequências de SAS (Sugarcane Assembled Sequences) (6), e para combinar todas as predições (7). Para comparar as predições usamos a ferramenta SGEval $(8,9)$. Aplicamos este fluxograma usando $90 \%$ de cobertura e $95 \%$ de identidade para validar os alinhamentos.

\subsection{Resultados e discussão}

O fato de que os preditores ab initio (MYOP e AUGUSTUS) apresentaram o mesmo resultado de precisão ${ }^{3}(94 \%)$ e de sensibilidade (36\%) não mostra qual entre os dois preditores ab initio foi melhor. Para começar a entender sobre as predições, usamos o programa SGEval (passo 9 da Figura 10.1) e assim conseguimos comparar os preditores ab initio usando um diagrama de Venn para nucleotídeos exônicos preditos (Figura 10.2). Observamos que as predições dos preditores fornecem resultados que se complementam. O MYOP previu mais nucleotideos mapeados em relação ao AUGUSTUS (223334nt versus 216168nt), e ele também previu exclusivamente uma quantidade maior de regiões codificadoras que o AUGUSTUS (793225nt versos 434273nt).

\footnotetext{
${ }^{2}$ http://pasa.sourceforge.net/

${ }^{3}$ Consideramos apenas as regiões preditas em introns mapeados como falsos positivos
} 


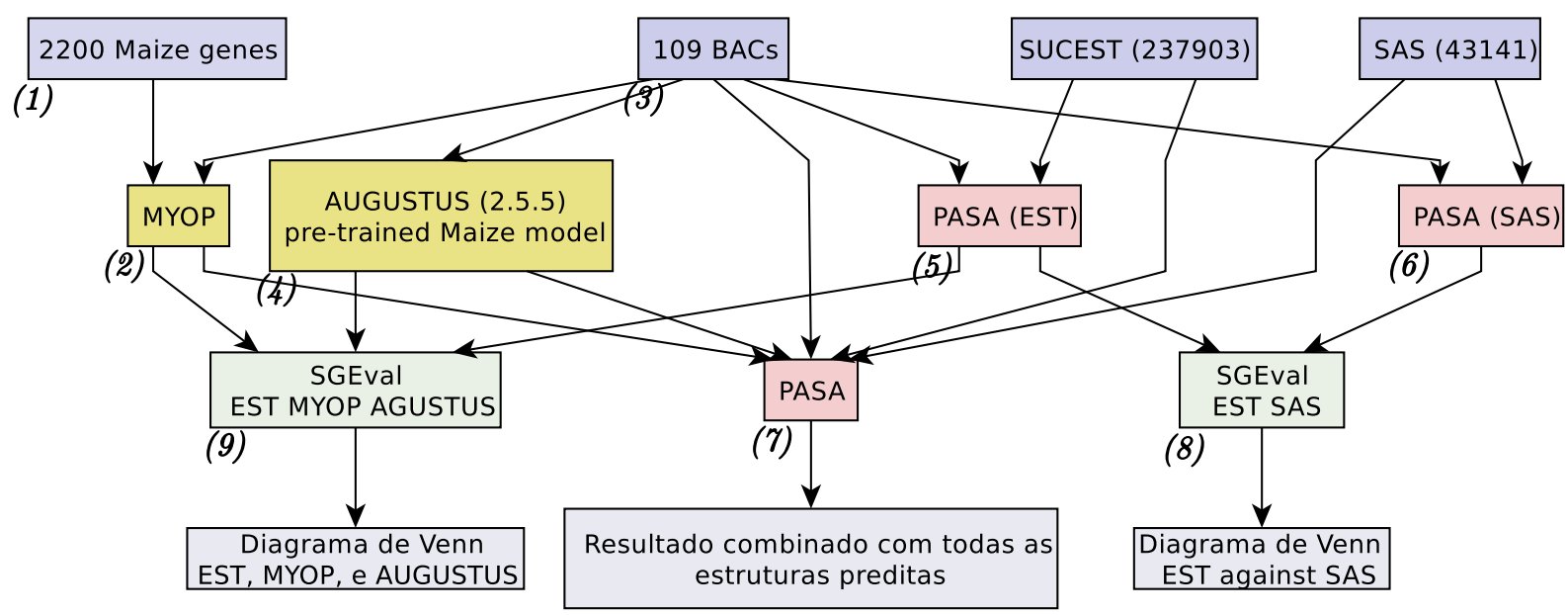

Alinhamento com $90 \%$ de cobertura e $95 \%$ identidade.

Figura 10.1: Fluxo de trabalho para predição em novos genomas

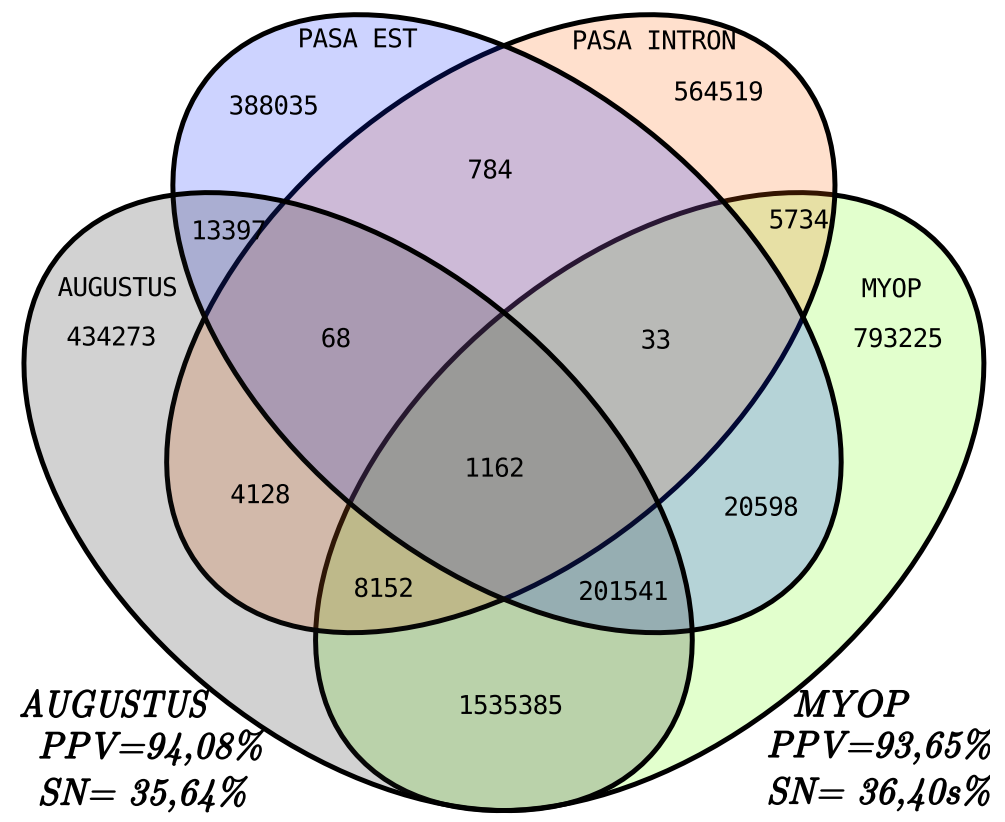

Figura 10.2: Diagrama de Venn que mostra nucleotídeos exônicos de cada anotação.

A Tabela 10.1 mostra a quantidade de genes preditos por preditor. Obtemos 696 estruturas preditas pelo MYOP ou AUGUSTUS com evidência de expressão, e observamos que o MYOP previu menos estruturas sem validação do que o AUGUSTUS ( 1207 versos 1469 ). Podemos concluir que as estruturas preditas pelo MYOP, geralmente, tem um comprimento maior do que aquelas preditas pelo AUGUSTUS, já que MYOP previu uma quantidade menor de estruturas com uma quantidade maior de nucleotídeos codificadores preditos. Em uma análise comparativa das predições do MYOP e do AUGUSTUS, o aluno Abdalla de Almeida (IQ-USP) analisou predições conflitantes entre AUGUSTUS e MYOP com genes do UNIPROT(Consortium et al., 2011), em 60\% dos casos o MYOP apresentou proteínas 
com cobertura maior com alguma proteína do UNIPROT.

Tabela 10.1: Quantidade de genes preditos por preditor

Preditor Número de genes preditos

AUGUSTUS sem validação 1469

Ao comparar o mapeamento feito com sequências de SAS (montagens feitas pelo CAP3 (Huang et al., 1999) das sequências de ESTs) com o mapeamento feito com sequências de ESTs, obtivemos 55332nt de SAS mapeados que não tem suporte de EST mapeado, 383758nt de ESTs mapeados sem suporte de SAS mapeados, e 231325nt foram mapeados tanto por EST quanto por SAS. Esses números indicam que há montagens de SAS que podem ser artefatos da montagem feita pelo CAP3.

Ainda há um grande caminho pela frente, um total de 388,035 nt mapeados por ESTS não foi detectado por nenhum preditor. Especulamos que as regiões que foram preditas apenas por ESTs são regiões que não codificam para proteínas (regiões UTRs ou genes de RNA não-codificadores). Para trabalhos futuros, podemos verificar quais regiões possuem evidência de RNA não-codificador de proteína. 


\section{Capítulo 11}

\section{Conclusão e considerações futuras}

Neste trabalho realizamos um amplo estudo sobre o problema computacional de predição de genes e mostramos que ainda há muitas possibilidades para melhorias. Apresentamos um protocolo para a implementação e um protocolo para avaliação de preditores de genes, que ajudam a produzir preditores de genes competitivos com relação aos melhores programas. Estes protocolos foram aplicados com sucesso em onze genomas distintos.

Um importante diferencial do nosso trabalho é que conseguimos explorar a modularidade do modelo GHMM, que define o conjunto de estruturas de genes que são previstas pelo preditor. Pequenas mudanças na arquitetura fornecem resultados significamente diferentes, e conhecer como as diferentes implementações influenciam na exatidão é importante para o desenvolvimento de novos preditores. A experimentação de diferentes modelagens era complicado, já que as implementações dos modelos probabilísticos não foram implementados visando a modularidade. Para realizarmos estudos sobre diferentes abordagens de predição, foi necessária a implementação de novas ferramentas:

- ToPS (Toolkit of Probabilistic Models of Sequence) é o primeiro arcabouço orientado a objetos (implementado em $\mathrm{C}++$ ) que fornece um conjunto de classes para a implementação e desenvolvimento de modelos probabilísticos que representam cadeias de caracteres em alfabetos finitos e arbitrários. ToPS apresenta uma hierarquia de classes capaz de representar modelos generativos, os quais descrevem como uma sequência é gerada. Implementamos 7 modelos no ToPS: (i) modelo de alcance variável de Markov; (ii) modelo oculto de Markov; (iii) modelo generalizado oculto de Markov; (iv) modelo de pares ocultos de Markov; (v) distribuição multinomial; (vi) cadeia não-homogênea de Markov; e (vii) cadeias interpoladas de Markov. Este arcabouço esta em processo continuo de desenvolvimento.

- MYOP (Make Your Own Predictor) é um ambiente computacional que tem como objetivo diminuir o trabalho para a construção de preditores de genes. O MYOP utiliza o ToPS e como resultado de um estudo mais profundo sobre os métodos computacionais de predição, conseguimos alcançar exatidão comparável aos programas de grande 
sucesso. A principal vantagem do MYOP é que ele permite implementar arquiteturas arbitrárias de GHMM, possibilitando a escolha da arquitetura que melhor represente os genes de um dado genoma.

- SGEval é o primeiro programa que considera explicitamente os eventos de splicing alternativo para a comparação de anotações de genes codificadores de proteínas. SGEval foi fundamental para conseguirmos análises específicas no processo de melhoria de preditores, enumerando os casos de falhas de predição e analisando esses com novos modelos. Ele foi implementado utilizando grafos de splicing (Sammeth et al., 2008), que é capaz de representar todas as variantes anotadas. SGEval facilita obter diversas estatísticas relevantes a predição de genes, além de facilitar no processo de criação de diagramas de Venn, que monstram com maiores detalhes os erros sistemáticos de cada preditor.

Mostramos experimentos que comparam algumas ideias concorrentes. Em particular, apresentamos uma nova estratégia, Target GHMM, para tratar a variabilidade do conteúdo GC. Observamos que ela consegue aumentar (de 22.62 para 24.90 ) o escore F do ponto de vista de estrutura dos genes e com uma variância menor (0.16 versos 2.33) nos testes de validação cruzada em $H$. sapiens. Esse resultado indica que há amplo espaço para melhorias de nossas predições.

O fato de que sequências de íntrons podem piorar os valores de exatidão indica que devemos direcionar estudos para a obtenção de melhores modelos para íntrons. Os melhores resultados são obtidos utilizando regiões intergênicas, que também não devem ser as mais adequadas, para treinar um submodelo, que é posteriormente aplicado tanto para estados do tipo íntron quanto para estados do tipo região intergênica.

Há diversas suposições (Majoros et al., 2007) que simplificam o problema de predição, mas que ao mesmo tempo influenciam na qualidade do preditor:

- Ausência de éxons não codificadores. Nenhum preditor de genes prevê corretamente os éxons não traduzidos. Dentro da bibliografia pesquisada, não encontramos nenhum modelo probabilístico que consiga discriminar éxons não-codificadores de íntrons. Desenvolver modelos probabilísticos que consigam diferenciar o conteúdo desses éxons com o conteúdo de íntrons não traduzidos é um grande desafio.

- Ausência de splicing alternativos. Os preditores não utilizam genes que apresentaram splicing alternativos para realizar o treinamento ou para construir os modelos GHMMs. Geralmente, a estrutura de maior probabilidade é encontrada e estruturas subótimas são listadas como predições de splicing alternativo. O preditor Augustus utiliza o modelo GHMM para fazer uma amostragem de um conjunto de estruturas dado a sequência de entrada (Stanke et al., 2006) e apenas estruturas que satisfazem algumas restrições são consideradas. Em nossos testes preliminares, com a abordagem de amostragem do preditor AUGUSTUS, não observamos aumento de precisão. Devemos 
lembrar que nenhum conhecimento adicional sobre o splicing alternativo está presente no modelo ou no processo de amostragem. Pretendemos realizar um estudo para identificar quais informações sobre splicing alternativo podemos utilizar para melhorar este tipo de análise.

Para tentar melhorar a especificidade das predições, podemos tentar ampliar o modelo de GHMM para representar dados de mapeamentos de sequências expressas, através de um alfabeto estendido que inclui os símbolos: (i) E, exons mapeados; (ii) I, introns mapeados; e (iii) EI, regiões mapeados com evidência de ser tanto exon quanto introns. Esta abordagem é motivadora, pois especulamos que podemos ganhar, através do uso desse novo alfabeto, a possibilidade de prever alguns eventos de splicing alternativo.

Inicialmente, podemos explorar algumas restrições que definem os quatro grupos principais de splicing alternativos. Essas restrições indicam que nem todas as estruturas subótimas são candidatas a transcritos alternativos:

- remoção de éxon alternativo, quando um éxon e íntrons flanqueadores são removidos do transcrito;

- uso alternativo de sítios aceitadores, quando há o reconhecimento de dois ou mais sítios no lado 5' do éxon;

- uso alternativo de sítios doadores, quando há o reconhecimento de dois ou mais sítios no lado 3' do éxon;

- retenção de íntrons, quando o íntron permanece no RNAm maduro;

Dentro da bibliografia que estudamos, nenhum preditor de genes restringe as subestruturas ótimas preditas dentro desses quatro grupos. Além disso, existem outras informações que poderiam ser utilizadas tais como a modelagem de sequências de exonic splicing enhancers (ESE) como um sinal adicional no éxon. RESCUEESE (Fairbrother et al., 2004) fornece uma relação de sequências ESEs em H. sapiens os quais poderiam ser utilizadas.

- Ausência de genes sobrepostos. Os modelos GHMMs da maior parte dos preditores representam ambas as fitas simultaneamente para evitar falsos positivos em genes sobrepostos e existem poucos estudos que mostram perda de especificidade quando modelamos apenas uma das fitas. A modelagem de ambas as fitas foi introduzida pelo programa Genemark (Borodovsky e McIninch, 1993) para predição em genomas procarióticos, e é utilizado tradicionalmente em preditores de genes eucarióticos. Queremos estudar a real influência desta suposição, pois muitos estudos mostram que eventos de genes sobrepostos são comuns em genomas eucarióticos (Makalowska et al., 2005; Sanna et al., 2008; Williams et al., 2005). Por exemplo, cerca de $10 \%$ dos genes foram classificados como sobrepostos dentro de um conjunto de 13, 484 pares de genes ortólogos de humano/camundongo (Sanna et al., 2008). 
- Apenas sequências canônicas GT..AG dos sítios de splicing. Sequências de splicing sem sequências canônicas não são encontradas devido a não modelagem desses sinais. Gostariamos de acrescentar no modelo GHMM a modelagem de sequências não canônicas, uma vez que acreditamos que não haverá perda significativa de especificidade por causa disso.

Os preditores procuram explicitamente pelas sequências canônicas (AG para sítio aceitador de íntron e GT para sítio doador de íntron) a fim de melhorar a especificidade (Majoros et al., 2007). Embora os pares canônicos em H. sapiens representem a grande maioria (99.24\%) (Burset et al., 2000), não há estudos que mostram que há perda de especificidade dos modelos GHMM que aceitam tais sequências.

- Ausência de erros de sequenciamento na sequência de entrada e símbolos de ambiguidades. Os algoritmos de predição supõe que não existem erros de sequenciamento nas sequências de entrada. Geralmente, eles buscam por uma estrutura dentro de um conjunto de estruturas consideradas válidas (todos os éxons consistentes com a fase de leitura). Um erro na sequência pode destruir a estrutura de um gene real a qual não será mais reconhecida corretamente. Dentro da bibliografia que pesquisamos, não há estudos sobre como tais erros influenciam preditores de genes. Além disso, uma vez que esses erros são comuns em genomas com baixa cobertura (novos genomas) e em sequenciamento de mRNAs, melhorar a qualidade das predições nestas condições é um desafio importante.

As ferramentas desenvolvidas forneceram resultados promissores e acreditamos que podem ser utilizadas para melhorar ainda mais a precisão dos preditores. Pretendemos utilizálas para continuar a desenvolver preditores de genes para outros genomas e para desenvolver técnicas de otimização para aplicarmos em cada genoma.

O arcabouço MYOP/ToPS/SGEval já tem sido utilizado em aplicações práticas. Foram criados preditores de genes para onze genomas: A. thaliana, C. elegans, Z. mays, P. falciparum, D. melanogaster, D. rerio, M. musculus, R. norvegicus, O. sativa, G. max e $H$. sapiens. Além disso, aplicamos as ferramentas para desenvolver um fluxo de trabalho para predição de genes no projeto de sequenciamento de cana de açúcar, onde nossas validações estimaram que o MYOP prevê estruturas de genes com maior correspondência a genes reais em $60 \%$ das predições conflitantes com o preditor Augustus, um dos preditores referência para a genômica atual. Devemos lembrar que estamos num longo processo de aprendizado considerando o problema de prever genes no genoma de cana de açúcar, um próximo passo consistirá em compilar um conjunto de genes razoavelmente amplo para realizarmos o treinamento de preditores mais específicos para este genoma

Finalmente, dois alunos estão trabalhando na extensão do TOPS. O aluno Ígor Bonadio tem como projeto de mestrado ampliar o ToPS para o uso de modelos discriminativos através da implementação dos Campos Aleatórios Condicionados (CRF - Conditional Random 
Fields) (Lafferty et al., 2001). O aluno Vitor Onuchic tem como projeto de mestrado desenvolver modelos probabilísticos para aplicar em novos algoritmos de alinhamento múltiplos de sequências. Além disso, Alexandre Rossi Paschoal em seu doutorado esta utilizando o arcabouço para a caracterização de RNAs não codificadores. 
94 CONCLUSÃO E CONSIDERAÇÕES FUTURAS 


\section{Apêndice A}

\section{Usando outros modelos com o ToPS}

Apresentamos o uso do ToPS para especificar uma HMM no Capítulo 4. Aqui, iremos mostrar como especificar e treinar outros modelos.

\section{A.0.1 Distribuição multinomial}

Especificamos a distribuição multinomial usando um vetor de valores de probabilidades. $\mathrm{O}$ arquivo fdd.txt descreve uma distribuição multinomial de dois simbolos: Sun com probabilidade 0.2 e o símbolo Rain com probabilidade 0.8 .

fdd.txt

model_name = "MultinomialDistribution"

alphabet $=($ "Sun", "Rain")

probabilities $=(0.2,0.8)$

A distribuição multinomial pode ser usada para representar histogramas. Neste caso, o parâmetor alphabet não é necessário. Estimamos um histograma usando, por exemplo, o método de Sheather (2004). O arquivo histogram.txt é um exemplo de um arquivo de configuração para o programa train.

histogram.txt

train_algorithm = "SmoothedHistogramKernelDensity"

training_set $=$ sequences.txt

\section{A.0.2 Cadeias de alcance variável de Markov}

Cadeias de alcance variável são descritos especificando a distribuição associadas com cada contexto. $\mathrm{O}$ arquivo vlmc.txt mostra um exemplo. 


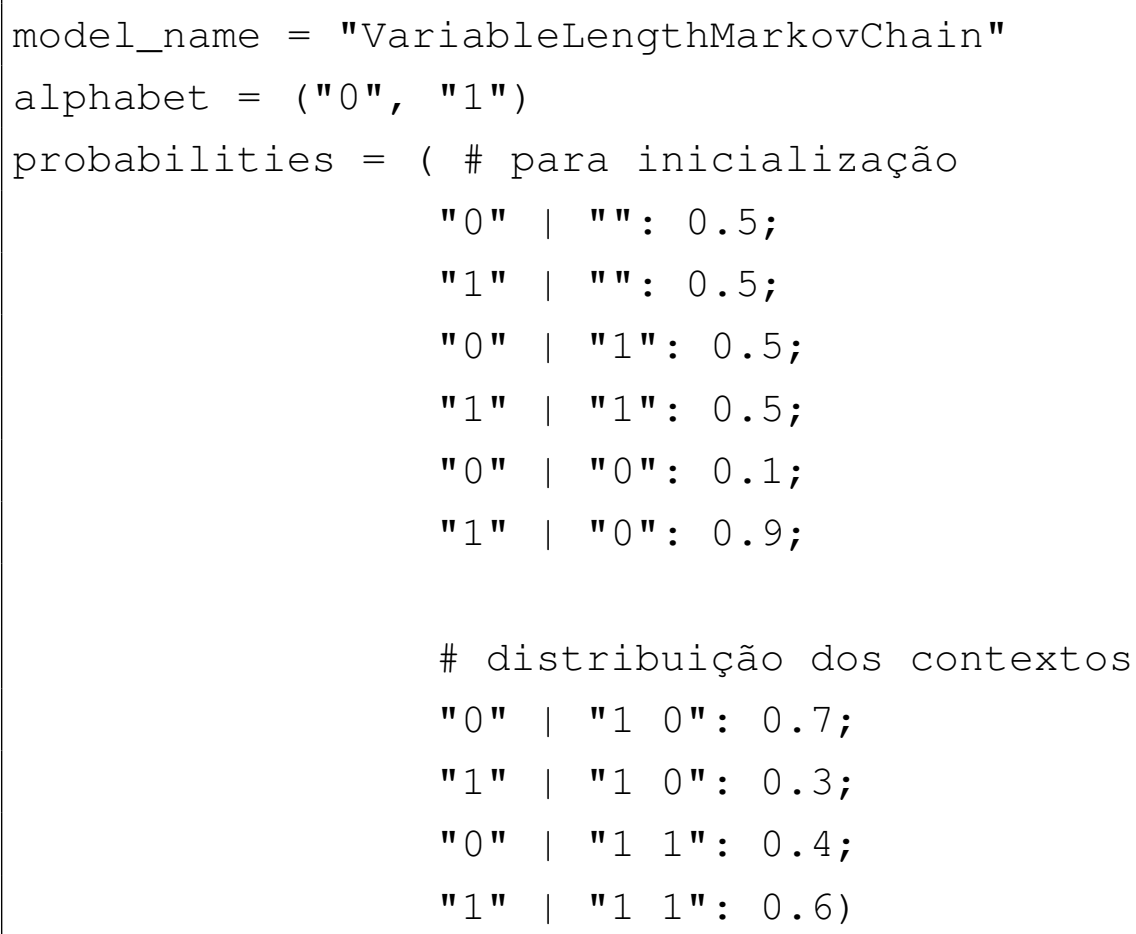

Para estimar as probabilidades, podemos aplicar o algoritmo Contexto (Galves e Löcherbach, 2008). O arquivo contextAlgorithm.txt especifica a tarefa do programa train.

contextAlgorithm.txt

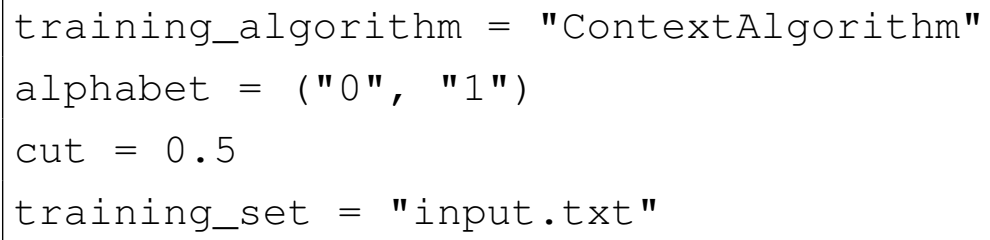

\section{A.0.3 Modelo não homogêneo de Markov}

Para criar um modelo para uma cadeia não-homogênea de Markov, podemos especificar as probabilidades condicionais de cada posição da sequência. O arquivo i hm. txt tem um exemplo de como especificamos o modelo: 
ihm.txt

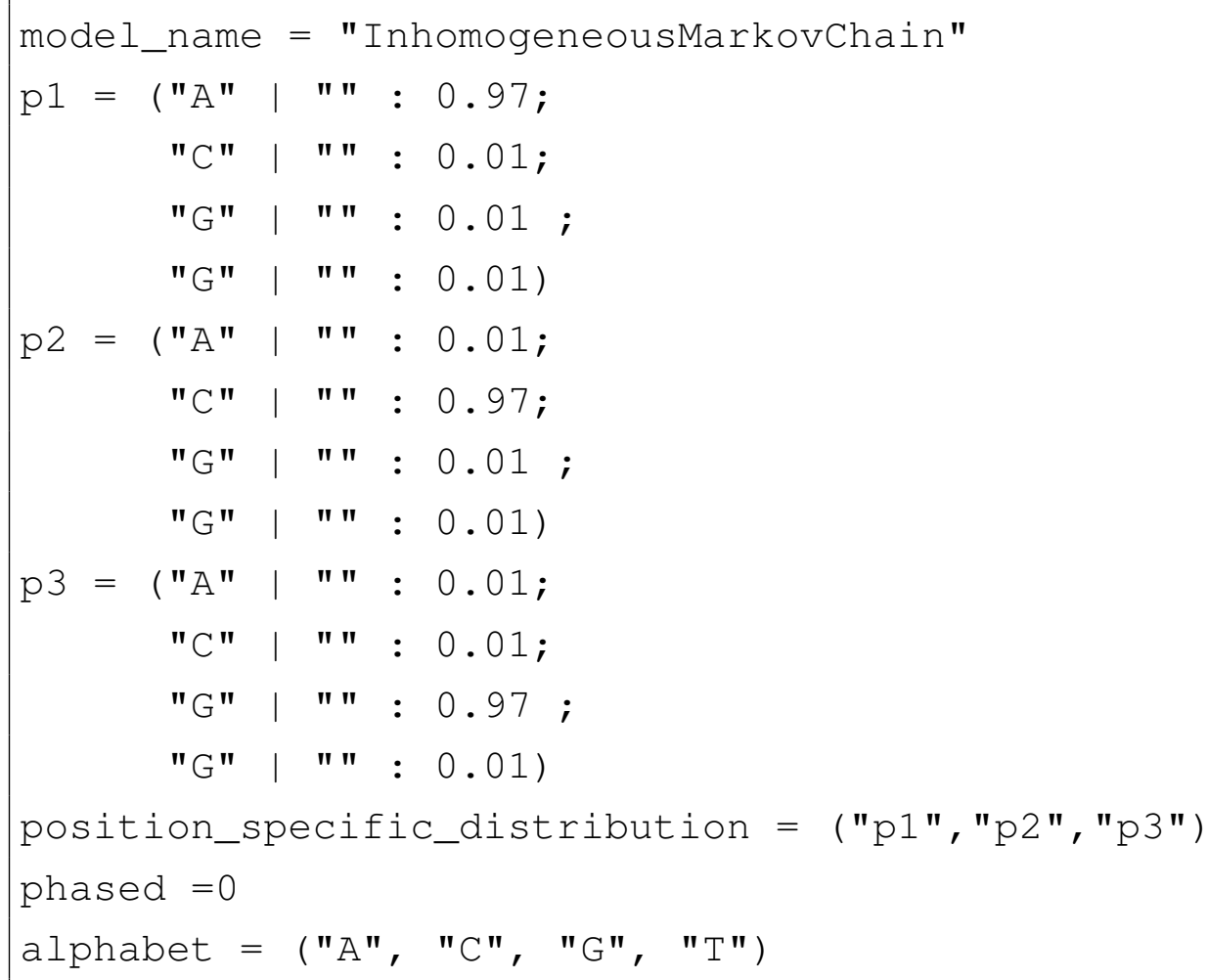

O argumento position_specific_distribution usa os parâmetros p1, p2, e p3 para especificar respectivamente as distribuições das posições 1,2, e 3 da sequência.

$\mathrm{O}$ arquivo wam.txt especifica um procedimento de treinamento, descrito em Burge (1997), para a cadeia não homogenea de Markov.

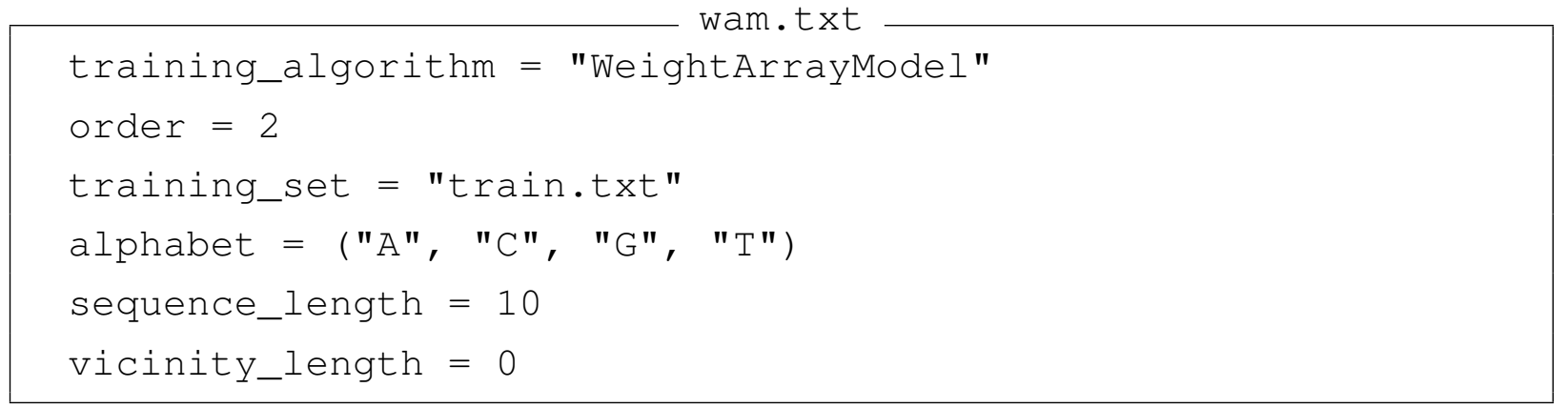

\section{A.1 Usando seleção de modelos}

Muitos modelos podem ter diferentes dimensionalidades que são definidos pelo usuário durante o treinamento Um exemplo típico incluem modelos de cadeias de Markov em que o usuário tem que escolher o valor para a ordem. Para ajudar a encontrar um conjunto melhor de tais parâmetros, ToPS contém dois critérios de seleção de modelos que podem ser usados com o algoritmo de treinamento. 
- Bayesian Information Criterion (BIC) (Schwarz, 1978): Este critério seleciona o modelo que tem o maior valor para a fórmula abaixo:

$\log$ (Máxima verossimilhança) - $\frac{1}{2}$ (números de parâmetros independentemente ajustados) $\times \log ($ tamanho da amostra $)$

- Akaike Information Criterion (AIC) (Akaike, 1974): Este critério seleciona o modelo com o menor valor da seguinte fórmula

$$
(-2) \log (\text { Máxima verossimilhança) }
$$

+2(números de parâmetros independentemente ajustados)

Para executar o critério de seleção o usuário deve especificar quatro argumentos:

- model_selection_criteria define o critério de seleção: BIC, ou AIC.

- begin define o conjunto de parâmetros a ser testados e seus valores iniciais.

- end define o valor final dos parâmetros especificados acima.

- step define o incremento dos valores de cada parâmetro a ser testado.

O arquivo bic.txt especifica que o ToPS irá usar o BIC. O treinamento consiste em calcular os valores de BIC para a cadeia estimada para cada corte no conjunto $\{0.0, \ldots, 1.0\}$, e irá devolver o modelo com o valor preferido de BIC.

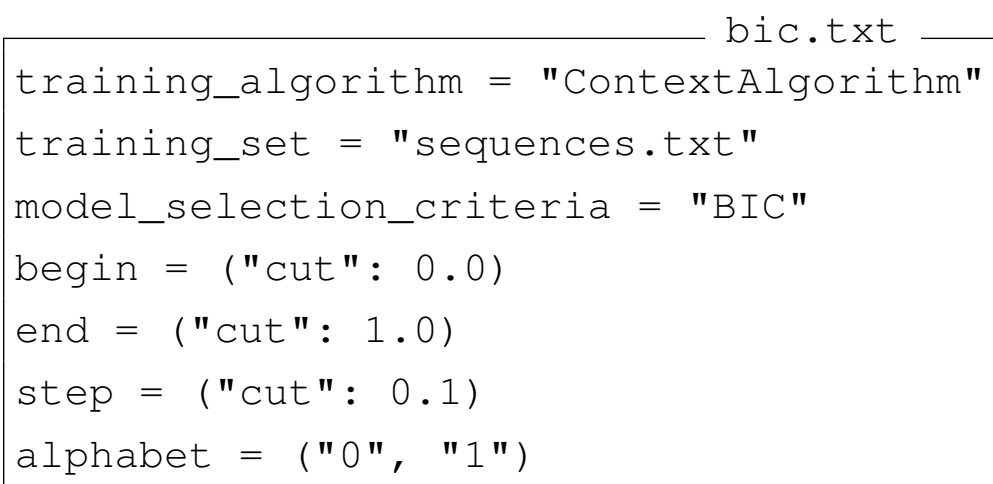




\section{Apêndice B}

\section{MYOP detalhes de uso}

Apresentamos aqui a descrição das ferramentas do MYOP e os detalhes de implementação.

\section{B.0.1 Predição de genes}

Para realizar a predição de novos genes em uma sequência genômica, o usuário deve usar o programa myop-predict.pl.

\section{Linha de comando}

myop-predict.pl -p modelo -c 4 -f sequencias.fasta

-g fixed_transition > predicoes.gtf

Os parâmetros do myop-predict.pl são:

- -p especifica o diretório em que o modelo de GHMM está.

- -c especifica o número de processos viterbi_decoding.

- -f especifica a sequência de entrada

Além desses parâmetros, o programa também tem alguns parâmetros opcionais:

- -g especifica a arquitetura da GHMM a ser usada

- -l lista os nomes das arquiteturas disponíveis

- -m especifica o tamanho máximo da janela deslizante

- -o especifica o tamanho da sobreposição da janela deslizante 


\section{B.0.2 Treinamento com genes de referência}

Para realizar o treinamento, precisamos ter um conjunto de genes anotados e uma arquitetura de predição já pré-montada que fica armazenada em um repositório com controle de versão. Escolhemos por usar o o GIT (http://git-scm.com), pois ele permite a criação de repositórios distribuídos. O objetivo de manter repositórios com todas as versões de uma mesma arquitetura é a de facilitar a reprodutibilidade de nossos experimentos. Para realizar o treinamento usamos o seguinte comando:

\section{Linha de comando}

myop-train.pl -r repositorio -g train.gtf -f train.fa

-o modelo_treinado -c 4

Os parâmetros do myop-train.pl são:

- -r parâmetro opcional que especifica o endereço do repositório

- -g especifica o arquivo no formato GTF que contém as anotações

- -f especifica o arquivo com as sequências

- - e especifica o diretório do modelo treinado

- -c especifica a quantidade de processos paralelos disparados para treinar os modelos.

\section{B.0.3 Treinamento sem genes de referência}

Para realizar o treinamento quando não conhecemos nenhum gene do genoma sequenciado, podemos usar a estratégia de treinamento iterativo o qual precisa de um modelo inicial treinado que de preferência foi treinado com algum outro genoma próximo. O processo iterativo consiste em retreinar o preditor usando sucessivamente as estruturas preditas pelo preditor anterior gerando um novo preditor. Para usar o processo iterativo de treinamento usamos o seguinte comando:

$$
\begin{aligned}
& \text { myop-iterative-training.pl -p hsapiens -f train.fa } \\
& \text {-i } 10 \text {-o modelo_treinado -c } 4
\end{aligned}
$$

Os parâmetros do myop-iterative-train.pl são:

- -p especifica o modelo inicial já treinado

- -f especifica o arquivo com as sequências genômicas

- -o especifica o diretório com o modelo treinado

- -c especifica a quantidade de processos paralelos disparados para treinar os modelos. 


\section{B.0.4 Desenvolvendo novas arquiteturas}

Um preditor do MYOP tem uma estrutura de diretórios que deve ser entendida antes de começar a desenvolver novas arquiteturas:

- cnf/ armazena os arquivos de configuração para a criação de modelos probabilísticos de cada região do gene. Esta pasta também armazena um arquivo chamado meta . cfg que contém metaparâmetros do preditor os quais são acessados em diversas tarefas, desde o treinamento, até a tradução da saída do viterbi_decoding.

- scripts / armazena programas específicos do preditor, tais como, os roteiros de montagem da GHMM e tradução da saída do programa viterbi_decoding para um arquivo de anotação no formato GTF.

- dataset/ armazena o conjunto de treinamento original o qual o preditor recebeu para treinar.

- ghmm/cnf/ armazena arquivos de configuração para treinar os submodelos da ghmm

- ghmm/dataset armazena o conjunto de treinamento de cada submodelo, após processamento do conjunto original

- ghmm/model armazena modelos treinados

Além disso, existem também as pastas ghmm.0, ghmm.1,.., ghmm.k que armazenam submodelos específicos de composição GC. O usuário específica três parâmetros: o menor valor de composição GC, o maior valor de composição GC, e a quantidade de bandas entre o menor valor e o maior valor. Para cada banda $k$, é criado uma pasta ghmm. $k$, que armazena os modelos treinados especificamente para a banda $k$ a qual corresponde a um intervalo de composição GC (veja Seção 8.5).

O arquivo meta. cfg mostra parâmetros que são usados em diversas tarefas distintas. Por exemplo, durante a extração do conjunto de treinamento para o sítio aceitador é necessário que o MYOP saiba o comprimento do sítio e a localização da sequência conservada AG que define o fim de um intron. Para isso, há dois parâmetros acceptor_length, que define o comprimento, e acceptor_offset, que define a quantidade de nucleotídeos antes da sequência conservada AG. De forma análoga, existem outros parâmetros correspodentes a outros sinais. Esses parâmetros também são usados durante a predição para traduzir a saída do programa viterbi_decoding no formato GTF (gene transfer format). 


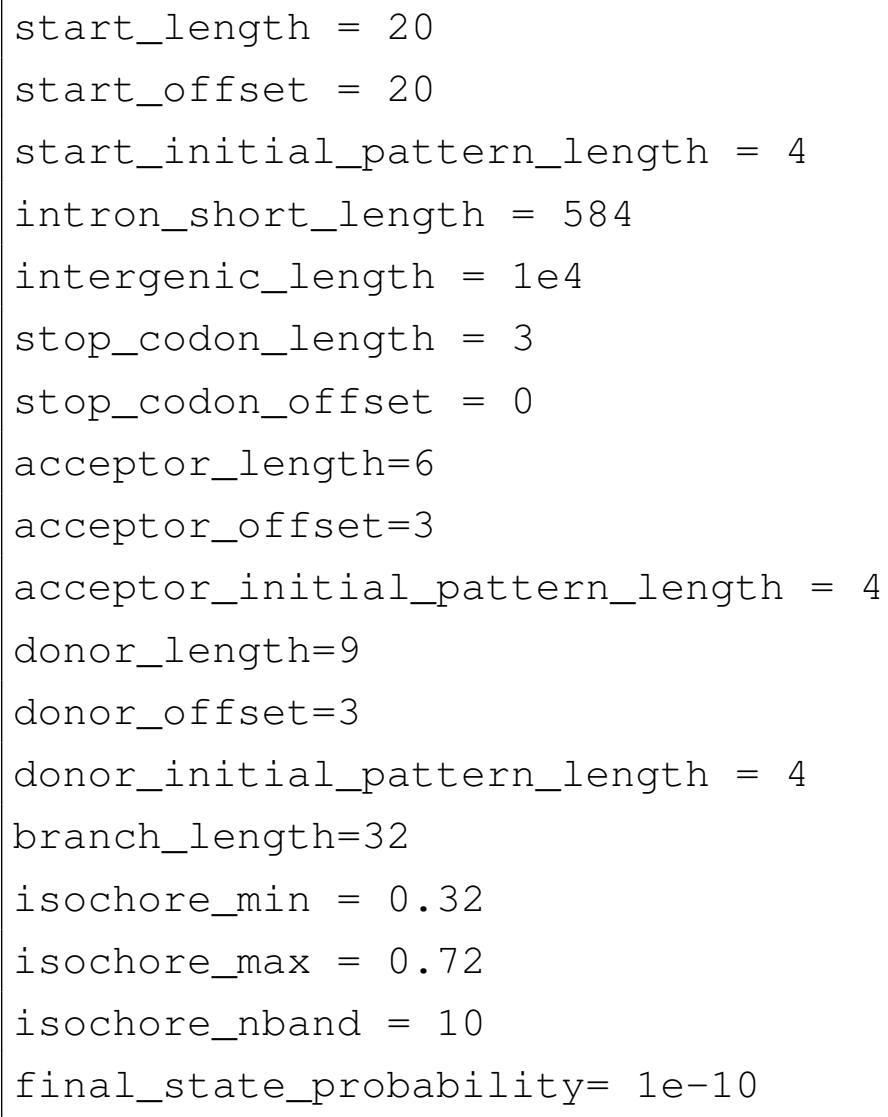

Para desenvolver novas arquiteturas, precisamos definir todos os submodelos de emissão e submodelos de duração que serão usados para representar cada região do gene. Para cada submodelo existe um arquivo de configuração que tem o mesmo formato usado pelo ToPS, mas com diretivas adicionais específicas para o uso dos programas do MYOP. Existe uma diretiva que fornece a linha de comando do processo de extrair as amostras de treinamento para o submodelo, e uma outra que fornece a linha de comando de como treinar o modelo. Esses arquivos estão no diretório cnf de uma arquitetura pré-montada.

Um exemplo de arquivo de configuração está na caixa acceptor.cfg. Este arquivo define o processo de treinamento do modelo probabilístico de emissão do sítio aceitador e está no formato ToPS. Além disso existem algumas diretivas especificas do MYOP:

- myop_generate_training_set especifica o comando que é usado para extrair uma amostra de treinamento a partir da amostra original.

- myop_train especifica o comando de como treinar o modelo

- myop_revcomp especifica o processo para gerar o modelo correspondente ao reverso complementar.

Além disso, podemos especificar cálculos usando os metaparâmetros do arquivo meta • cfg usando a diretiva " $\$\{\} "$. 


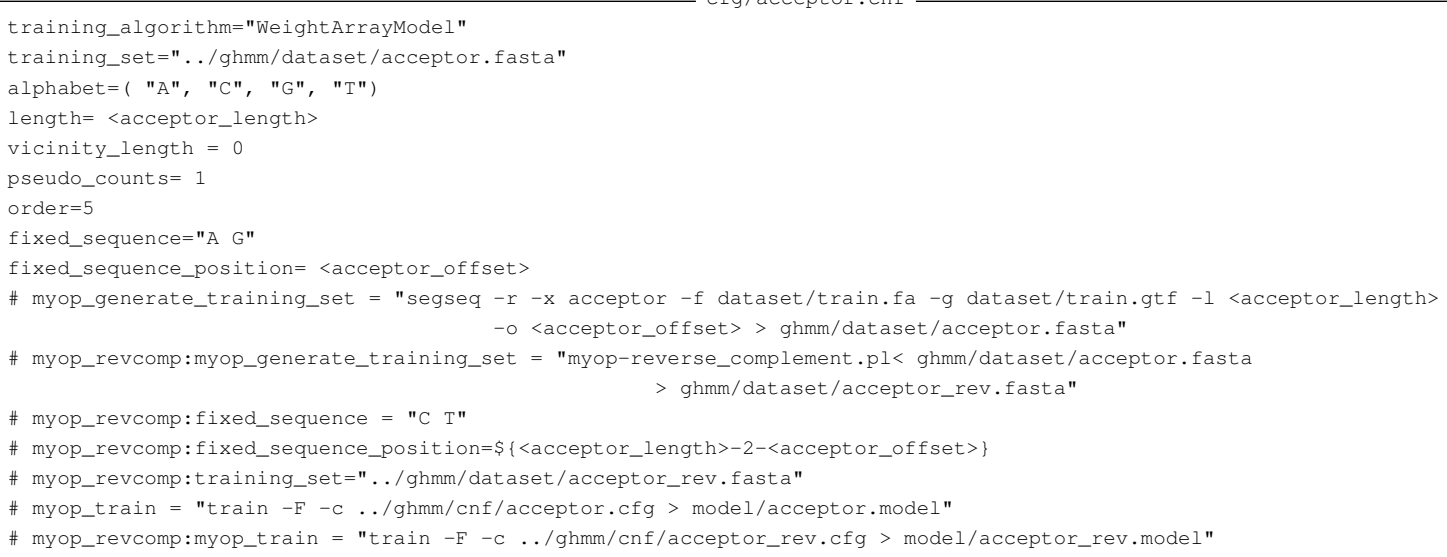

Para cada preditor, pelo menos um programa para montar cada GHMM de forma automática deve ser escrito. Esse programa combina os submodelos e constrói um arquivo de configuração do modelo da GHMM e fica aramazenado no diretório scripts/. O nome do programa começa com o prefixo build_ghmm. Após executar o programa, a descrição da GHMM fica armazenada no diretório ghmm/model/. Um preditor pode ter várias arquiteturas de GHMM diferentes, e para cada arquitetura deve existir um programa diferente. Por exemplo, implementamos no MYOP as arquiteturas intron_geometric e intron_short e existem o programa build_ghmm_intron_short.pl e build_ghmm _intron_geometric.pl os quais devolvem respectivamente os arquivos $\mathrm{ghmm} / \mathrm{model} /$ ghmm_intron_short.model e ghmm/model/ghmm_intron_geometric.model.

Finalmente, para cada modelo GHMM é necessário a implementação de um outro programa que traduz o caminho encontrado pelo viterbi_decoding para um arquivo de anotação, por exemplo, um arquivo no formato GTF (gene transfer format). Em particular, para a arquitetura intron_geometric, existe o programa scripts/tops_to_gtf _intron_geometric.pl o qual realiza esta tarefa.

Em vez de começar a implementação e desenvolvimento da arquitetura a partir do zero, é recomendável que o usuário crie novas arquiteturas através de pequenas modificações de arquiteturas já implementadas e que já foram testadas. Isto economiza o tempo de avaliação e permite comparar as melhoras obtidas de um modelo para a modificação do mesmo. Quando o usuário encontrar um modelo melhor que a anterior, ele pode criar um novo ramo no repositório de arquiteturas, ou criar um novo repositório independente.

\section{B.0.5 Programas auxiliares}

Além dos programas usados para treinar e prever genes, MYOP é formado por outros programas de suporte escritos na linguagem Perl. Estes programas são usados para preparar todos os modelos de predição de genes, e devem ser conhecidos pelos usuários que pretendem desenvolver novas arquiteturas.

A Figura B.1 mostra o pipeline que é executado automaticamente para treinar um preditor de genes. A primeira etapa consiste em inicializar os arquivos de configurações de cada 
submodelo de acordo com os parâmetros de treinamento. O segundo passo serve para gerar um conjunto de treinamento para cada submodelo. Com os parâmetros e o conjunto de treinamento, é feito no terceiro passo o treinamento dos submodelos. Finalmente, usando os submodelos treinados é especificado um ou mais modelos de GHMMs.

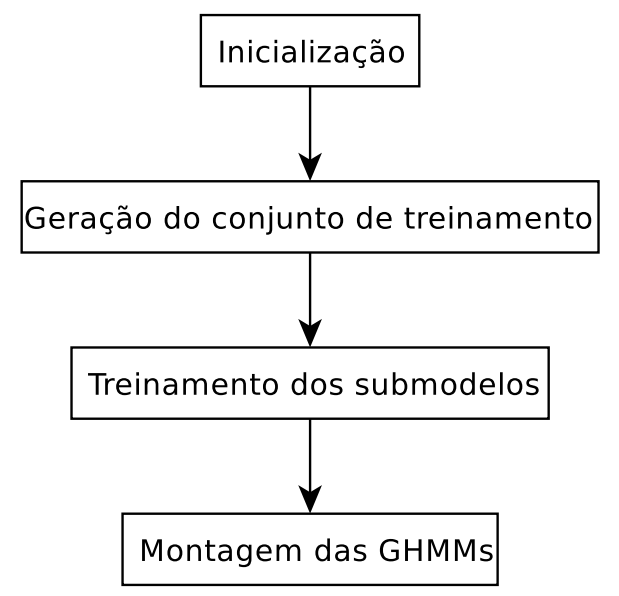

Figura B.1: $M Y O P$ passos para treinamento

\section{Inicialização do preditor}

O MYOP recebe a arquitetura pré-montada e realiza um conjunto de inicializações através da execução do programa myop-setup.pl. Um preditor tem um conjunto de metaparâmetros usados em diversas etapas. Por exemplo, o comprimento de cada sensor de sinal deve ser conhecido durante a extração do conjunto de treinamento, durante o treinamento do modelo, e durante o processo de decodificação da sequência. O programa auxiliar myop-setup.pl faz a leitura dos metaparâmetros, que ficam armazenados no arquivo cnf/meta.cfg, constrói os arquivos de configuração substituindo os valores dos respectivos metaparâmetros, e armazena os novos arquivos na pasta ghmm/cnf.

Ele é executado dentro do diretório do preditor e não recebe nenhum parâmetro. A linha de comando abaixo:

myop-setup.pl

Linha de comando

\section{Geração dos conjuntos de treinamento}

Após a inicialização, o MYOP extrai da amostra original de treinamento o conjunto de treinamento de cada submodelo. Para cada arquivo de configuração na pasta ghmm/cnf, o programa myop-generate_training_set.pl executa um comando especificado usando a diretiva myop_generate_training _set. O usuário pode opcionalmente usar o programa que implementamos chamado de segseq (segment sequence). Ele serve para extrair 
a partir de um arquivo no formato multi-FASTA e um arquivo no formato GTF sequências dos sítios de splicing, exons (inicial, interno,final, e único), região intergênica, introns, todas as regiões que não codificam proteínas, as regiões que codificam proteínas e as regiões de início e fim de tradução.

O myop-generate_training_set.pl deve ser executado dentro do diretório do preditor.

Linha de comando

myop-generate_training_set.pl -c 4

O parâmetro -c indica a quantidade de processos paralelos que são disparados.

\section{Treinamento dos submodelos}

Após a extração do conjunto de treinamento, podemos realizar o treinamento dos submodelos. Para isso, existe o programa myop-train_submodels.pl o qual executa o comando especificado pela diretiva myop_train que opcionalmente está no arquivo de configuração. O myop-train_submodels.pl deve ser executado dentro do diretório do preditor.

myop-train_submodels.pl -c 4

O parâmetro -c indica a quantidade de processos paralelos que são disparados.

\section{Montando as GHMMs}

Após o treinamento dos submodelos, o MYOP executa os roteiros de construção da GHMM que ficam no diretório scripts. Finalmente, depois deste passo o preditor está pronto para ser usado pelo myop-predict.pl. O myop-build_ghmm.pl deve ser executado dentro do diretório do preditor.

myop-build_ghmm.pl

\section{Linha de comando}

\section{Inicialização do preditor}

O MYOP recebe a arquitetura pré-montada e realiza um conjunto de inicializações através da execução do programa myop-setup.pl. Um preditor tem um conjunto de metaparâmetros usados em diversas etapas. Por exemplo, o comprimento de cada sensor de sinal deve ser conhecido durante a extração do conjunto de treinamento, durante o treinamento do modelo, e durante o processo de decodificação da sequência. O programa auxiliar myop-setup.pl faz a leitura dos metaparâmetros, que ficam armazenados no arquivo 
cnf/meta.cfg, constrói os arquivos de configuração substituindo os valores dos respectivos metaparâmetros, e armazena os novos arquivos na pasta ghmm/cnf.

Ele é executado dentro do diretório do preditor e não recebe nenhum parâmetro. A linha de comando abaixo:

Linha de comando

myop-setup.pl 


\section{Apêndice C}

\section{Outras curvas de aprendizados}

Neste apêndice, colocamos outras curvas de aprendizados, Figuras C.1, C.2, C.3, e C.4, C.5

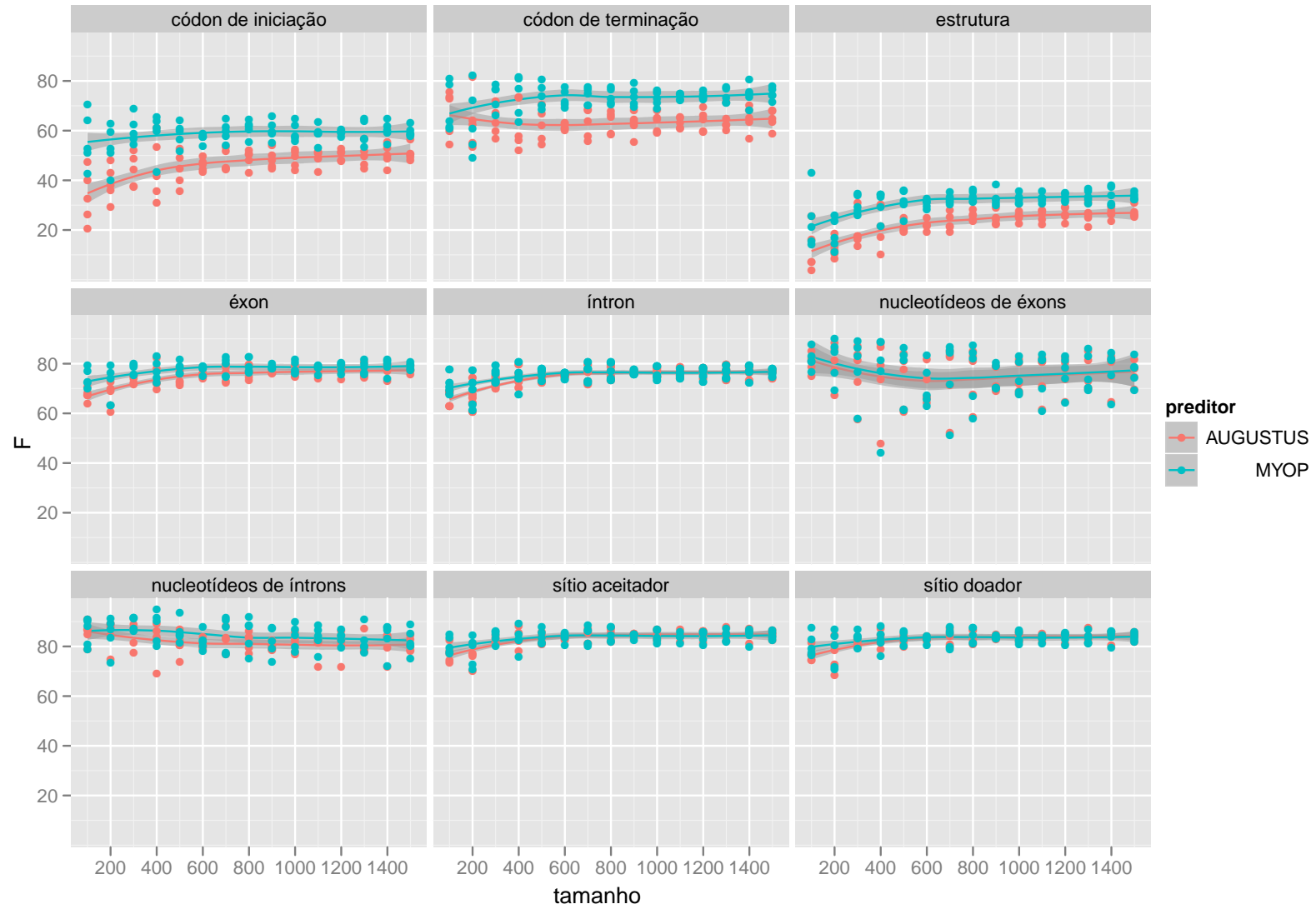

Figura C.1: Exatidão dos preditores AUGUSTUS e MYOP em D. rerio em relação ao tamanho da amostra de treinamento 


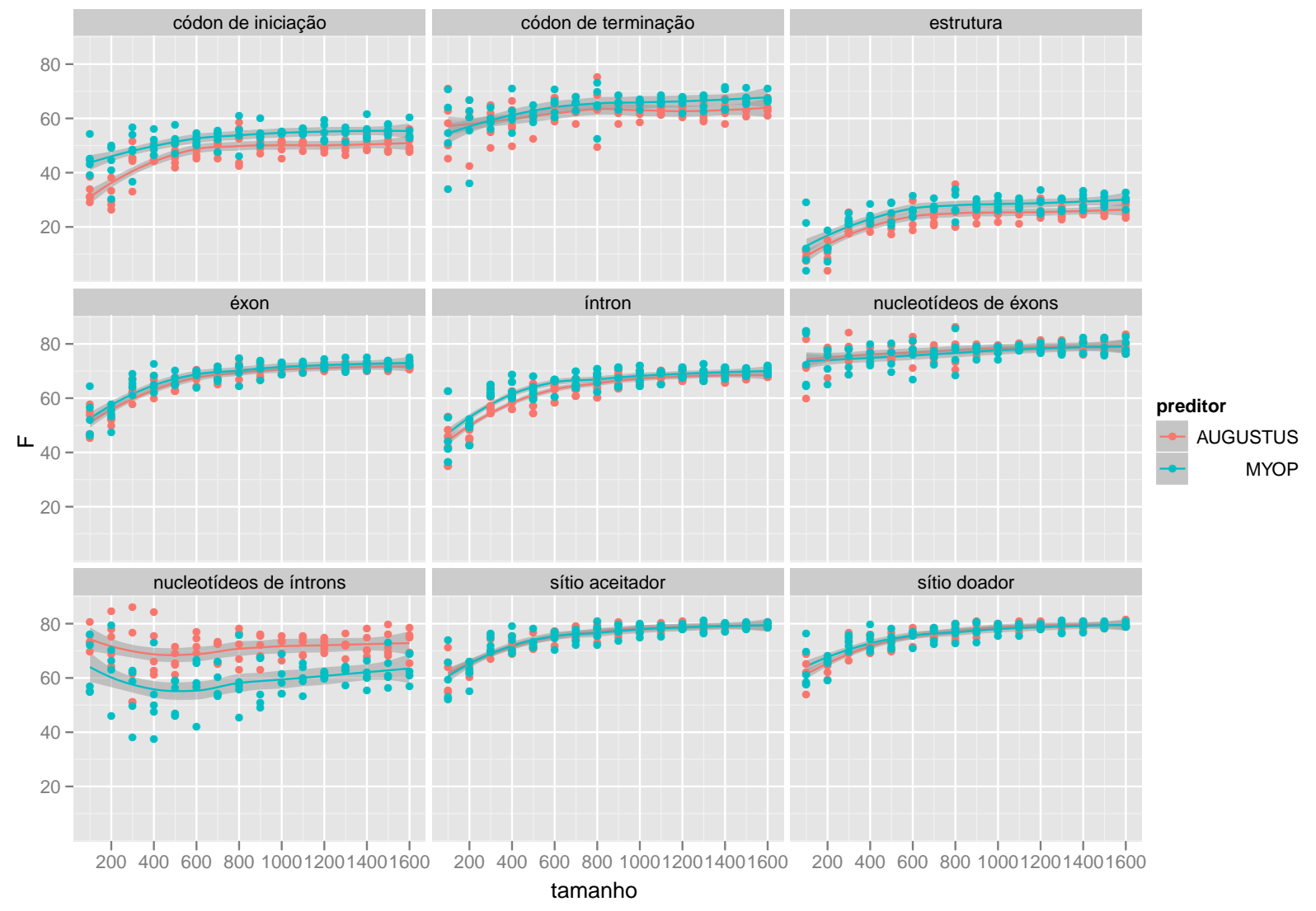

Figura C.2: Exatidão dos preditores AUGUSTUS e MYOP em R. norvegicus em relação ao tamanho da amostra de treinamento 


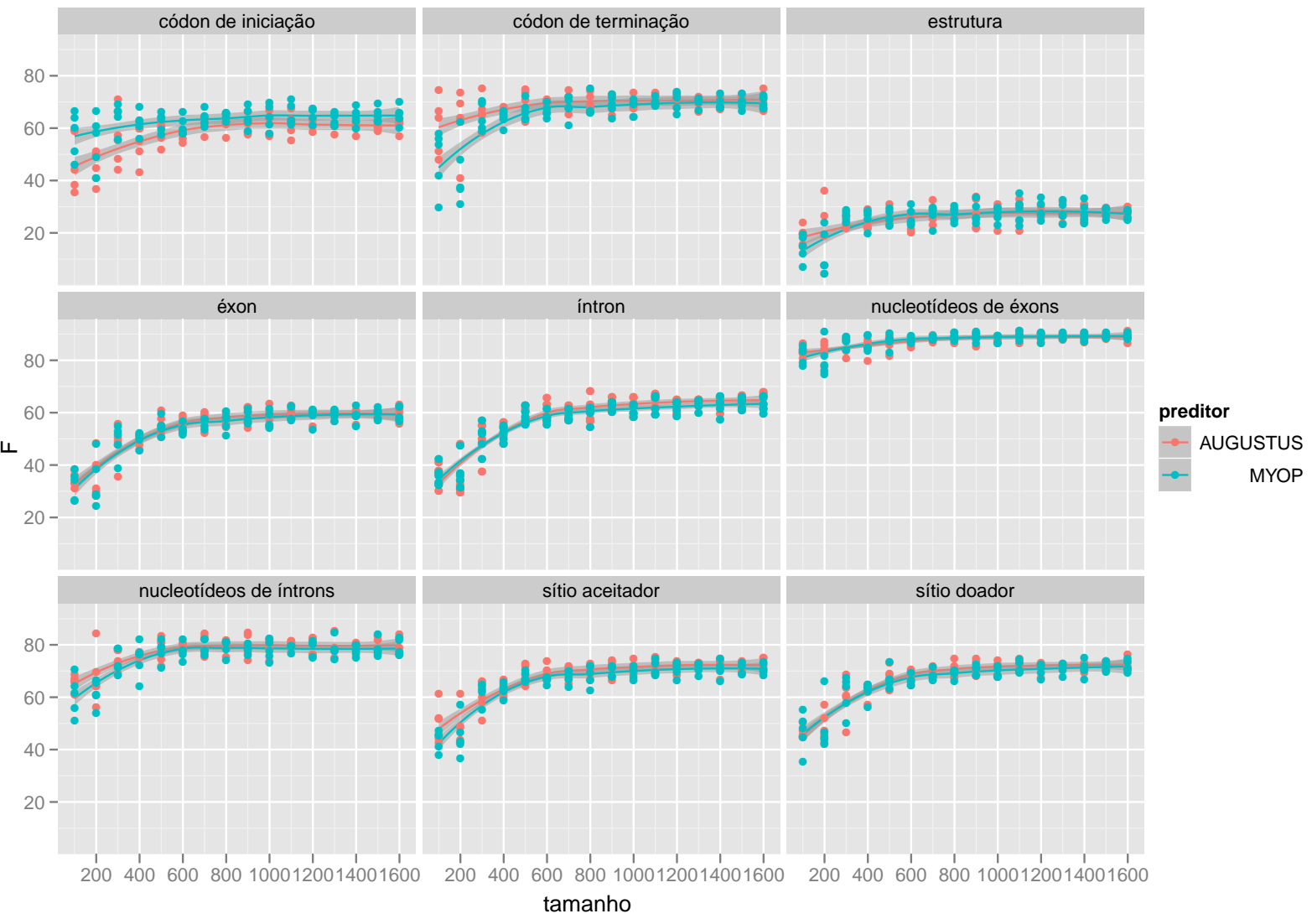

Figura C.3: Exatidão dos preditores AUGUSTUS e MYOP em O. sativa em relação ao tamanho da amostra de treinamento 


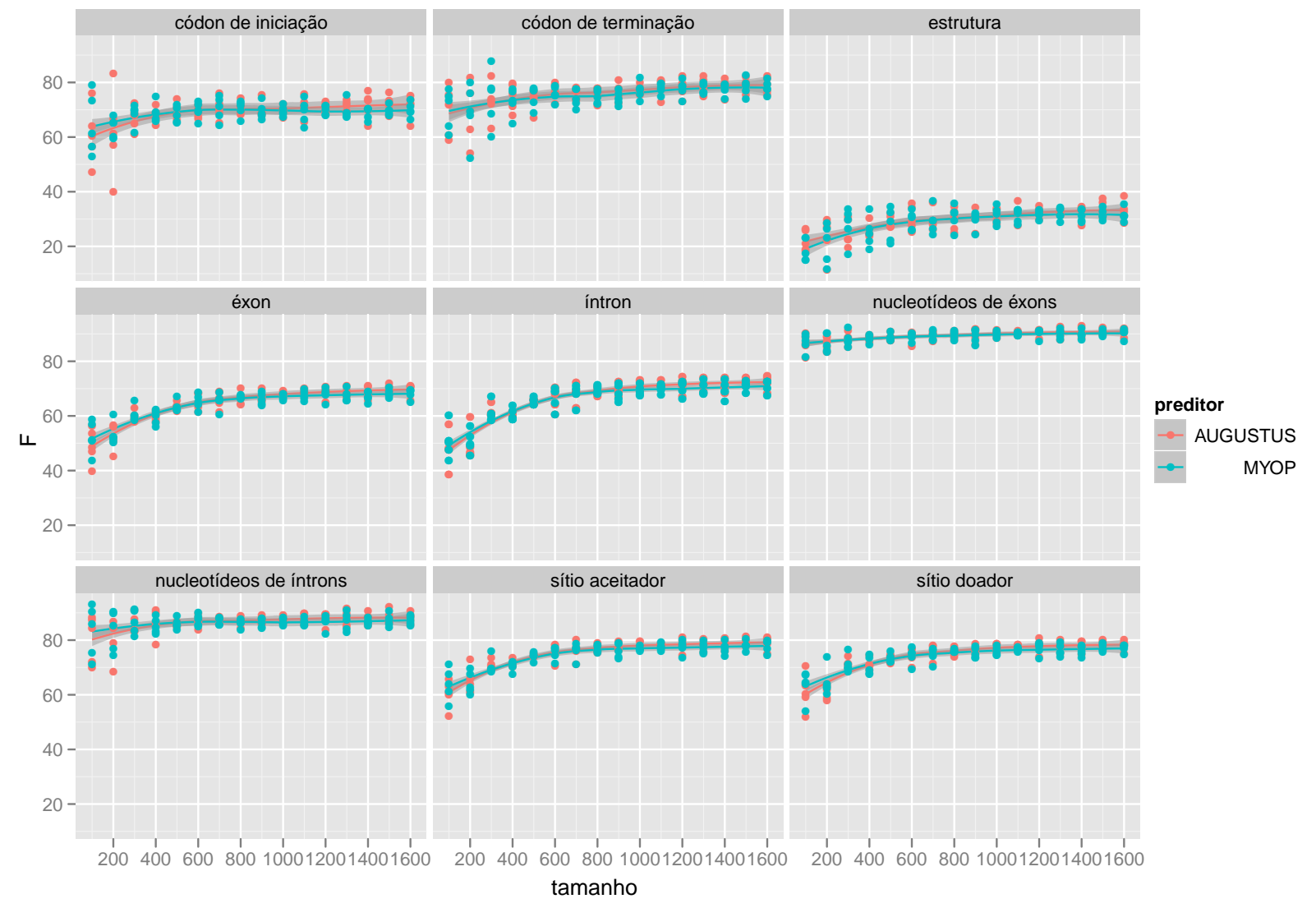

Figura C.4: Exatidão dos preditores AUGUSTUS e MYOP em G. max em relação ao tamanho da amostra de treinamento 


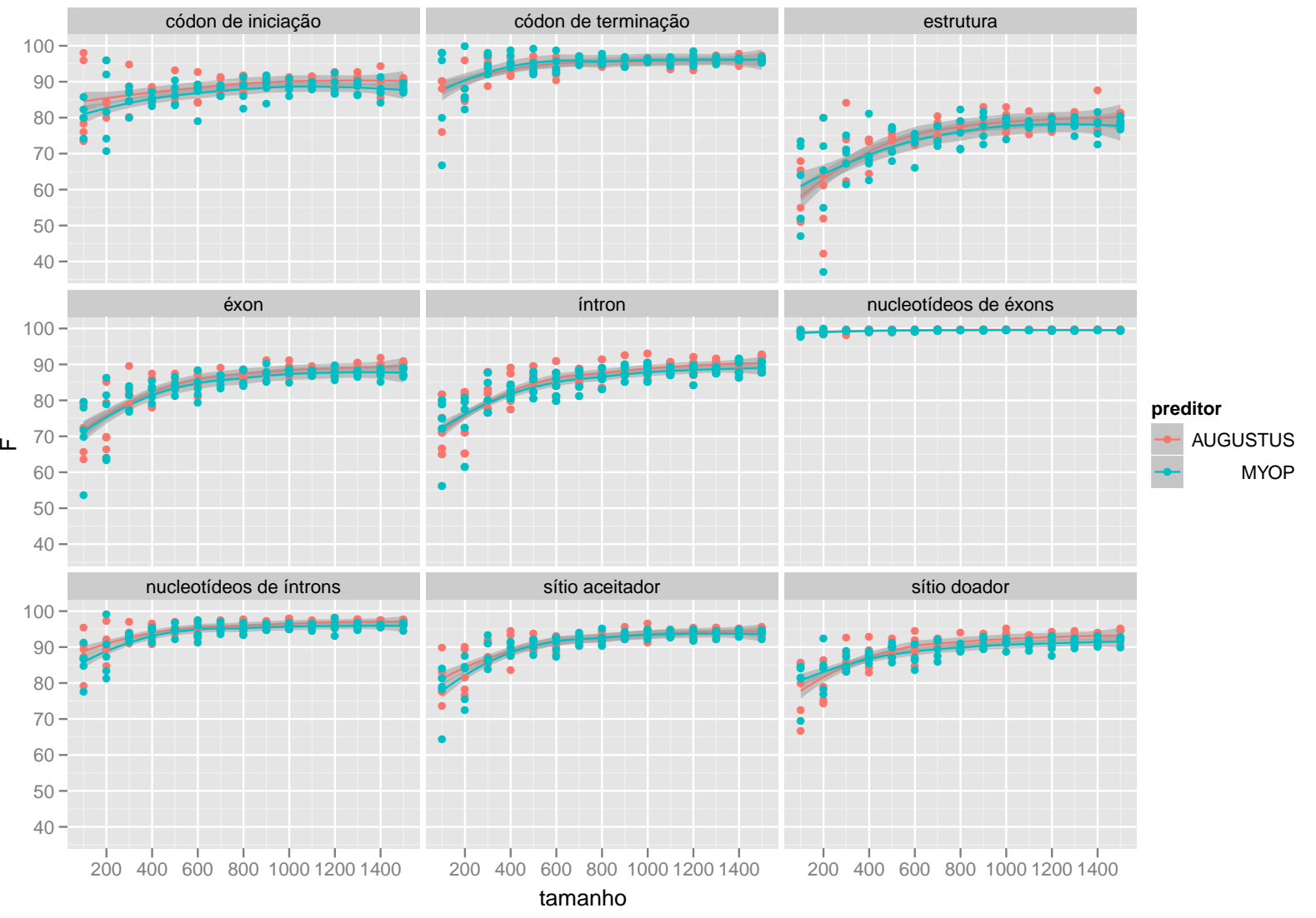

Figura C.5: Exatidão dos preditores AUGUSTUS e MYOP em P. falciparum em relação ao tamanho da amostra de treinamento 


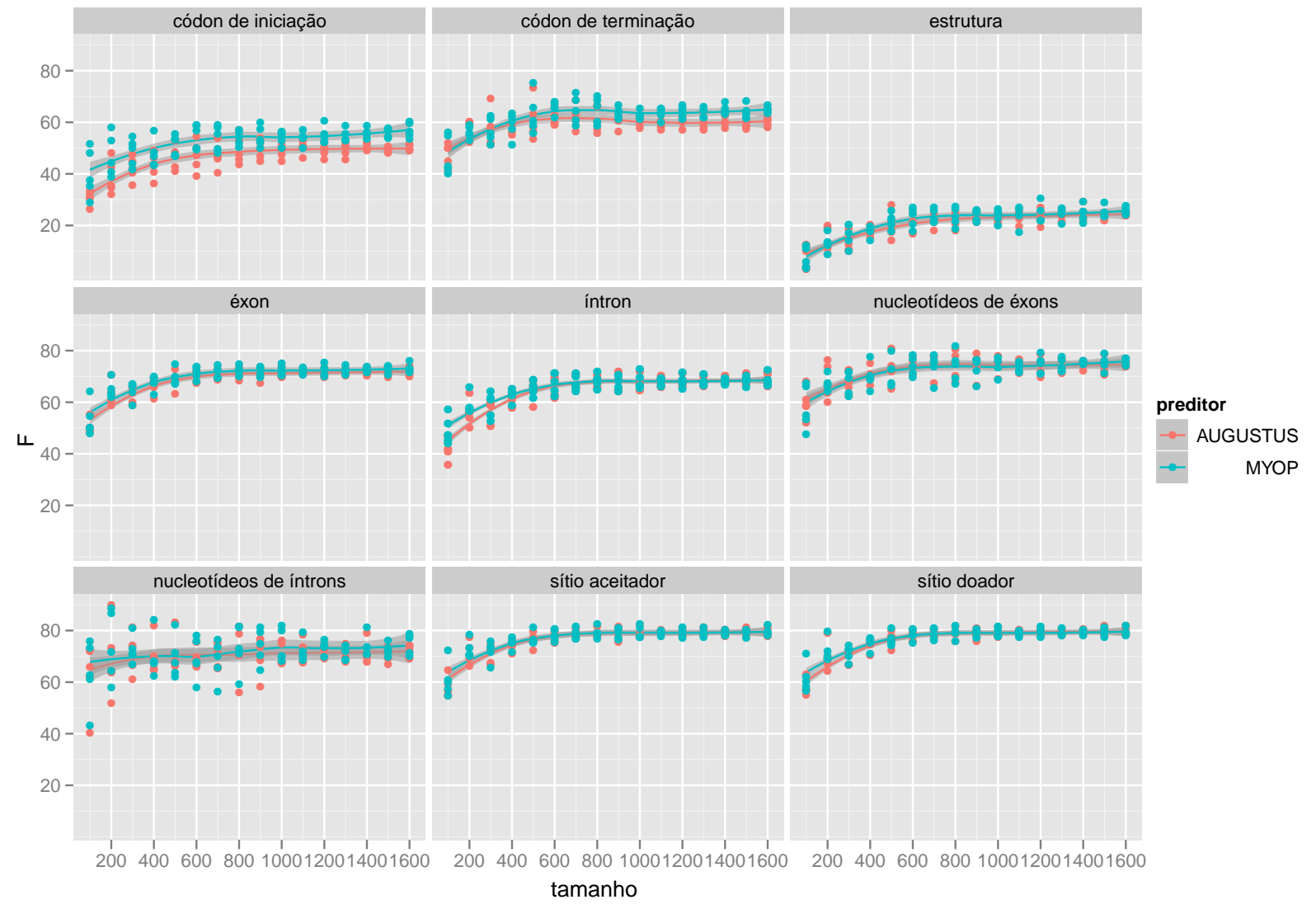

Figura C.6: Exatidão dos preditores AUGUSTUS e MYOP em M. musculus em relação ao tamanho da amostra de treinamento 


\section{Referências Bibliográficas}

Akaike(1974) H Akaike. A new look at the statistical model identification. IEEE transactions on automatic control, AC-19:716-723. Citado na pág. 98

Allen e Salzberg(2005) Jonathan E Allen e Steven L Salzberg. Jigsaw: integration of multiple sources of evidence for gene prediction. Bioinformatics, 21(18):3596-603. doi: 10. 1093/bioinformatics/bti609. URL http://bioinformatics.oxfordjournals.org/cgi/content/ full $/ 21 / 18 / 3596$ ?view $=$ long\&pmid $=16076884$. Citado na pág. 1,75

Axelson-Fisk(2010) Marina Axelson-Fisk. Comparative Gene Finding: Models, algorithms and implementation. Springer. Citado na pág. 1

Bertone et al.(2004) Paul Bertone, Viktor Stolc, Thomas E Royce, Joel S Rozowsky, Alexander E Urban, Xiaowei Zhu, John L Rinn, Waraporn Tongprasit, Manoj Samanta, Sherman Weissman, Mark Gerstein e Michael Snyder. Global identification of human transcribed sequences with genome tiling arrays. Science, 306(5705):2242-6. doi: 10. 1126/science.1103388. Citado na pág. 7

Borodovsky e McIninch(1993) M. Borodovsky e J. McIninch. Genmark: Parallel gene recognition for both DNA strands. Computer Chem, 17:123-133. Citado na pág. 10, 11, 12, 14,91

Burge(1997) C. Burge. Identification of genes in human genomic DNA. Tese de Doutorado, Stanford University. Citado na pág. 1, 7, 10, 11, 12, 15, 21, 22, 27, 41, 56, 60, 68, 97

Burge(1998) C. Burge. Modeling dependencies in pre-mRNA splicing signals. Computational Methods in Molecular Biology, 32:129-164. Citado na pág. 10

Burset e Guigò(1996) M. Burset e R. Guigò. Evaluation of gene structure prediction programs. Genomics, 34:353-367. doi: 10.1006/geno.1996.0298. Citado na pág. 47, 54, 56, 57, 75

Burset et al.(2000) M Burset, I A Seledtsov e V V Solovyev. Analysis of canonical and non-canonical splice sites in mammalian genomes. Nucleic Acids Research, 28(21):436475. Citado na pág. 92

Cawley et al.(2001) S. E. Cawley, A. I. Wirth e T. P. Speed. Phat-a gene finding program for plasmodium falciparum. Mol Biochem Parasitol, 118:167-174. Citado na pág. 1, 8, 11, 61, 83

Coghlan et al.(2008) Avril Coghlan, Tristan J Fiedler, Sheldon J McKay, Paul Flicek, Todd W Harris, Darin Blasiar e Lincoln D Stein. nGASP-the nematode genome annotation assessment project. BMC bioinformatics, 9:549. ISSN 1471-2105. doi: 10.1186/1471-2105-9-549. URL http://www.pubmedcentral.nih.gov/articlerender.fcgi? artid $=2651883 \&$ tool $=$ pmcentrez\&rendertype $=$ abstract. Citado na pág. $1,54,74$ 
Consortium et al.(2011) UniProt Consortium et al. Ongoing and future developments at the universal protein resource. Nucleic Acids Res, 39(Suppl 1):D214-D219. Citado na pág. 85,87

DeCaprio et al.(2007) D. DeCaprio, J.P. Vinson, M.D. Pearson, P. Montgomery, M. Doherty e J.E. Galagan. Conrad: Gene prediction using conditional random fields. Genome Research, 17(9):1389. Citado na pág. 2, 8

Dong e Searls(1994) S. Dong e D. B. Searls. Gene structure prediction by linguistic methods. Genomics, 23:540-551. doi: 10.1006/geno.1994.1541. Citado na pág. 7, 11

Duda et al.(2001) R. O. Duda, P. E. Hart e D. G. Stork. Pattern Classification (2nd Edtion). Wiley Interscience Publication. Citado na pág. 55

Durbin et al.(1998) R. Durbin, S. R. Eddy, A. Krogh e G. Mitchison. Biological sequence analysis: Probabilistic models of proteins and nucleic acids. Cambridge University Press. Citado na pág. 1, 27, 28

Fairbrother et al.(2004) WG Fairbrother, GW Yeo, R Yeh, P Goldstein, M Mawson, PA Sharp e CB Burge. Rescue-ese identifies candidate exonic splicing enhancers in vertebrate exons. Nucleic Acids Research, 32(Web Server Issue):W187. Citado na pág. 91

Ferrari e Galves(1997) P. A. Ferrari e J. A. Galves. Acoplamento e processos estocásticos. Colóquio Brasileiro de Matemática, Rio de Janeiro, 1997. Citado na pág. 8

Florea et al.(1998) L Florea, G Hartzell, Z Zhang, G M Rubin e W Miller. A computer program for aligning a cdna sequence with a genomic dna sequence. Genome Research, 8 (9):967-74. URL http://genome.cshlp.org/content/8/9/967.long. Citado na pág. 85

Galves e Löcherbach(2008) Antonio Galves e Eva Löcherbach. Stochastic chains with memory of variable length. arXiv, math.PR. URL http://arxiv.org/abs/0804.2050v1. 17 pages. Citado na pág. 96

Gamma et al.(1994) E. Gamma, R. Helm, R. Johnson e J. Vlissides. Design Patterns: Elements of Reusable Object-Oriented Software. Addison Wesley, Massachusetts. Citado na pág. 36, 37

Giegerich e zu Siederdissen() Robert Giegerich e Christian Höner zu Siederdissen. Semantics and ambiguity of stochastic RNA family models. IEEE/ACM transactions on computational biology and bioinformatics / IEEE, ACM, 8(2):499-516. ISSN 1557-9964. doi: 10.1109/TCBB.2010.12. URL http://www.ncbi.nlm.nih.gov/pubmed/21233528. Citado na pág. 62

Gross et al.(2007) Samuel S Gross, Chuong B Do, Marina Sirota e Serafim Batzoglou. Contrast: a discriminative, phylogeny-free approach to multiple informant de novo gene prediction. Genome Biol, 8(12):R269. doi: 10.1186/gb-2007-8-12-r269. URL http:// genomebiology.com/content/8/12/R269. Citado na pág. 2, 7, 8, 55

Guédon(2003) Y. Guédon. Estimating hidden semi-Markov chains from discrete sequences. Journal of Computational and Graphical Statistics, 12(3):604-?? Citado na pág. 3, 12, 16, 19, 27

Guigo(2000) R Guigo. An assessment of gene prediction accuracy in large dna sequences. Genome Research, 10(10):1631-1642. doi: 10.1101/gr.122800. Citado na pág. 1, 53, 56 
Guigó et al.(2006) Roderic Guigó, Paul Flicek, Josep F Abril, Alexandre Reymond, Julien Lagarde, France Denoeud, Stylianos Antonarakis, Michael Ashburner, Vladimir B Bajic, Ewan Birney, Robert Castelo, Eduardo Eyras, Catherine Ucla, Thomas R Gingeras, Jennifer Harrow, Tim Hubbard, Suzanna E Lewis e Martin G Reese. EGASP: the human ENCODE Genome Annotation Assessment Project. Genome biology, 7 Suppl 1(Suppl 1):S2.1-31. ISSN 1465-6914. doi: 10.1186/gb-2006-7-s1-s2. URL http://www.pubmedcentral.nih.gov/articlerender.fcgi? artid $=1810551 \&$ tool $=$ pmcentrez\&rendertype=abstract. Citado na pág. $1,54,74$

Haas et al.(2003) Brian J Haas, Arthur L Delcher, Stephen M Mount, Jennifer R Wortman, Roger K Smith, Linda I Hannick, Rama Maiti, Catherine M Ronning, Douglas B Rusch, Christopher D Town, Steven L Salzberg e Owen White. Improving the arabidopsis genome annotation using maximal transcript alignment assemblies. Nucleic Acids Research, 31 (19):5654-66. URL http://nar.oxfordjournals.org/cgi/content/full/31/19/5654. Citado na pág. 86

Harte(2008) D. Harte. Reference manual package: HiddenMarkov. Statistics Research Associates Limited, Wellington, New Zealand, 2008. Citado na pág. 38

Huang et al.(2006) Huang, Li, Chen e Wu. An approach of encoding for prediction of splice sites using svm. Biochimie. ISSN 0300-9084. doi: 10.1016/j.biochi.2006.03.006. Citado na pág. 10

Huang et al.(1999) Xiaoqiu Huang, Anup Madan, Xiaoqiu Huang e Anup Madan. CAP3 : A DNA Sequence Assembly Program. Genome Research, páginas 868-877. doi: 10.1101/ gr.9.9.868. Citado na pág. 88

Keibler e Brent(2004) E. Keibler e M.R. Brent. Eval: A software package for analysis of genome annotations. feedback. Citado na pág. 3, 57

Keibler e Brent(2003) Evan Keibler e Michael R Brent. Eval: a software package for analysis of genome annotations. BMC bioinformatics, 4:50. ISSN 1471-2105. doi: 10. 1186/1471-2105-4-50. URL http://www.pubmedcentral.nih.gov/articlerender.fcgi?artid= $270064 \&$ tool $=$ pmcentrez\&rendertype $=$ abstract. Citado na pág. 47

Kent(2002) W James Kent. Blat-the blast-like alignment tool. Genome Research, 12 (4):656-64. doi: 10.1101/gr.229202.ArticlepublishedonlinebeforeMarch2002. URL http: //genome.cshlp.org/content/12/4/656.long. Citado na pág. 85

Klapuri e Davy(2006) A. Klapuri e M. Davy. Signal processing methods for music transcription. Springer-Verlag New York Inc. Citado na pág. 27

$\operatorname{Korf}(\mathbf{2 0 0 4})$ I. Korf. Gene finding in novel genomes. feedback. Citado na pág. 43, 85

Korf et al.(2001) I. Korf, P. Flicek, D. Duan e M.R. Brent. Integrating genomic homology into gene structure prediction. Bioinformatics, 17(Suppl 1):S140-S148. Citado na pág. 2, 27

Krebs et al.(2011) Jocelyn E. Krebs, Elliott S. Goldstein e Stephen T. Kilpatrick. Lewin's Genes $X$. Jones and Bartlett Publishers. Citado na pág. 5

Krogh(1997) A. Krogh. Two methods for improving performance of an HMM and their application for gene finding. Em In Proc. Fifth Int. Conf. Intelligent System for Molecular Biology, páginas 179-186. Citado na pág. 11 
Kulp. et al.(1996) D. Kulp., D. Haussler., M. G. Reese. e F. H. Eeckman. A generalized hidden Markov model for the recognition of human genes in DNA. Proc Int Conf Intell Syst Mol Biol, 4:134-142. Citado na pág. 1, 2, 11, 12, 27

Lafferty et al.(2001) J. Lafferty, A. McCallum e F. Pereira. Conditional Random Fields: Probabilistic Models for Segmenting and Labeling Sequence Data. Em Machine LearningInternational Workshop then conference, páginas 282-289. Citado na pág. 93

Lomsadze et al.(2005) A. Lomsadze, V. Ter-Hovhannisyan, Y. O. Chernoff e M. Borodovsky. Gene identification in novel eukaryotic genomes by self-training algorithm. Nucleic Acids Res, 33:6494-6506. doi: 10.1093/nar/gki937. Citado na pág. 11, 41

Machado-Lima et al.(2010) A. Machado-Lima, A. Kashiwabara e A. Durham. Decreasing the number of false positives in sequence classification. BMC genomics, 11(Suppl 5):S10. Citado na pág. 60, 71

Machler e Buhlmann(2004) M. Machler e P. Buhlmann. Variable length Markov chains: Methodology, Computing, and Software. Journal of Computational \& Graphical Statistics, 13(2):435-455. Citado na pág. 38

Majoros e Salzberg(2004) W. H. Majoros e S. L. Salzberg. An empirical analysis of training protocols for probabilistic gene finders. BMC Bioinformatics, 5:206. doi: 10. 1186/1471-2105-5-206. Citado na pág. 17

Majoros et al.(2004) W. H. Majoros, M. Pertea e S. Salzberg. TigrScan and GlimmerHMM: two open source ab initio eukaryotic gene-finders. Bioinformatics, 20:28782879. doi: 10.1093/bioinformatics/bth315. Citado na pág. 2, 11, 12, 27, 42

Majoros et al.(2005a) W. H. Majoros, M. Pertea e S. L. Salzberg. Efficient implementation of a generalized pair hidden markov model for comparative gene finding. Bioinformatics, 21:1782-1788. doi: 10.1093/bioinformatics/bti297. Citado na pág. 19

Majoros et al.(2005b) W.H. Majoros, M. Pertea, A.L. Delcher e S.L. Salzberg. Efficient decoding algorithms for generalized hidden Markov model gene finders. BMC Bioinformatics, 6(1):16. Citado na pág. 21, 22, 23

Majoros et al.(2007) W.H. Majoros, I. Status e L. Availability. Methods for Computational Gene Prediction. Cambridge University Press. Citado na pág. 1, 2, 6, 22, 23, 42, 53, 54, 64, $81,90,92$

Makalowska et al.(2005) Izabela Makalowska, Chiao-Feng Lin e Wojciech Makalowski. Overlapping genes in vertebrate genomes. Computational biology and chemistry, 29(1): 1-12. doi: 10.1016/j.compbiolchem.2004.12.006. Citado na pág. 91

Manning e Schütze(1999) C.D. Manning e H. Schütze. Foundations of statistical natural language processing. MIT Press. Citado na pág. 27

Mathé et al.(2000) C. Mathé, M. F. Sagot, T. Schiex e P. Rouzé. Current methods of gene prediction, their strengths and weaknesses. Nucleic Acid Rese, 30:4103-4117. Citado na pág. $1,7,10$

Munch e Krogh(2006) K. Munch e A. Krogh. Automatic generation of gene finders for eukaryotic species. BMC Bioinformatics, 7:263. doi: 10.1186/1471-2105-7-263. Citado na pág. 11 
Nilsen e Graveley(2010) Timothy W Nilsen e Brenton R Graveley. Expansion of the eukaryotic proteome by alternative splicing. Nature, 463(7280):457-63. ISSN 1476-4687. doi: 10.1038/nature08909. URL http://www.ncbi.nlm.nih.gov/pubmed/20110989. Citado na pág. $3,6,57,82$

Parra et al.(2000) G. Parra, E. Blanco e R. Guigò. Geneid in drosophila. Genome Res, 10:511-515. Citado na pág. 11

Pavy et al.(1999) N. Pavy, S. Rombauts, P. Déhais, C. Mathé, D. V. Ramana, P. Leroy e P. Rouzé. Evaluation of gene prediction software using a genomic data set: application to arabidopsis thaliana sequences. Bioinformatics, 15:887-899. ISSN 1367-4803. Citado na pág. $54,55,56,57$

R Development Core Team(2008) R Development Core Team. R: A Language and Environment for Statistical Computing. R Foundation for Statistical Computing, Vienna, Austria, 2008. URL http://www.R-project.org. ISBN 3-900051-07-0. Citado na pág. 27

Rabiner(1989) L. R. Rabiner. A tutorial on Hidden Markov Models and selected applications in speech recoginition. Em Proccedings of the IEEE, volume 77, páginas 257-286. Citado na pág. 3, 12, 19, 27, 30, 32

Reese e Eeckman(1997) M. G. Reese e F. H. Eeckman. Improved splice site detection in Genie. J Comp Biol, 4:311-323. Citado na pág. 10, 11

Reese et al.(2000) Martin G Reese, David Kulp, Hari Tammana e David Haussler. Genie Gene Finding in Drosophila melanogaster. Genome Research, (510):529-538. Citado na pág. 67

Rissanen(1983) J. Rissanen. A universal data compression system. Information Theory, IEEE Transactions on, 29(5):656-664. Citado na pág. 27

Rogic et al.(2001) S. Rogic, A. K. Mackworth e F. B. Ouellette. Evaluation of gene-finding programs on mammalian sequences. Genome Res, 11:817-832. doi: 10.1101/gr.147901. Citado na pág. 54, 55, 56, 57

Salzberg et al.(1998) S. Salzberg, A. L. Delcher, S. Kasif e O. White. Microbial gene identification using Interpolated Markov Models. Nucleic Acids Research, 26:544-548. Citado na pág. 10, 11

Salzberg et al.(1999) S. Salzberg, M. Pertea, A. Delcher, M. J. Gardner e H. Tettelin. Interpolated Markov models for eukaryotic gene finding. Genomics, 59:24-24. doi: 10. 1006/geno.1999.5854. Citado na pág. 11

Sammeth et al.(2008) Michael Sammeth, Sylvain Foissac e Roderic Guigó. A general definition and nomenclature for alternative splicing events. PLoS computational biology, 4(8):e1000147. ISSN 1553-7358. doi: 10.1371/journal.pcbi.1000147. URL http://www.pubmedcentral.nih.gov/articlerender.fcgi?artid=2467475\&tool= pmcentrez\&rendertype=abstract. Citado na pág. 48, 49, 90

Sanna et al.(2008) CR Sanna, WH Li e L Zhang. Overlapping genes in the human and mouse genomes. BMC Genomics, 9(1):169. Citado na pág. 91 
Schlueter et al.(2003) S.D. Schlueter, Q. Dong e V. Brendel. Geneseqer@ plantgdb: Gene structure prediction in plant genomes. Nucleic acids research, 31(13):3597-3600. Citado na pág. 85

Schwarz(1978) Gideon Schwarz. Estimating the dimension of a model. The Annals of Statistics, 6(2):461-464. URL http://www.jstor.org/stable/2958889. Citado na pág. 62, 98

Schweikert et al.(2009) Gabriele Schweikert, Alexander Zien, Georg Zeller, Jonas Behr, Christoph Dieterich, Cheng Soon Ong, Petra Philips, Fabio De Bona, Lisa Hartmann, Anja Bohlen, Nina Krüger, Sören Sonnenburg e Gunnar Rätsch. mgene: accurate svm-based gene finding with an application to nematode genomes. Genome Research, 19(11):213343. doi: 10.1101/gr.090597.108. URL http://genome.cshlp.org/content/19/11/2133.long. Citado na pág. 2

Sharp(1994) P. A. Sharp. Split genes and RNA splicing. Cell, 77:805-815. Citado na pág. 5

Sheather(2004) S.J. Sheather. Density estimation. Statistical Science, 19(4):588-597. Citado na pág. 68,95

Shoemaker et al.(2001) D D Shoemaker, E E Schadt, C D Armour, Y D He, P GarrettEngele, P D McDonagh, P M Loerch, A Leonardson, P Y Lum, G Cavet, L F Wu, S J Altschuler, S Edwards, J King, J S Tsang, G Schimmack, J M Schelter, J Koch, M Ziman, M J Marton, B Li, P Cundiff, T Ward, J Castle, M Krolewski, M R Meyer, M Mao, J Burchard, M J Kidd, H Dai, J W Phillips, P S Linsley, R Stoughton, S Scherer e M S Boguski. Experimental annotation of the human genome using microarray technology. Nature, 409(6822):922-7. doi: 10.1038/35057141. Citado na pág. 7

Slater e Birney(2005) G. Slater e E. Birney. Automated generation of heuristics for biological sequence comparison. Bmc Bioinformatics, 6(1):31. Citado na pág. 85

Staden(1984) R. Staden. Computer methods to locate signals in nucleic acid sequences. Nucleic Acids Res, 12:505-519. Citado na pág. 9, 11

Stanke(2003) M. Stanke. Gene prediction with a hidden Markov model. Tese de Doutorado, Universität Göttingen. Citado na pág. 1, 62, 66, 67, 68, 71, 83

Stanke e Waack(2003) M. Stanke e S. Waack. Gene prediction with a hidden Markov model and a new intron submodel. Bioinformatics, 19 Suppl 2:II215-II225. Citado na pág. $11,12,15,60,62,65$

Stanke et al.(2006) M Stanke, O Keller, I Gunduz, A Hayes, S Waack e B Morgenstern. Augustus: ab initio prediction of alternative transcripts. Nucleic Acids Research, 34(Web Server):W435-W439. doi: 10.1093/nar/gkl200. Citado na pág. 10, 57, 90

Taylor e Karlin(1998) Howard M. Taylor e Samuel Karlin. An Introduction to stochastic modeling. Academic Press. Citado na pág. 8

Vettore et al.(2001) A.L. Vettore, F.R. Silva, E.L. Kemper e P. Arruda. The libraries that made sucest. Genetics and Molecular Biology, 24(1-4):1-7. Citado na pág. 86

Wang(2003) J. Wang. GFPE: gene-finding program evaluation. Bioinformatics, 19(13): 1712-1713. ISSN 1460-2059. doi: 10.1093/bioinformatics/btg216. URL http://www. bioinformatics.oupjournals.org/cgi/doi/10.1093/bioinformatics/btg216. Citado na pág. 3, 47 
Williams et al.(2005) Bryony A P Williams, Claudio H Slamovits, Nicola J Patron, Naomi M Fast e Patrick J Keeling. A high frequency of overlapping gene expression in compacted eukaryotic genomes. Proc Natl Acad Sci USA, 102(31):10936-41. doi: 10.1073/pnas.0501321102. Citado na pág. 91

Wu e Watanabe(2005) T.D. Wu e C.K. Watanabe. Gmap: a genomic mapping and alignment program for mrna and est sequences. Bioinformatics, 21(9):1859. Citado na pág. 85

Yeo e B.(2004) G. Yeo e Christopher B. Maximum entropy modeling of short sequence motifs with applications to rna splicing signals. J Comput Biol, 11:377-394. doi: 10.1089/ 1066527041410418. Citado na pág. 10

Zhang(2002) M. Q. Zhang. Computational prediction of eukaryotic protein-coding genes. Nat Rev Genet, 3:698-698. doi: 10.1038/nrg890. Citado na pág. 1, 2, 53

Zhang e Marr(1993) M. Q. Zhang e T. G. Marr. A weight array method for splicing signal analysis. Computer Applied in Bioscience, 9:499 - 509. Citado na pág. 9, 11 